NBER WORKING PAPER SERIES

\title{
THE PROPAGATION OF MONETARY POLICY SHOCKS IN A HETEROGENEOUS PRODUCTION ECONOMY
}

\author{
Ernesto Pastén \\ Raphael Schoenle \\ Michael Weber \\ Working Paper 25303 \\ http://www.nber.org/papers/w25303 \\ NATIONAL BUREAU OF ECONOMIC RESEARCH \\ 1050 Massachusetts Avenue \\ Cambridge, MA 02138 \\ November 2018
}

We thank Klaus Adam, Susanto Basu, Carlos Carvalho, Xavier Gabaix, Gita Gopinath, Yuriy Gorodnichenko, Bernard Herskovic, Hugo Hopenhayn, Pete Klenow, Alireza Tahbaz-Salehi, Harald Uhlig, and conference and seminar participants at the Annual Inflation Targeting Seminar of the Banco Central do Brasil, AEA, Banque de France Conference on Price Setting and Inflation, BIS, Brandeis, Cambridge, Carlos III, Cleveland Fed conference on Inflation: Drivers and Dynamics Conference, EEA, Einaudi, FGV Sao Paulo, Konstanz seminar on Monetary Theory, Oxford, St. Louis Fed, SED, Toulouse. Pasten is grateful for the support of the Universite de Toulouse Capitole during his stays in Toulouse. Weber thanks the Fama-Miller Center at the University of Chicago Booth School of Business and the Fama Research Fund for financial support. We also thank Will Cassidy, Seongeun Kim, Matt Klepacz and Michael Munsell for excellent research assistance. The views expressed herein are those of the authors and do not necessarily reflect the views of the National Bureau of Economic Research or the Central Bank of Chile.

NBER working papers are circulated for discussion and comment purposes. They have not been peer-reviewed or been subject to the review by the NBER Board of Directors that accompanies official NBER publications.

(C) 2018 by Ernesto Pastén, Raphael Schoenle, and Michael Weber. All rights reserved. Short sections of text, not to exceed two paragraphs, may be quoted without explicit permission provided that full credit, including ( $)$ notice, is given to the source. 
The Propagation of Monetary Policy Shocks in a Heterogeneous Production Economy

Ernesto Pastén, Raphael Schoenle, and Michael Weber

NBER Working Paper No. 25303

November 2018

JEL No. E20,E32,E52

\section{$\underline{\text { ABSTRACT }}$}

We study the transmission of monetary policy shocks in a model in which realistic heterogeneity in price rigidity interacts with heterogeneity in sectoral size and input-output linkages, and derive conditions under which these heterogeneities generate large real effects. Empirically, heterogeneity in the frequency of price adjustment is the most important driver behind large real effects, whereas heterogeneity in input-output linkages contributes only marginally, with differences in consumption shares in between. Heterogeneity in price rigidity further is key in determining which sectors are the most important contributors to the transmission of monetary shocks, and is necessary but not sufficient to generate realistic output correlations. In the model and data, reducing the number of sectors decreases monetary non-neutrality with a similar impact response of inflation. Hence, the initial response of inflation to monetary shocks is not sufficient to discriminate across models and for the real effects of nominal shocks.

Ernesto Pastén

Central Bank of Chile

Agustinas 1180

Santiago

Chile

and Toulouse School of Economics

epasten@bcentral.cl

Raphael Schoenle

Brandeis University

Department of Economics

Mail Stop 021

415 South Street

Waltham, MA 02454

schoenle@brandeis.edu
Michael Weber

Booth School of Business

University of Chicago

5807 South Woodlawn Avenue

Chicago, IL 60637

and NBER

michael.weber@chicagobooth.edu 


\section{Introduction}

Understanding how monetary policy transmits to the real economy and why nominal shocks have real effects are vital questions in monetary economics. Recent insights suggest heterogeneity on the household side might change completely the transmission mechanism of monetary policy through general equilibrium effects on labor income (see Kaplan, Moll, and Violante (2018)). But large heterogeneities are also present on the production side of the economy. Firms differ in the degree of nominal rigidities, which can result in strategic complementary in price setting; sectors differ in size, which might result in aggregate fluctuations due to idiosyncratic shocks; and different sectors use different intermediate input mixes to produce output, which can also give rise to idiosyncratic origins of business-cycle fluctuations. ${ }^{1}$

We present new theoretical insights into the transmission of monetary policy shocks in an economy in which all three heterogeneities are present and interact with each other. First, we show real effects of nominal shocks are bigger if the share of intermediate inputs is high or if sticky-price sectors are important suppliers to the rest of the economy, to large sectors and to flexible-price sectors on impact, but to sticky price sectors following the shock. ${ }^{2}$ Second, the level of disaggregation is central for the real effects of monetary policy. More granular economies result in larger real effects with similar price responses on impact. Third, the importance of specific sectors for the transmission of monetary policy shocks depends on which heterogeneities are present, and how they interact.

On the empirical side, our contribution lies in the calibration of a detailed model of the U.S. economy to study the quantitative importance of the different types of heterogeneities. We calibrate a 350-sector version of the model to the input-output (I/O) tables from the Bureau of Economic Analysis (BEA) and the micro-data underlying the producer price index (PPI) from the Bureau of Labor Statistics (BLS). First, we find heterogeneity in price stickiness is the main driver of real output effects: It more than doubles real effects relative to an economy with homogeneous price stickiness. Additionally allowing for heterogeneity in consumption shares increases real effects by $16 \%$ on impact, and $4 \%$ cumulatively. The marginal effects of heterogeneous I/O linkages are smaller than the effects of price stickiness.

\footnotetext{
${ }^{1}$ See, for example, the works of Carvalho (2006) and Nakamura and Steinsson (2008) for the importance of heterogeneous price stickiness, and Gabaix (2011) and Acemoglu, Carvalho, Ozdaglar, and TahbazSalehi (2012) for the relevance of heterogeneities in sector size and input mixes.

${ }^{2}$ Some of the results are well known. The dynamic prediction in the network setting is most distinctly new (see Basu (1995), Huang and Liu (2004), Shamloo (2010)), and Bouakez, Cardia, and Ruge-Murcia $(2014))$
} 
Second, the choice of disaggregation plays an important role empirically. A 350-sector economy has a $20 \%$ (34\%) larger cumulative real effect of monetary policy shocks than a less granular 58-(8-)sector model. However, across choices of aggregation, the response of inflation to the monetary policy shock is similar on impact and on average during the first few periods. The large differences in real output effects with similar impact responses of inflation across different levels of aggregation caution against drawing inference for the conduct of monetary policy from the initial response of inflation to monetary policy shocks.

Third, heterogeneity in price rigidity is key in determining which sectors are the most important contributors to the transmission of monetary shocks. Relative to uniform responses under homogeneous and flexible prices, heterogeneity in price rigidity results in a differential sectoral response. Moreover, going from homogeneous to heterogeneous price rigidity increases the response of the 10 most important sectors by a factor of 5 to 8 . At the same time, the 10 smallest sectoral responses remain relatively unchanged. Allowing for other heterogeneities has effects that are smaller by an order of magnitude across specifications. However, allowing for full network heterogeneity cuts the response of the least important sectors by a factor of 3 to 4 . In this context, we also show heterogeneity in price stickiness is a necessary but not a sufficient condition to generate realistic output correlations across sectors.

Taken together, these results show (i) Heterogeneous price stickiness is the central force for the real effects of nominal shocks; intermediate inputs increase the real effects of monetary shocks, but heterogeneity in the I/O structure is less important; (ii) disaggretation matters for the real effects of monetary policy shocks but leaves the impact response of inflation largely unchanged; and (iii) price stickiness that differs across sectors changes the identity and importance of the most important sectors for the transmission of monetary shocks.

What mechanisms drive these results? In the model, firms set prices as a markup over a weighted average of future marginal costs. We identify four distinct channels through which I/O linkages and the heterogeneities of sector size and price stickiness affect the marginal-cost process. First, marginal costs of final-goods producers depend directly on the sector-specific input price index. Second, sector-specific wages depend indirectly on I/O linkages because the optimal mix of inputs depends on the relative price of intermediate inputs and labor. Third and fourth, the heterogeneities across sectors in total production, value-added, and intermediate inputs create wedges between sectoral participation in total output, production, and total GDP that feed back into marginal costs. These channels interact in shaping the response to nominal shocks in a very intuitive 
way: How important is the output of a given sector for final-goods production? How flexible are the output prices of the goods the sector uses in production? How important is the sector as a producer for total consumption?

We develop further, analytical intuition for the interaction of the three heterogeneities in a simplified model. In this economy, we gradually add each heterogeneity, and prove results analytically when possible. We start with an economy that features I/O linkages that can be homogeneous or heterogeneous across sectors. Key to this step is that price rigidity is homogeneous across sectors, and sectoral participation in GDP equals sectoral participation in total production. I/O linkages per se amplify the real effects of monetary policy, as in Nakamura and Steinsson (2008). However, heterogeneity in consumption shares and I/O linkages does not matter, because sectoral production and consumption shares do not produce wedges.

We then add heterogeneity in Calvo parameters. This addition generates a humpshaped response in consumption, because flexible-price firms compete with sticky-price firms. Firms with flexible prices adjust prices in a staggered fashion and by less on impact than in a model with homogeneous Calvo rates across sectors. The dispersion of price stickiness amplifies cumulative real effects following an identical impact of consumption as in Carvalho (2006), Carvalho and Schwartzman (2015), and Alvarez et al. (2016a). Heterogeneity in I/O linkages and consumption shares does not affect the impact response relative to an economy with homogeneous price stickiness and also does not have any systematic effect following the impact response.

Last, we allow for fully unrestricted heterogeneity in sector weights in GDP and in I/O linkages. This additional degree of heterogeneity results in wedges between consumption prices and sectoral intermediate input prices, which influence sectoral marginal costs. Heterogeneity in I/O linkages can amplify or dampen the output response. For example, the economy may resemble more of a flexible-price economy or a sticky-price economy, depending on the interaction of sector size, the importance of sectors as suppliers to other sectors, and sectoral price stickiness. We characterize the interactions and their influence on real effects of monetary policy by three relations: (i) first-order out-degrees to sector size, (ii) first-order outdegrees adjusted by average flexibility to sector size, and (iii) covariances between sectoral linkages and size with price stickiness.

\section{A. Literature review}

Our paper contributes new insights to the literature on the transmission of monetary policy shocks in a network economy. Basu (1995) shows a roundabout production 
structure can magnify the importance of price rigidities through its effect on marginal costs, and results in larger welfare losses of demand-driven business cycles. Huang and Liu (2004) study the persistence of monetary shocks in a multi-sector model with roundabout production and fixed contract length. Their pioneering work theoretically shows that intermediate inputs amplify the importance of rigid prices with no impact on wage stickiness. Nakamura and Steinsson (2010) develop a multi-sector menu-cost model and show in a calibration of a six-sector version that heterogeneity in price stickiness together with I/O linkages can explain persistent real effects of nominal shocks with moderate degrees of price stickiness. Carvalho and Lee (2011) show a multi-sector Calvo model with intermediate inputs can reconcile why firms adjust more quickly to idiosyncratic shocks than to aggregate shocks (see also Boivin et al. (2009) and Shamloo (2010)). Bouakez, Cardia, and Ruge-Murcia (2014) estimate a multi-sector Calvo model with production networks using aggregate and sectoral data, and find evidence of heterogeneity in frequencies of price adjustments across sectors.

We contribute several new insights to this literature. Our most important empirical innovation is to study the importance of networks on the propagation of nominal shocks in a detailed, 350-sector calibration of the U.S. economy. Second, we show both theoretically and empirically that reducing the number of sectors in our model decreases monetary non-neutrality. By contrast, the empirical impact response of inflation is similar across aggregation choices, and hence is not a sufficient statistic for monetary non-neutrality. Finally, we point out a new identity effect: Heterogeneity in price rigidity is key in determining which sectors are the most important contributors to the transmission of monetary shocks. Heterogeneity in price rigidity is also necessary to generate realistic correlations in output across sectors to monetary policy shocks.

A high degree of specialization is a general, key feature of modern production economies. Gabaix (2011) and Acemoglu et al. (2012) show theoretically the network structure and the firm-size distribution are potentially important propagation mechanisms for aggregate fluctuations originating from firm and industry shocks. Acemoglu, Akcigit, and Kerr (2015) and Barrot and Sauvagnat (2016) show empirical evidence for the propagation of idiosyncratic supply shocks through the I/O structure. Carvalho (2014) provides an overview of this fast-growing literature. Idiosyncratic shocks propagate through changes in prices. In a companion paper (see Pasten, Schoenle, and Weber (2018)), we study how price rigidities affect the importance of idiosyncratic shocks as an origin of aggregate fluctuations.

Other recent applications of production networks in different areas of macroeconomics 
include Bigio and Lao (2017) who study the amplification of financial frictions through production networks, and Ozdagli and Weber (2017), who empirically show I/O linkages are a key propagation channel of monetary policy to the stock market. Additionally, Kelly, Lustig, and Van Nieuwerburgh (2013) study the joined dynamics of the firm-size distribution and stock return volatilities. Herskovic, Kelly, Lustig, and Van Nieuwerburgh (2016) and Herskovic (2018) study asset-pricing implications of production networks.

\section{Model}

This section presents our full blown New Keynesian model. We highlight in particular how heterogeneities in price rigidities, sectoral size, and the network structure enter the model.

\section{A. Firms}

A continuum of monopolistically competitive firms $j$ operates in different sectors. We index firms by their sector, $k=1, \ldots, K$, and by $j \in[0,1]$. The set of consumption goods is partitioned into a sequence of subsets $\left\{\Im_{k}\right\}_{k=1}^{K}$ with measure $\left\{n_{k}\right\}_{k=1}^{K}$ such that $\sum_{k=1}^{K} n_{k}=1$.

The first, real heterogeneity - heterogeneity in sectoral I/O linkages - enters via the production function of firm $j$ in sector $k$, which is given by

$$
Y_{k j t}=L_{k j t}^{1-\delta} Z_{k j t}^{\delta}
$$

where $L_{k j t}$ is labor and $Z_{k j t}$ is an aggregator of intermediate inputs

$$
Z_{k j t} \equiv\left[\sum_{r=1}^{K} \omega_{k r}^{\frac{1}{\eta}} Z_{k j t}(r)^{1-\frac{1}{\eta}}\right]^{\frac{\eta}{\eta-1}} .
$$

Here, $Z_{k j t}(r)$ denotes the intermediate input use by firm $j$ in sector $k$ in period $t$. The aggregator weights $\left\{\omega_{k r}\right\}_{k, r}$ satisfy $\sum_{r=1}^{K} \omega_{k r}=1$ for all sectors $k$. We allow these weights to differ across sectors, which is a central ingredient of our analysis.

In turn, $Z_{k j t}(r)$ is an aggregator of goods produced in sector $r$,

$$
Z_{k j t}(r) \equiv\left[n_{r}^{-1 / \theta} \int_{\Im_{r}} Z_{k j t}\left(r, j^{\prime}\right)^{1-\frac{1}{\theta}} d j^{\prime}\right]^{\frac{\theta}{\theta-1}}
$$

$Z_{k j t}\left(r, j^{\prime}\right)$ is the amount of goods firm $j^{\prime}$ in sector $r$ produces that firm $k, j$ uses as input. 
Demand for intermediate inputs $Z_{k j t}(r)$ and $Z_{k j t}\left(r, j^{\prime}\right)$ is given by the following demand equations

$$
\begin{aligned}
Z_{k j t}(r) & =\omega_{k r}\left(\frac{P_{r t}}{P_{t}^{k}}\right)^{-\eta} Z_{k j t}, \\
Z_{k j t}\left(r, j^{\prime}\right) & =\frac{1}{n_{r}}\left(\frac{P_{r j^{\prime} t}}{P_{r t}}\right)^{-\theta} Z_{k j t}(r) .
\end{aligned}
$$

$P_{r j^{\prime} t}$ is the price firm $j^{\prime}$ in sector $r$ charges, $P_{r t}$ is a sectoral price index, and $P_{t}^{k}$ is an input-price index; we define both price indices below. In steady state, all prices are identical, and $\left\{\omega_{k r}\right\}_{r=1}^{K}$ is the share of costs that firm $k, j$ spends on inputs from sector $r$ and, hence, equals cell $k, r$ in the I/O Tables (see online appendix). We refer to $\left\{\omega_{k r}\right\}_{r=1}^{K}$ as "I/O linkages." As a result, in steady state, all $n_{r}$ firms in sector $r$ share the demand of firm $k, j$ for goods that sector $r$ produces equally.

Away from steady state, a gap exists between the price index of sector $r, P_{r t}$, and the input price index, $P_{t}^{k}$, that is relevant for firms in sector $k$. It distorts the share of sector $r$ in the costs of firms in sector $k$. Similarly, price dispersion across firms within sector $r$ determines the dispersion of demand of firms in sector $k$ for goods in sector $r$. Price indices relevant for the demand of intermediate inputs across sectors are defined as

$$
\begin{gathered}
P_{t}^{k}=\left[\sum_{r=1}^{K} \omega_{k r} P_{r t}^{1-\eta}\right]^{\frac{1}{1-\eta}}, \\
P_{r t}=\left[\frac{1}{n_{r}} \int_{\Im_{r}} P_{r j^{\prime} t}^{1-\theta} d j^{\prime}\right]^{\frac{1}{1-\theta}} .
\end{gathered}
$$

Our second heterogeneity - heterogeneity of price rigidity - originates from our assumption about price setting. Firms set prices as in Calvo (1983), but we allow for differences in Calvo rates across sectors, $\left\{\alpha_{k}\right\}_{k=1}^{K}$. That is, the objective of firm $j, k$ is given

$$
\max _{P_{k j t}} \mathbb{E}_{t} \sum_{s=0}^{\infty} Q_{t, t+s} \alpha_{k}^{s}\left[P_{k j t} Y_{k j t+s}-M C_{k j t+s} Y_{k j t+s}\right]
$$

where $M C_{k j t}=\frac{1}{1-\delta}\left(\frac{\delta}{1-\delta}\right)^{-\delta} W_{k t}^{1-\delta}\left(P_{t}^{k}\right)^{\delta}$ are marginal costs after imposing the optimal mix of labor and intermediate inputs

$$
\delta W_{k t} L_{k j t}=(1-\delta) P_{t}^{k} Z_{k j t}
$$


The optimal pricing problem takes the standard form

$$
\sum_{s=0}^{\infty} Q_{t, t+s} \alpha_{k}^{s} Y_{k j t+s}\left[P_{k t}^{*}-\frac{\theta}{\theta-1} M C_{k j t+s}\right]=0 .
$$

$Y_{k j t+s}$ is the total output of firm $k, j$ at period $t+s, Q_{t, t+s}$ is the stochastic discount factor between period $t$ and $t+s$, and $\theta$ is the elasticity of substitution within sector. ${ }^{3}$

The optimal price for all adjusting firms within a given sector is identical, $P_{k t}^{*}$, allowing simple aggregation. Hence, the law of motion for sectoral prices is

$$
P_{k t}=\left[\left(1-\alpha_{k}\right) P_{k t}^{* 1-\theta}+\alpha_{k} P_{k t-1}^{1-\theta}\right]^{\frac{1}{1-\theta}} \forall k
$$

\section{B. Households}

A large number of infinitely lived households exist. Households have a love for variety, and derive utility from consumption and leisure. Households supply all different types of labor. The representative household has additively separable utility in consumption and leisure and maximizes

$$
\max \mathbb{E}_{0} \sum_{t=0}^{\infty} \beta^{t}\left(\frac{C_{t}^{1-\sigma}-1}{1-\sigma}-\sum_{k=1}^{K} \int_{\Im_{k}} g_{k} \frac{L_{k j t}^{1+\varphi}}{1+\varphi} d j\right)
$$

subject to

$$
P_{t} C_{t}=\sum_{k=1}^{K} W_{k t} \int_{\Im_{k}} L_{k j t} d j+\sum_{k=1}^{K} \Pi_{k t}+I_{t-1} B_{t-1}-B_{t} .
$$

The budget constraint states nominal expenditure equals nominal household income. $C_{t}$ and $P_{t}$ are aggregate consumption and prices, which we define below. $L_{k j t}$ and $W_{k t}$ are labor employed and wages paid by firm $j$ in sector $k$. Households own firms and receive net income, $\Pi_{k t}$, as dividends. Bonds, $B_{t}$, pay a nominal gross interest rate of $I_{t-1}$.

Aggregate consumption is

$$
C_{t} \equiv\left[\sum_{k=1}^{K} \omega_{c k}^{\frac{1}{\eta}} C_{k t}^{1-\frac{1}{\eta}}\right]^{\frac{\eta}{\eta-1}}
$$

\footnotetext{
${ }^{3}$ We assume firms do not discriminate between demand from households and other firms.
} 
where $C_{k t}$ is the aggregation of sectoral consumption

$$
C_{k t} \equiv\left[n_{k}^{-1 / \theta} \int_{\Im_{k}} C_{k j t}^{1-\frac{1}{\theta}} d j\right]^{\frac{\theta}{\theta-1}}
$$

$C_{k j t}$ is the consumption of goods that firm $j$ in sector $k$ produces.

We allow the elasticity of substitution across sectors $\eta$ to differ from the elasticity of substitution within sectors $\theta$. We also allow the consumption weights $\left\{\omega_{c k}\right\}$ to differ across sectors, which is the third heterogeneity across sectors in our model. The weights satisfy $\sum_{k=1}^{K} \omega_{c k}=1$.

Households' demand for sectoral goods $C_{k t}$ and firm goods $C_{k j t}$ is

$$
\begin{aligned}
C_{k t} & =\omega_{c k}\left(\frac{P_{k t}}{P_{t}^{c}}\right)^{-\eta} C_{t}, \\
C_{k j t} & =\frac{1}{n_{k}}\left(\frac{P_{k j t}}{P_{k t}}\right)^{-\theta} C_{k t} .
\end{aligned}
$$

We solve in the online appendix for the steady state of the economy. We show the consumption weights $\left\{\omega_{c k}\right\}_{r=1}^{K}$ determine the steady-state shares of sectors in total consumption (or value-added production). In the following, we refer to $\left\{\omega_{c k}\right\}_{r=1}^{K}$ as "consumption shares." Heterogeneity in sectoral size enters through these shares. Away from steady state, a gap between sectoral prices, $\left\{P_{r t}\right\}_{r=1}^{K}$, and aggregate consumption prices, $P_{t}^{c}$, distorts the share of sectors in aggregate consumption. ${ }^{4}$

The consumption price index $P_{t}^{c}$ is given by

$$
P_{t}^{c}=\left[\sum_{k=1}^{K} \omega_{c k} P_{k t}^{1-\eta}\right]^{\frac{1}{1-\eta}},
$$

and sectoral prices follow

$$
P_{k t}=\left[\frac{1}{n_{k}} \int_{\Im_{k}} P_{k j t}^{1-\theta} d j\right]^{\frac{1}{1-\theta}} .
$$

\footnotetext{
${ }^{4}$ The measure of firms in sector $k, n_{k}$, and the consumption shares are related in equilibrium (see online appendix).
} 


\section{Monetary policy}

The monetary authority sets the short-term nominal interest rate, $I_{t}$, according to a Taylor rule

$$
I_{t}=\frac{1}{\beta}\left(\frac{P_{t}}{P_{t-1}}\right)^{\phi_{\pi}}\left(\frac{C_{t}}{\bar{C}}\right)^{\phi_{y}} e^{\mu_{t}} .
$$

$\mu_{t}$ is a monetary shock following an $\operatorname{AR}(1)$ process with persistence $\rho_{\mu}$. Thus, monetary policy reacts to aggregate consumption inflation and aggregate consumption.

\section{Equilibrium conditions and definitions}

$$
\begin{aligned}
& B_{t}=0 \\
& L_{k t}=\int_{\Im_{k}} L_{k j t} d j, \\
& W_{t} \equiv \sum_{k=1}^{K} n_{k} W_{k t}, \\
& L_{t} \equiv \sum_{k=1}^{K} L_{k t}, \\
& Y_{k j t}=C_{k j t}+\sum_{k^{\prime}=1}^{K} \int_{\Im_{k^{\prime}}} Z_{k^{\prime} j^{\prime} t}(k, j) d j^{\prime} .
\end{aligned}
$$

Equation (15) is the market-clearing condition in bond markets. Equation (16) defines aggregate labor in sector $k$. Equations (17) and (18) give aggregate wage (which is a weighted average of sectoral wages) and aggregate labor (which linearly sums up hours worked in all sectors). Equation (19) is Walras' law for the output of firm $j$ in sector $k$.

\section{Heterogeneities and Marginal Costs}

The dynamic behavior of marginal costs is crucial for understanding the response of the economy to a monetary policy shock. This section develops intuition for the effects of heterogeneity in price stickiness, I/O linkages, and sectoral size on marginal costs, and the real effects of monetary policy. We focus on the role of heterogeneity in I/O linkages. Our main, analytical propositions in the next section, however, do not require reading this section first. 
We highlight how I/O linkages affect marginal costs and demand through four distinct channels. In particular, a new wedge emerges that drives marginal costs: I/O linkages create a wedge between the aggregate consumption price index and intermediate input price indices that affects marginal costs.

The reduced-form system that embeds marginal costs has $K+1$ equations and unknowns: value-added production $c_{t}$ and $K$ sectoral prices $\left\{p_{k t}\right\}_{k=1}$. In the following description of the system, small letters denote log deviations from steady state. The first equation is

$$
\sigma \mathbb{E}_{t}\left[c_{t+1}\right]-\left(\sigma+\phi_{c}\right) c_{t}+\mathbb{E}_{t}\left[p_{t+1}^{c}\right]-\left(1+\phi_{\pi}\right) p_{t}^{c}+\phi_{\pi} p_{t-1}^{c}=\mu_{t}
$$

which is a combination of the household Euler equation and the Taylor rule. The equation describes how variations in value-added production, $c_{t}$, and aggregate consumption prices, $p_{t}^{c}$, respond to the monetary policy shock, $\mu_{t}$.

Note $p_{t}^{c}$ is given by

$$
p_{t}^{c}=\sum_{k=1}^{K} \omega_{c k} p_{k t} .
$$

In addition, $K$ equations governing sectoral prices

$$
\beta \mathbb{E}_{t}\left[p_{k t+1}\right]-(1+\beta) p_{k t}+p_{k t-1}=\kappa_{k}\left(p_{k t}-m c_{k t}\right),
$$

complete the system, where $\kappa_{k} \equiv\left(1-\alpha_{k}\right)\left(1-\alpha_{k} \beta\right) / \alpha_{k}$ measures the degree of price flexibility.

\section{A. The effect of I/O linkages on marginal cost}

Here, we show that I/O linkages crucially affect marginal costs. We distinguish between the use of intermediate inputs per se (i.e., $\delta>0$ ) and heterogeneous usage of intermediate inputs across sectors (i.e., $\omega_{k r} \neq \omega_{k^{\prime} r} \forall k, \forall k^{\prime} \neq k$, and $\forall r$ ). Although our focus is on I/O linkages, heterogeneity in sectoral size $\omega_{c k}$ and in pricing frictions is also present through $\kappa_{k}$. We first derive how I/O linkages affect several intermediate, key variables.

First, I/O linkages affect the measure of sectors, $\left\{n_{k}\right\}_{k=1}^{K}$. The measure reflects the weighted average of the consumption share of sector $k, \omega_{c k}$, and the importance of sector $k$ as a supplier to the economy, $\zeta_{k}$

$$
n_{k}=(1-\psi) \omega_{c k}+\psi \zeta_{k t},
$$


where

$$
\zeta_{k} \equiv \sum_{k^{\prime}=1}^{K} n_{k^{\prime} t} \omega_{k^{\prime} k} .
$$

We refer to $\zeta_{k}$ as the "outdegree" of sector $k$, analogous to Acemoglu et al. (2012). The outdegree of sector $k$ is the weighted sum of intermediate input use from sector $k$ by all other sectors $\omega_{k^{\prime} k}$, with weights $n_{k^{\prime} t}$. In steady state, all firms are identical and we can interpret $n_{k}$ as the size of sector $k$.

Without intermediate inputs $(\delta=0), \psi \equiv \delta(\theta-1) / \theta=0$, and only consumption shares determine sector size. By contrast, when firms use intermediate inputs for production $(\delta>0)$, heterogeneity in I/O linkages results in additional heterogeneity in sector size. The outdegree of sector $k$ is higher when sector $k$ is a supplier to many sectors or is a supplier of large sectors.

The vector $\aleph$ of sector sizes $\left\{n_{k}\right\}_{k=1}^{K}$ solves

$$
\aleph=(1-\psi)\left[\mathbb{I}_{K}-\psi \Omega^{\prime}\right]^{-1} \Omega^{C},
$$

where $\mathbb{I}_{K}$ is the identity matrix of dimension $K, \Omega$ is the I/O matrix in steady state with elements $\left\{\omega_{k k^{\prime}}\right\}$, and $\Omega^{C}$ is the vector of consumption shares, $\left\{\omega_{c k}\right\}$.

Second, heterogeneity in I/O linkages implies each sector faces a different intermediate input price index

$$
p_{t}^{k}=\sum_{k^{\prime}=1}^{K} \omega_{k k^{\prime}} p_{k^{\prime} t} .
$$

In particular, the sector- $k$ intermediate input price index responds more to variation in the prices of another sector $k^{\prime}$ when that sector is a large supplier to sector $k$.

\section{A.1 Direct effect on sectoral marginal costs}

With intermediate inputs in production $(\delta>0)$, sectoral marginal costs are a weighted average of sectoral wages, but also sectoral intermediate input price indices

$$
m c_{k t}=(1-\delta) w_{k t}+\delta p_{t}^{k}
$$

The sectoral intermediate input price index, $p_{t}^{k}$, reflects heterogeneity in I/O linkages. All else equal, an increase in the price of another sector $k^{\prime}$ implies higher costs of the intermediate input mix. Heterogeneity in I/O linkages allows this channel to differ across sectors. 


\section{A.2 Indirect effect through sectoral wages}

I/O linkages also affect sectoral wages $\left\{w_{k t}\right\}$ indirectly because the efficient mix of labor and intermediate inputs in equation (5) depends on relative input prices. The production function implicitly defines sectoral labor demand for a given level of production $y_{k t}$

$$
y_{k t}=l_{k t}+\delta\left(w_{k t}-p_{t}^{k}\right)
$$

In a model without I/O linkages $(\delta=0)$, sectoral labor demand is inelastic after conditioning on sectoral production $y_{k t}$. Here, I/O linkages $(\delta>0)$ imply labor demand depends negatively on wages, because higher wages lead firms to substitute labor for intermediate inputs.

Combining the production function and sectoral labor supply yields

$$
w_{k t}=\frac{1}{1+\delta \varphi}\left[\varphi y_{k t}+\sigma c_{t}+\delta \varphi\left(p_{t}^{k}-p_{t}^{c}\right)\right]+p_{t}^{c}
$$

Thus, the optimal choice implies a wedge between sectoral intermediate input prices and aggregate consumption prices, $\left(p_{t}^{k}-p_{t}^{c}\right)$.

What is the role of this wedge? In a model without I/O linkages $(\delta=0)$, wages respond one to one to variations in aggregate consumption prices $p_{t}^{c}$ through their effect on labor supply. An increase in sector $k^{\prime}$ prices positively affects wages in sector $k$. The relevant elasticity is tied to the consumption share of sector $k^{\prime}, \omega_{c k^{\prime}}$. This effect is captured by the last term of equation (29).

In the presence of $\mathrm{I} / \mathrm{O}$ linkages $(\delta>0)$, this last term continues to affect wages. However, the wedge $\left(p_{t}^{k}-p_{t}^{c}\right)$ now additionally comes into play: An increase in sector $k^{\prime}$ prices has an additional, positive effect on sector $k$ wages when the share of sector $k^{\prime}$ as a supplier of sector $k$ is larger than its consumption share, that is, when $\omega_{k k^{\prime}}>\omega_{c k^{\prime}}$. Intuitively, if sector $k^{\prime}$ is a large supplier to sector $k$, a positive variation in $p_{k^{\prime} t}$ has a larger effect on increasing the cost of intermediate inputs for firms in sector $k$. As a result, firms in sector $k$ increase the demand for labor, and sector $k$ wages go up.

\section{A.3 Effect on sectoral demand}

Next, we show I/O linkages can heterogeneously affect how variations in aggregate demand $y_{t}$ transmit into sectoral demand, $\left\{y_{k t}\right\}_{k=1}^{K}$. This follows because sectoral demand is given by

$$
y_{k t}=y_{t}-\eta\left[p_{k t}-(1-\psi) p_{t}^{c}-\psi \widetilde{p}_{t}\right]
$$


where

$$
\widetilde{p}_{t} \equiv \sum_{k=1}^{K} n_{k} p_{t}^{k} .
$$

Sectoral demand depends on the sectoral relative price, $p_{k t}$, relative to a weighted average of aggregate consumption prices, $p_{t}^{c}$, and an "average sector-relevant" price, $\widetilde{p}_{t}$. The latter weights sector-relevant aggregate prices by the size of sectors. We can write it as

$$
\widetilde{p}_{t}=\sum_{k=1}^{K} \zeta_{k} p_{k t},
$$

that is, the sum of variations in sectoral prices weighted by their outdegrees $\left\{\zeta_{k}\right\}_{k=1}^{K}$.

Following an increase in prices of another sector $k^{\prime}$, the share of sector $k$ in total demand increases in the outdegree of that other sector. This increase is stronger than the increase in an economy without intermediate inputs if that sector is a big supplier in the whole economy: $\zeta_{k^{\prime}}>\omega_{c k^{\prime}}$.

\section{A.4 Effect on total demand}

Finally, aggregate demand, $y_{t}$, also interacts with heterogeneity in I/O linkages. Aggregating Walras' law across all industries yields

$$
y_{t}=(1-\psi) c_{t}+\psi z_{t}
$$

where $z_{t}$ is the total amount of intermediate inputs. The pure presence of intermediate inputs creates a wedge between total production, $y_{t}$, and value-added production, $c_{t}$. The dynamics of $z_{t}$ around the steady state depend on the heterogeneity in I/O linkages across sectors.

We solve for $z_{t}$, combining Walras' law, the aggregate production function, aggregate labor supply, and the aggregation of efficient mixes between labor and intermediate inputs,

$$
z_{t}=\frac{[(1+\varphi)(1-\psi)+\sigma(1-\delta)] c_{t}-(1-\delta)\left(\widetilde{p}_{t}-p_{t}^{c}\right)}{(1-\psi)+\varphi(\delta-\psi)}
$$

In an economy with no I/O linkages $(\delta=0, \psi=0)$, output equals consumption, $y_{t}=c_{t}$. With intermediate inputs $(\delta>0), z_{t}$ varies positively with $c_{t}$ : More value-added production requires more intermediate inputs. This channel shows up as the first term in the numerator of equation (34). At the same time, an increase in prices of a given sector $k^{\prime}$ has a negative effect on $z_{t}$ when that sector is central in the economy. This second 
effect is captured by the wedge $\left(\widetilde{p}_{t}-p_{t}^{c}\right)$, the second term in the numerator of equation (34), equivalent to the condition that sectors are relatively more central than their GDP share implies: $\zeta_{k^{\prime}}>\omega_{c k^{\prime}}$. Then, an increase in prices of big suppliers in the economy results in higher prices for intermediate inputs for many sectors and/ or bigger sectors. These sectors then substitute intermediate inputs for labor, and the aggregate demand for intermediate inputs decreases.

To simplify exposition, we write the relationship between $y_{t}$ and $c_{t}$ as

$$
y_{t}=\left(1+\psi \Gamma_{c}\right) c_{t}-\psi \Gamma_{p}\left(\widetilde{p}_{t}-p_{t}^{c}\right)
$$

where $\Gamma_{c} \equiv \frac{(1-\delta)(\sigma+\varphi)}{(1-\psi)+\varphi(\delta-\psi)}, \Gamma_{p} \equiv \frac{1-\delta}{(1-\psi)+\varphi(\delta-\psi)}$.

\section{B. Overall solution for log-linearized marginal costs}

We combine equations that we derived in the previous subsections to express marginal costs in terms of value-added production and sectoral prices

$$
\begin{aligned}
m c_{k t}= & {\left[1+\frac{(1-\delta) \varphi \eta}{1+\delta \varphi}\right] p_{t}^{c}+\delta \frac{1+\varphi}{1+\delta \varphi}\left(p_{t}^{k}-p_{t}^{c}\right)+(1-\delta) \frac{\varphi \psi\left(\eta-\Gamma_{p}\right)}{1+\delta \varphi}\left(\widetilde{p}_{t}-p_{t}^{c}\right)(36) } \\
& -\frac{(1-\delta) \varphi \eta}{1+\delta \varphi} p_{k t}+\frac{1-\delta}{1+\delta \varphi}\left[\sigma+\varphi\left(1+\psi \Gamma_{c}\right)\right] c_{t} .
\end{aligned}
$$

By contrast, in an otherwise identical economy with no I/O linkages $(\delta=0)$, marginal costs are given by

$$
m c_{k t}^{\delta=0}=(1+\varphi \eta) p_{t}^{c}-\varphi \eta p_{k t}+(\sigma+\varphi) c_{t}
$$

There, an increase in prices of other sectors, $p_{k^{\prime} t}$, increases marginal costs. This effect uniformly depends on elasticities $1+\varphi \eta$, and specifically, on the heterogeneity in consumption shares $\omega_{c k^{\prime}}$.

In our setting, new effects arise. The first line of equation (36) shows how sectoral prices affect sectoral marginal costs in an economy with I/O linkages $(\delta>0)$. The effect of prices of other sectors on sector $k$ marginal costs - contained in aggregate consumption prices via the first term - continues to be present, but is now mitigated because $1+$ $(1-\delta) \varphi \eta /(1+\delta \varphi)<(1+\varphi \eta)$. At the same time, I/O linkages create new channels. In particular, prices of another sector $p_{k^{\prime} t}$ have a stronger effect on $m c_{k t}$ if (i) sector $k^{\prime}$ is a big supplier to sector $k$; that is, $\omega_{k k^{\prime}}>\omega_{c k^{\prime}}$ so that the wedge $\left(p_{t}^{k}-p_{t}^{c}\right)>0$ (second term on the right-hand side of equation (36)); and (ii) sector $k^{\prime}$ is a big supplier in the whole economy; that is, $\zeta_{k^{\prime}}>\omega_{c k^{\prime}}$ so that the wedge $\left(\tilde{p}_{t}-p_{t}^{c}\right)>0$ (third term on the right-hand 
side of equation (36)). The overall direct effect of variations in $p_{k^{\prime} t}$ on $m c_{k t}$ is

$$
\frac{(1-\delta)\left[1+(1-\psi) \varphi \eta+\psi \varphi \Gamma_{p}\right]}{1+\delta \varphi} \omega_{c k^{\prime}}+\delta \frac{1+\varphi}{1+\delta \varphi} \omega_{k k^{\prime}}+(1-\delta) \frac{\varphi \psi\left(\eta-\Gamma_{p}\right)}{1+\delta \varphi} \zeta_{k^{\prime}}
$$

The last two terms of equation (36) are standard. The fourth term on the right-hand side of equation (36) shows sector $k$ marginal costs decrease in sector $k$ prices. The demand for sectoral output is a decreasing function of its price, and hence, wages in sector $k$. The fifth term on the right-hand side of equation (36) shows marginal costs increase in value-added production $c_{t}$.

\section{Theoretical Results}

Here, we present new, closed-form results for the response of inflation and consumption to a monetary policy shock. In doing so, we benchmark our economy with heterogeneity in price rigidity against an economy where prices are homogeneously rigid. We highlight how the I/O structure interacts with the pricing frictions and heterogeneity in sectoral size and shapes our results. We show that the identity effect - which sector contributes the most to monetary transmission - can be crucially affected. Also, the level of aggregation can be key for the degree of monetary non-neutrality. The latter two insights provide important guidance for monetary policymakers trying to correctly assess the transmission of monetary policy shocks to output and inflation.

\section{A. Monetary non-neutrality in the simplified model}

We start by introducing three assumptions that allow us to obtain results in closed form. First, household utility is $\log$ in consumption, $\sigma=1$, and linear in leisure, $\varphi=0$, such that

$$
w_{t}=c_{t}+p_{t}^{c}
$$

Second, a cash-in-advance constraint exists for final-goods consumption only,

$$
m_{t}=c_{t}+p_{t}^{c}
$$

where $p_{t}^{c} \equiv \sum_{k=1}^{K} \omega_{c k} p_{k t}$ 
Third, firms fully discount the future when they adjust prices $(\beta=0)$, so

$$
p_{k t}^{*}=m c_{k t}
$$

Combining all these equations with the sectoral aggregation of prices

$$
p_{k t}=\left(1-\alpha_{k}\right) p_{k t}^{*}+\alpha_{k} p_{k t-1}
$$

yields

$$
p_{k t}=\left(1-\alpha_{k}\right)\left[(1-\delta) m_{t}+\delta p_{t}^{k}\right]+\alpha_{k} p_{k t-1} \text { for } k=1, \ldots, K
$$

with solution for the sectoral vector of prices

$$
p_{t}=(1-\delta) \sum_{\tau=0}^{\infty}\left([\mathbb{I}-\delta(\mathbb{I}-A) \Omega]^{-1} A\right)^{\tau}[\mathbb{I}-\delta(\mathbb{I}-A) \Omega]^{-1}(\mathbb{I}-A) \iota m_{t-\tau}
$$

where $\Omega$ denotes the matrix of I/O weights, $\Omega^{c}$ the vector of consumption weights, and $A$ the diagonal matrix of $\alpha_{k}$.

In the following, we use equations (40) and (43) to build intuition on the determinants of monetary non-neutrality in the model. In particular, we assume the economy is in steady state when a permanent monetary shock hits at period $t^{*}$ such that $m_{t}=m$ for all $t \geq t^{*}$ and $m_{t}=0$ for all $t<0$. We focus on characterizing the response of the aggregate consumption price index $p_{t}^{c}$ to the shock in three cases. In this simplified model, the aggregate price response is a sufficient statistic for the real output response.

First, we consider the case in which price stickiness is homogeneous across sectors. This assumption sets up a useful benchmark for the following cases that feature heterogeneity in price stickiness, as well as our subsequent discussion of the effect of sectoral aggregation. At the same time, we are not placing any restrictions on the sectoral GDP shares $\omega_{c k}$ and the I/O structure $\left\{\omega_{k k^{\prime}}\right\}$ yet.

Proposition 1 When price stickiness is homogeneous across sectors, $\alpha_{k}=\alpha$ for all $k$, the response of aggregate consumption prices to a permanent monetary policy shock is

$$
p_{t}^{c}(\alpha)=\left[1-\left(\frac{\alpha}{1-\delta(1-\alpha)}\right)^{t-t^{*}+1}\right] m \quad \text { for } \quad t \geq t^{*}
$$

such that

(1) $p_{t}^{c}(\alpha)$ is decreasing in $\delta$ for any $t \geq t^{*}$, and 
(2) heterogeneity of consumption shares $\left\{\omega_{c k}\right\}_{k=1}^{K}$ and I/O linkages $\left\{\omega_{k k^{\prime}}\right\}_{k, k^{\prime}=1}^{K}$ is irrelevant for the response of aggregate consumption prices to the monetary shock.

Proof. See Appendix.

The proposition presents two insights. First, the stickiness of marginal costs increases in $\delta$; hence, the responsiveness of the aggregate consumption price index to the monetary policy shock decreases in $\delta$. As a result, a lesser price response means stronger monetary non-neutrality. This results mimics the insights of the network multiplier in Basu (1995). Second, heterogeneity of consumption shares and I/O linkages are irrelevant for monetary non-neutrality with homogeneous price stickiness across sectors.

What happens if we allow for heterogeneity in price stickiness? The next proposition shows heterogeneity of price rigidity amplifies (mitigates) the response of output (prices) in all periods except upon impact - when it has no effect. This result follows, as a first step, from a simplified I/O structure. We fully relax this assumption in the subsequent proposition.

Proposition 2 In an economy in which price stickiness is heterogeneous across sectors and I/O linkages are identical to consumption shares, $\omega_{k k^{\prime}}=\omega_{c k^{\prime}}$ for all $k, k^{\prime}$, the response of aggregate consumption prices to a permanent monetary policy shock is

$p_{t}^{c}=\frac{1-\delta}{1-\delta(1-\bar{\alpha})}\left(1-\sum_{k=1}^{K} \omega_{c k} \alpha_{k}^{t-t^{*}+1}\right) m+\frac{\delta}{1-\delta(1-\bar{\alpha})} \sum_{\tau=1}^{t-t^{*}}\left(\sum_{k=1}^{K} \omega_{c k} \alpha_{k}^{\tau}\left(1-\alpha_{k}\right)\right) p_{t-\tau}^{c} \quad$ if $t \geq t^{*}$,

where $\bar{\alpha} \equiv \sum_{k=1}^{K} \omega_{c k} \alpha_{k}$, such that

(1) The sectoral heterogeneity of price stickiness and consumption shares are irrelevant for the response of output to the monetary shock on impact.

(2) $p_{t}^{c} \leq p_{t}^{c}(\bar{\alpha})$ for $t>t^{*}$. The response of the aggregate consumption prices for $t \geq t^{*}$ is weakly decreasing in the dispersion of price stickiness, and depends on heterogeneities $\left\{\omega_{k k^{\prime}}=\omega_{c k^{\prime}}\right\}$.

Proof. See Appendix

Proposition 2 studies a simplified steady-state network economy in which sectoral output is used in equal proportions by consumers and other sectors. In this economy, sectoral heterogeneity in price stickiness amplifies monetary non-neutrality, as in Carvalho (2006) and Carvalho and Schwartzman (2015). In particular, sectoral heterogeneity of price stickiness does not affect the impact response, but increases the persistence 
of monetary non-neutrality. However, in an economy in which firms set prices in a forward-looking manner $(\beta>0)$, the increased persistence of monetary non-neutrality would also imply stronger monetary non-neutrality on impact.

What happens in the fully unrestricted case when price stickiness, sectoral size, and I/O linkages are heterogeneous across sectors?

Proposition 3 Let $p_{t}^{c}$ denote the response of the aggregate consumption price index to a permanent monetary shock in an economy with no restrictions on the sectoral heterogeneity of price stickiness $\left\{\alpha_{k}\right\}$, sectoral size $\left\{\omega_{c k}\right\}$, and I/O linkages $\left\{\omega_{k k^{\prime}}\right\}$. In this economy,

$$
p_{t}^{c}=(1-\delta)\left(1-\sum_{k=1}^{K} \omega_{c k} \alpha_{k}^{t-t^{*}+1}\right) m+\delta \sum_{\tau=0}^{t-t^{*}} \sum_{k=1}^{K}\left(\sum_{k^{\prime}=1}^{K} \omega_{c k^{\prime}} \alpha_{k^{\prime}}^{\tau}\left(1-\alpha_{k^{\prime}}\right) \omega_{k^{\prime} k}\right) p_{k t-\tau} \quad \text { for } \quad t \geq t^{*},
$$

with $p_{k t-\tau}=0$ if $t<t^{*}$ such that

(1) The response of $p_{t}^{c}$ is weaker on impact than in Proposition 2, when $u_{k} \equiv$ $\sum_{k^{\prime}=1}^{K} \omega_{c k^{\prime}}\left(1-\alpha_{k^{\prime}}\right) \omega_{k^{\prime} k}>(1-\bar{\alpha}) \omega_{c k}$ for the sectors with the stickiest prices.

(2) The response of $p_{t}^{c}$ for $t>t^{*}$ is more persistent than in Proposition 2, when for sectors with the stickiest prices, either of the following conditions hold: (i) $\bar{\omega}_{k} \equiv$ $\frac{1}{K} \sum_{k^{\prime}=1}^{K} \omega_{k^{\prime} k}>\omega_{c k}$, (ii) $u_{k}>(1-\bar{\alpha}) \omega_{c k}$, (iii) $\operatorname{COV}\left(\omega_{c k^{\prime}} \alpha_{k^{\prime}}^{\tau}\left(1-\alpha_{k^{\prime}}\right), \omega_{k^{\prime} k}\right)>0$.

Proof. See Appendix.

The fully unrestricted interaction creates an even richer transmission of monetary policy shocks. In doing so, the exact interaction of nominal and real heterogeneities is crucial for understanding the effects of a monetary shock on output and prices. The implications we find are completely new to the literature.

First, upon impact, the price effect is weaker - and hence monetary non-neutrality larger - than under the restricted heterogeneity of I/O linkages in Proposition 2. This effect happens when the largest sectors with the stickiest prices are also important suppliers to the largest, most flexible sectors. Second, in subsequent periods, aggregate price changes become more persistent given the three conditions in the second part of the proposition. In conjunction with the first result, this increased persistence means more persistence and larger monetary non-neutrality than under restricted heterogeneity. ${ }^{5}$

In particular, a corollary of these results is a novel identity effect: The extent to which a sector transmits monetary policy shocks depends on the exact interaction of heterogeneity in pricing frictions and heterogeneity in sectoral size and I/O linkages. The

\footnotetext{
${ }^{5}$ Note that we have left a contemporaneous term in the second right-hand side term of the proposition to make it more comparable to Proposition 2. The online appendix contains an explicit solution in terms of parameters and the monetary shock only.
} 
following corollaries summarize the impact of each sector on aggregate prices, first upon impact only, and then for all subsequent periods.

Corollary 1 Upon impact, each sectoral contribution to the decay of aggregate prices is given

(1) independently of heterogeneity in I/O linkages under homogeneous price rigidity, and by

$$
\left(\frac{(1-\delta)(1-\alpha)}{1-\delta(1-\alpha)}\right) \omega_{c k} m, \text { and }
$$

(2) by a function of heterogeneities under heterogeneous price rigidity,

$$
e_{k}^{\prime} \Omega^{c}(1-\delta)[\mathbb{I}-\delta(\mathbb{I}-A) \Omega]^{-1}(\mathbb{I}-A) \iota m
$$

where $e_{k}$ is the kth basis vector, $\Omega$ the matrix of $I / O$ weights, $\Omega^{c}$ the vector of consumption weights, $A$ the diagonal matrix of $\alpha_{k}$, and $\iota$ a unit vector. In the special case of $\omega_{c k^{\prime}}=\omega_{k k^{\prime}}$, the $k$ th element equals $\left(\frac{(1-\delta)\left(1-\alpha_{k}\right)}{1-\delta(1-\bar{\alpha})}\right) \omega_{c k} m$.

Corollary 2 In subsequent periods, $t>t^{*}$, each sectoral contribution to aggregate prices is pinned down

(1) independently of heterogeneity in I/O linkages under homogeneous price rigidity,

$$
\left[1-\left(\frac{\alpha}{1-\delta(1-\alpha)}\right)^{t-t^{*}+1}\right] \omega_{c k} m, \text { and }
$$

(2) by the interaction of the heterogeneities under heterogeneous price rigidity,

$$
e_{k}^{\prime} \Omega^{c}(1-\delta) \sum_{\tau=0}^{t-t^{*}}\left([\mathbb{I}-\delta(\mathbb{I}-A) \Omega]^{-1} A\right)^{\tau}[\mathbb{I}-\delta(\mathbb{I}-A) \Omega]^{-1}(\mathbb{I}-A) \iota m_{t-\tau}
$$

where $e_{k}$ is the $k$ th basis vector, $\Omega$ the matrix of input-output weights, $\Omega^{c}$ the vector of consumption weights and $A$ the diagonal matrix of $\alpha_{k}$.

Proof. See Appendix.

The importance of each sector crucially depends on the interaction of heterogeneities. Timing also plays an important role, whether we consider the impact response, or subsequent responses. The ranking of importance across the different cases can clearly change. For example, sectors that are important upon impact may be less important later on. Similarly, heterogeneity in I/O linkages can influence the importance of a sector. 
Ultimately, the extent to which the interaction of heterogeneities can affect the relative importance of sectors for aggregate fluctuations is an empirical question.

We have not placed any restrictions on the total effect of monetary policy. Monetary policy shocks could easily generate the same real effects under different assumptions about which heterogeneities are present, whereas sectors are differently important in generating the same real effects. For example, consider a two-sector economy that generates a particular path of real output and prices following a monetary policy shocks. Now, if we simply flip all parameter values for the two sectors, the aggregate paths of output and prices remain identical. At the same time, the loading of monetary policy transmission flips. This identity effect may be important, for example, when optimally targeting monetary policy.

\section{B. The effect of sectoral aggregation}

Most of the literature so far studies models with only a limited number of sectors such as 6 or 30 . In this subsection, we study in the simplified model whether the choice of aggregation matters for the effect of monetary policy shocks on key macroeconomic aggregates. In particular, we compare the effects of a permanent monetary policy shock on aggregate consumption prices at two levels of disaggregation: one with $K$ sectors (denoted by $p_{t}^{c}$ ), and another in which random pairs of sectors are merged log-linearly, so it has $K / 2$ sectors (denoted by $\bar{p}_{t}^{c}$ ). For simplicity, we assume $K$ is even. In mathematical terms, we compare

$$
\begin{aligned}
p_{t}^{c} & \equiv \sum_{k=1}^{K} \omega_{c k} p_{k t}, \\
\bar{p}_{t}^{c} & \equiv \sum_{k^{\prime}=1}^{K / 2} \bar{\omega}_{c k^{\prime}} \bar{p}_{k^{\prime} t}
\end{aligned}
$$

such that

$$
\begin{aligned}
\bar{\omega}_{c k^{\prime}} & \equiv \omega_{c 2 k^{\prime}-1}+\omega_{c 2 k^{\prime}}, \\
\bar{p}_{k^{\prime} t} & \equiv \lambda_{k^{\prime}} p_{2 k^{\prime}-1}+\left(1-\lambda_{k^{\prime}}\right) p_{2 k^{\prime}}, \\
\lambda_{k^{\prime}} & =\frac{\omega_{c 2 k^{\prime}-1}}{\omega_{c 2 k^{\prime}-1}+\omega_{c 2 k^{\prime}}} .
\end{aligned}
$$

for $k^{\prime}=1, \ldots, K / 2$. This specification is without loss of generality when merging two consecutive sectors, because the ordering of sectors is arbitrary. 
In addition, Calvo parameters are aggregated among merged sectors by

$$
\bar{\alpha}_{k^{\prime}} \equiv \lambda_{k^{\prime}} \alpha_{2 k^{\prime}-1}+\left(1-\lambda_{k^{\prime}}\right) \alpha_{2 k^{\prime}}
$$

and their I/O linkages as

$$
\omega_{k^{\prime} s^{\prime}}=\xi_{k^{\prime}}\left(\omega_{2 k^{\prime}-1,2 s^{\prime}-1}+\omega_{2 k^{\prime}-1,2 s^{\prime}}\right)+\left(1-\xi_{k^{\prime}}\right)\left(\omega_{2 k^{\prime}, 2 s^{\prime}-1}+\omega_{2 k^{\prime}, 2 s^{\prime}}\right)
$$

for $k^{\prime}, s^{\prime}=1, \ldots, K / 2$. The weights $\xi_{k^{\prime}}$ equal the shares of sectors in total intermediate input use of the merged sectors.

First, we show that monetary non-neutrality is higher in a more disaggregated economy in the absence of I/O linkages $(\delta=0)$.

Proposition 4 When $\delta=0$, the difference in the response of consumption prices to a permanent monetary shock at the two levels of disaggregation is given by

$$
\bar{p}_{t}^{c}-p_{t}^{c}=\sum_{k^{\prime}=1}^{K / 2} \bar{\omega}_{c k^{\prime}}\left[\lambda_{k^{\prime}} \alpha_{2 k^{\prime}-1}^{t-t^{*}+1}+\left(1-\lambda_{k^{\prime}}\right) \alpha_{2 k^{\prime}}^{t-t^{*}+1}-\bar{\alpha}_{k^{\prime}}^{t-t^{*}+1}\right] m
$$

such that (i) $p_{t}^{c}=\bar{p}_{t}^{c}$ for $t=t^{*}$, (ii) $p_{t}^{c}<\bar{p}_{t}^{c}$ for $t>t^{*}$, (iii) $\bar{p}_{t}^{c}-p_{t}^{c}$ is increasing in the dispersion of Calvo parameters among merged sectors, and (iv) $\bar{p}_{t}^{c}-p_{t}^{c}$ is increasing in the consumption shares of merged sectors with the highest dispersion of Calvo parameters among merged sectors.

Proof. See Appendix.

This proposition is an application of Jensen's inequality. The larger the dispersion of frequency of price changes among merged sectors, the smaller the monetary non-neutrality as the level of disaggregation becomes increasingly more coarse relative to a more finely disaggregated economy. The difference in monetary non-neutrality across the two levels of disaggregation increases as time passes after the impact response when both are identical. The intuition for this result is the same as in our analysis above: Aggregating sectors overstates the response of prices to a monetary policy shock, because the measure of first-time responders is higher when the two sectors have the same frequency of price changes than when they exhibit different frequencies but with the same mean.

Next, we show a new result to the literature: Further disaggregation also leads to more monetary non-neutrality by overstating the amplification introduced by intermediate inputs. We show this result under restricted heterogeneity of the production network ( $\left.\omega_{s k}=\omega_{c k}\right)$. 
Proposition 5 When $\delta \in(0,1)$ and $\omega_{s k}=\omega_{c k}$ for all $s, k=1, . ., K$, the difference in the response of consumption prices to a permanent monetary shock at the two levels of disaggregation is given by

$$
\begin{aligned}
\bar{p}_{t}^{c}-p_{t}^{c}= & \frac{1-\delta}{1-\delta(1-\bar{\alpha})} \sum_{k^{\prime}=1}^{K / 2} \bar{\omega}_{c k^{\prime}}\left(\lambda_{k^{\prime}} \alpha_{2 k^{\prime}-1}^{t-t^{*}+1}+\left(1-\lambda_{k^{\prime}}\right) \alpha_{2 k^{\prime}}^{t-t^{*}+1}-\bar{\alpha}_{k^{\prime}}^{t-t^{*}+1}\right) m \\
& -\frac{\delta}{1-\delta(1-\bar{\alpha})} \sum_{\tau=1}^{\infty}\left(\sum_{k^{\prime}=1}^{K / 2} \bar{\omega}_{c k^{\prime}}\left[\begin{array}{c}
\lambda_{k^{\prime}}\left(1-\alpha_{2 k^{\prime}-1}\right) \alpha_{2 k^{\prime}-1}^{\tau}+\left(1-\lambda_{k^{\prime}}\right)\left(1-\alpha_{2 k^{\prime}}\right) \alpha_{2 k^{\prime}}^{\tau} \\
-\left(1-\bar{\alpha}_{k^{\prime}}\right) \bar{\alpha}_{k^{\prime}}^{\tau}
\end{array}\right]\right) p_{t-\tau}^{c},
\end{aligned}
$$

where $p_{t}^{c}=0$ if $t<t^{*}$. Results (i) through (iv) in the previous proposition continue to hold and are amplified by the intermediate input channel.

Proof. See Appendix.

Intermediate inputs introduce strategic complementarity in the response of prices to a monetary shock, which implies consumption prices are more persistent at a finer level of disaggregation. This effect is stronger when merged sectors with more heterogeneous frequencies of price changes are also sectors with more homogeneous consumption shares, for a stronger short-term response of aggregate prices. The effect also increases when merged sectors with higher consumption shares have lower frequencies of price changes.

Third, the next proposition relaxes any restriction in the I/O structure of the production network. Now, the effect of aggregation on the amplification effect of monetary non-neutrality introduced by intermediate inputs is an intricate combination of the sectoral distributions of the frequency of price changes, consumption weights, and I/O linkages.

Proposition 6 When $\delta \in(0,1)$ and I/O linkages are unrestricted, the difference in the response of consumption prices to a permanent monetary shock at the two levels of disaggregation is given by

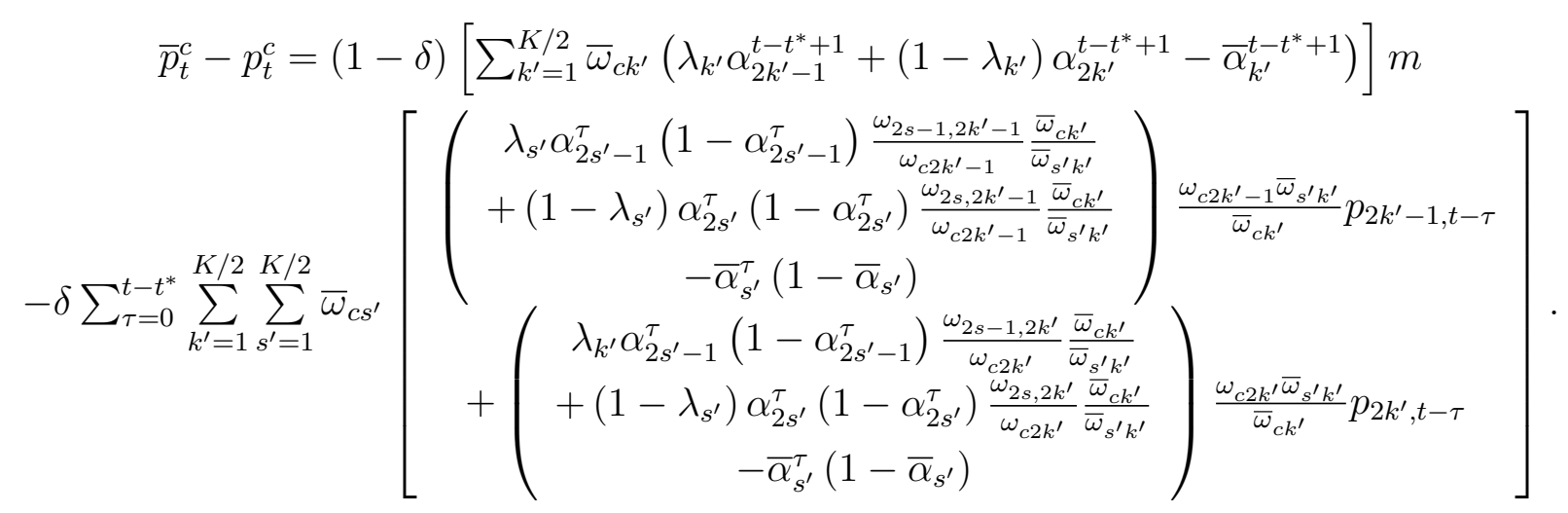

Proof. See Appendix. 
So far, Jensen's inequality captures the whole effect of sectoral aggregation, because the response of aggregate prices to a monetary shock depends on the sum of non-linear functions of the sectoral frequency of price changes, $\left\{\alpha_{k}\right\}_{k=1}^{K}$. The same is true in this proposition for the first line on the RHS of the expression for $\bar{p}_{t}^{c}-p_{t}^{c}$. However, it is not true for the amplification term that is due to intermediate input use. In particular, for each of the rounded parentheses in the second line in the above expression, now the difference between the two levels of aggregation depends non-trivially on the I/O linkages. Compared to Proposition 5, we now could have more or less monetary non-neutrality. In the fully heterogeneous setting, the exact quantitative effect will therefore depend on the joint distribution of heterogeneities, which we study empirically below.

\section{Data and Calibration}

A detailed calibration to the U.S. economy is one of the contributions of this paper. The data we use can potentially provide the basis for many other model evaluations, including detailed policy analyses. The main data contribution lies in pinning down three sources of heterogeneity: different combinations of intermediate inputs for production, different sectoral sizes, and heterogeneous Calvo rates. In making these choices, the granularity of the I/O data determines the definition of sectors for the PPI data. We now describe the data we use to construct the I/O linkages, measures of sectoral size, and price stickiness.

\section{A. Input-Output tables}

The BEA produces I/O tables detailing the dollar flows between all producers and purchasers in the U.S. Producers include all industrial and service sectors, as well as household production. Purchasers include industrial sectors, households, and government entities. The BEA constructs the I/O tables using Census data that are collected every five years. The BEA has published I/O tables every five years beginning in 1982 and ending with the most recent tables in 2012. The I/O tables are based on NAICS industry codes. Prior to 1997, the I/O tables were based on SIC codes.

The I/O tables consist of two basic national-accounting tables: a "make" table and a "use" table. The make table shows the production of commodities by industry. Rows present industries, and columns present the commodities each industry produces. Looking across columns for a given row, we see all the commodities a given industry produces. The sum of the entries comprises industry output. Looking across rows for a given column, we see all industries producing a given commodity. The sum of the entries adds up to the 
output of a commodity. The use table contains the uses of commodities by intermediate and final users. The rows in the use table contain the commodities, and the columns show the industries and final users that utilize them. The sum of the entries in a row is the output of that commodity. The columns document the products each industry uses as inputs and the three components of "value added": compensation of employees, taxes on production and imports less subsidies, and gross operating surplus. The sum of the entries in a column adds up to industry output.

We utilize the I/O tables for 2002 to create an industry network of trade flows. The BEA defines industries at two levels of aggregation: detailed and summary accounts. We use both levels of aggregation to create industry-by-industry trade flows. The tables also pin down sectoral size.

The BEA provides concordance tables between NAICS codes and I/O industry codes. We follow the BEA's I/O classifications with minor modifications to create our industry classifications. We account for duplicates when NAICS codes are not as detailed as I/O codes. In some cases, an identical set of NAICS codes defines different I/O industry codes. We aggregate industries with overlapping NAICS codes to remove duplicates.

We combine the make and use tables to construct an industry-by-industry matrix that details how much of an industry's inputs other industries produce (see section II of the online appendix for details).

\section{B. Price stickiness data}

We use the confidential microdata underlying the producer price data (PPI) from the BLS to calculate the frequency of price adjustment at the industry level. ${ }^{6}$ The PPI measures changes in selling prices from the perspective of producers, and tracks prices of all goods-producing industries, such as mining, manufacturing, and gas and electricity, as well as the service sector. ${ }^{7}$

The BLS applies a three-stage procedure to determine the sample of individual goods. In the first stage, to construct the universe of all establishments in the U.S., the BLS compiles a list of all firms filing with the Unemployment Insurance system. In the second and third stages, the BLS probabilistically selects sample establishments and goods based on either the total value of shipments or the number of employees. The BLS collects prices

\footnotetext{
${ }^{6}$ The data have been used before in Nakamura and Steinsson (2008), Goldberg and Hellerstein (2011), Bhattarai and Schoenle (2014), Gilchrist, Schoenle, Sim, and Zakrajšek (2015), Gorodnichenko and Weber (2016), Weber (2015), and D'Acunto, Liu, Pflueger, and Weber (2016).

${ }^{7}$ The BLS started sampling prices for the service sector in 2005 . The PPI covers about $75 \%$ of the service sector output. Our sample ranges from 2005 to 2011.
} 
from about 25,000 establishments for approximately 100,000 individual items on a monthly basis. The BLS defines PPI prices as "net revenue accruing to a specified producing establishment from a specified kind of buyer for a specified product shipped under specified transaction terms on a specified day of the month." Prices are collected via a survey that is emailed or faxed to participating establishments. Individual establishments remain in the sample for an average of seven years until a new sample is selected to account for changes in the industry structure.

We calculate the frequency of price adjustment at the goods level, FPA, as the ratio of the number of price changes to the number of sample months. For example, if an observed price path is $\$ 10$ for two months and then $\$ 15$ for another three months, one price change occurs during five months, and the frequency is $1 / 5$. We aggregate goods-based frequencies to the BEA industry level.

The overall mean monthly frequency of price adjustment is $19 \%$, which implies an average duration, $-1 / \ln (1-F P A)$, of 4.6 months. Table A.1 and Figure A.1 in the online appendix summarize the distribution of the frequency of price changes and document a large right tail. Substantial heterogeneity is present in the frequency across sectors, ranging from as low as $4.01 \%$ for the semiconductor manufacturing sector (duration of 24.43 months) to $93.75 \%$ for dairy production (duration of 0.36 months).

\section{Parameter Calibration}

We calibrate our model at different levels of detail to analyze monetary non-neutrality. One contribution is the calibration of a highly disaggregated 350-sector economy, which we discuss in this section, and contrast with a 58-sector model, but delegate the details of the 58-sector model to the online appendix.

We calibrate the model at the monthly frequency using standard parameter values in the literature (see Table 1). The coefficient of relative risk aversion $\sigma$ is 1 , and $\beta=0.9975$, implying an annual risk-free interest rate of $3 \%$. We set $\varphi=2$, implying a Frisch elasticity of labor supply of 0.5 . We set $\delta$, the average share of inputs in the production function, to 0.5, in line with Basu (1995) and empirical estimates. We set the within-sector elasticity of substitution $\theta$ to 6 , implying a steady-state markup of $20 \%$, and the across-sector elasticity of substitution $\eta$ to 2, in line with Carvalho and Lee (2011). We set the parameters in the Taylor rule to standard values of $\phi_{\pi}=1.24$ and $\phi_{c}=0.33 / 12$ (see Rudebusch (2002)). The persistence parameter of monetary shocks is $\rho=0.9$.

We investigate the robustness of our findings to permutations in parameter values in section III of the online appendix. Overall, the main conclusions of this section remain 
unaffected by variations in assumptions. The robustness section also includes an analysis of how changes in the tails of the frequency distribution affect our findings.

\section{Empirical Results}

\section{A. Monetary policy shocks and monetary non-neutrality}

In this section, we present our first empirical result: Heterogeneity in price stickiness is the main driver behind real effects of monetary policy. At the same time, the interaction of heterogeneous price stickiness, sector size, and I/O linkages can lower or amplify real effects, but only by small amounts. This result, however, depends on the level of granularity. The response of inflation is also mainly driven by heterogeneity in the frequency of price changes, but little by heterogeneity in sector size or I/O linkages.

We proceed by studying the response of consumption, inflation, and real marginal costs to a $1 \%$ monetary policy shock. The benchmark economy is a homogeneous model economy with homogeneous Calvo rates equal to the average Calvo rate, and sectoral sizes and $\mathrm{I} / \mathrm{O}$ shares equal to $1 / K$. We develop step-wise intuition analogous to section IV.

We calibrate six different cases to arrive at our results. We start with an economy with perfectly flexible prices, in which consumption shares and I/O linkages are homogeneous $\left(\omega_{k k^{\prime}}=\omega_{c k}=1 / K\right)$, and add one kind of heterogeneity at a time. Table 2 lists the different combinations of frequencies of price adjustments across sectors, sector sizes, and I/O linkages we study. Table 3 and Figure 1 show our results.

In our first case, prices are flexible and adjust fully on impact. We allow for the existence of I/O linkages, but we constrain them to be homogeneous. That is, every sector uses equal shares of inputs $1 / K$ from all other sectors. When all sectors have the same degree of price stickiness, the monetary shock affects all sectors equally, and consumption prices, $p_{t}^{c}$, and sectoral intermediate input prices, $p_{t}^{k}$, are identical. No price wedges distort marginal costs (see equation 36). Our model boils down to a textbook New Keynesian model in which the steady-state share of intermediate inputs, $\delta$, also affects the response of consumption. In a New Keynesian model with fully flexible prices, prices fully absorb the monetary policy shock, and we do not see any effect on real consumption or marginal costs (solid lines in Figure 1).

We add homogeneous price stickiness across sectors that is equal to a consumptionshare weighted average in the economy of $19 \%$ in case 2 . We know from the discussion of case 1 that our model behaves like a standard New Keynesian model. Price stickiness reduces the impact response of inflation by $30 \%$ (-1.98 vs. -2.94 , see Table 3$)$, and leads 
to a large impact drop in consumption of $2.56 \%$. Both the inflation and consumption responses are persistent. Figure 1 shows the response in the blue lines marked by + .

We do not study the interaction of homogeneous price stickiness, heterogeneous sector size, and heterogeneous I/O structure. We know from Proposition 1 that the response of consumption and inflation is independent of heterogeneity in sectoral size and $\mathrm{I} / \mathrm{O}$ linkages when price stickiness is homogeneous across sectors.

In case 3, we introduce heterogeneity in price stickiness. We keep sectoral size and I/O linkages homogeneous. As a result, sectoral prices react differently to a monetary shock, because heterogeneity in price stickiness introduces complementarity in price adjustment. Under the assumptions of this case, however, sectoral weights of all aggregate prices are the same, so that $p_{t}^{k}=p_{t}^{c}=\widetilde{p}_{t}$ for all sectors $k$, and the wedges between price indices that affect marginal cost are absent.

We see in Figure 1 (blue dashed line) a negative selection effect - older prices are less likely to change, and real effects are larger - dominates any of the other factors that influence markups, and real effects of monetary policy are now substantially larger and the price effect is muted. The real effects of monetary policy both on impact and cumulatively more than double compared to an economy with homogeneous but equal average price stickiness (see Table 3). The inflation response, instead, is substantially muted (see blue dashed line in Figure 1). Our results confirm the intuition for economies with strategic complementarity in price setting of Carvalho and Schwartzman (2015) and Nakamura and Steinsson (2010) and Proposition 2 in our simplified model. Relative to the predictions of the simplified model, the impact difference in the price response relative to the previous case also highlights the role of forward-looking price setters.

Case 4 introduces heterogeneity in consumption weights. I/O linkages are also heterogeneous but as a knife-edge case equal to consumption weights $\left(\omega_{k k^{\prime}}=\omega_{c k}\right)$. Empirically, allowing for heterogeneity in consumption weights on impact decreases the real effects of monetary policy by $16 \%$ and increases the response of inflation by $36 \%$ relative to case 3. Overall, the change in the assumption on consumption shares and I/O linkages relative to case 3 only marginally decreases the cumulative real effects by $4 \%$. However, it increases the total response of inflation by $52 \%$ compared to the case in which we allow for heterogeneity in price stickiness only (compare blue dotted line to blue dashed line in Figure 1). This finding is in line with Proposition 2, where heterogeneity in consumption weights can have a dynamic effect.

Case 5 examines an economy in which I/O linkages are homogeneous but consumption weights are heterogeneous. This case corresponds to Proposition 3 in the simplified model, 
where we allow consumption and I/O weights to differ. It is now no longer the case that $p_{t}^{k}=p_{t}^{c}$ and $\zeta_{k}=\omega_{c k}$, which opens up two additional wedges in marginal costs (see equation (36)). Empirically, we find a small effect on output and inflation on impact, relative to the previous case. Although the cumulative effect on output is also small, going from -66.01 to -68.34 , the cumulative effect on inflation is a bit larger, going from -7.19 to -5.90 (see blue dash-dotted line in Figure 1).

Case 6 studies the interaction in our fully unrestricted economy. The real effects of monetary policy are now a bit smaller on impact than in the case of homogeneous I/O linkages and equal sector size, by $18 \%$, whereas the impact drop in inflation is larger by $41 \%$. The cumulative real effect is only $3 \%$ smaller, whereas the cumulative inflation response is $58 \%$ larger (see blue x markers in Figure 1). Overall, the real effect of monetary policy is quantitatively and qualitatively not substantially different from the previous cases - once we allow for heterogeneity in the frequency of price adjustment.

Intuitively, the interaction of all three heterogeneities is not important because sectoral price stickiness, sector size, and outdegrees are empirically almost uncorrelated: The correlation of price stickiness with consumption weights is 0.05 , with first-order outdegrees 0.47 , and the correlation of outdegrees with sector size is 0.01 .

In summary, heterogeneity in price stickiness is the main driver of the real effects of monetary policy shocks in our calibration of a 350-sector economy to the empirical distribution of price stickiness from the BLS, and sectoral size and the I/O structure from the BEA. I/O linkages and heterogeneity in sectoral size have some effect, but these effects are smaller than the effects of price stickiness. These findings suggest no strong systematic relationship between price flexibility and the importance of sectors as suppliers of flexible sectors, or the economy as a whole.

\section{B. Heterogeneity across sectors, and identity effects}

Our analysis shows substantial heterogeneity in the sectoral responses to the common, monetary policy shock. Which sector transmits the monetary policy shock the most depends crucially on our specification of heterogeneities. This finding presents another new and important result of our paper, especially for policymakers. Heterogeneity in markup responses reflects heterogeneity in real output and identity effects.

We present these results by focusing on the 10 most and least important sectoral output contributors to the real effects of monetary policy. Table 4 reports the respective cumulative real effects of monetary policy shocks in Panels A and B for our different cases.

We know from the discussion above and section IV that all sectors are equally 
responsive in cases 1 and 2. Only once we allow for heterogeneous price stickiness in case 3 , we see differential sectoral responses. The heterogeneity in real effects across sectors is substantially amplified for the most responsive sectors in Panel B, by a factor of 5 to 8 . At the same time, the least responsive sectors in Panel A are relatively less affected. As we move across cases, some additional variation occurs, but overall, dispersion changes little. This result confirms our findings above that heterogeneity in consumption shares or I/O structure is not important for the amplification of monetary policy shocks empirically. The only exception occurs for the least responsive sectors. Their response is cut by a factor of 3 to 4 as we allow for heterogeneous input-output linkages in case 6 . This is an important result: Even if input-output linkages have little differential aggregate impact, they matter for relative importance of sectors when monetary shocks are transmitted.

The associated, underlying identity effects are also clearly visible. While we cannot illustrate the differential ordering that arises only due to heterogeneous price stickiness, Figure 2 illustrates the effect on the most and least responsive sectors when we go from case 3 to case 6 . Rankings change beyond rank 7 , but generally little for the most important sectors. In line with the above, ranks substantially change for least important sectors, by up to 60 ranks. Hence, the exact choice of heterogeneities is clearly important for the identity of sectors in the transmission mechanism.

Heterogeneity in markups reflects the heterogeneity in real output effects. Price markups are of independent importance and interest, because they measure the inefficiency in the economy and are equivalent to a countercyclical labor wedge (see Gali et al. (2007)). In our setting, the product market wedge is the sole driver of the labor wedge which is consistent with recent empirical work by Bils, Klenow, and Malin (2014). ${ }^{8}$ The level of markups in the full model is higher than in the homogeneous benchmark case, and markups display a rich, dynamic pattern. We report these findings in Figure 3.

The effect of fully interacted heterogeneities in our model becomes clear in comparison to the completely homogeneous economy. The markup responses of the homogeneous economy are summarized in Panel (a) of Figure 3. All sectoral responses are fast-decaying and identical across all percentiles. The markup response is more than $3 \%$ on impact, with a half-life of eight periods.

By contrast, two differential facts emerge for the full model (case 6): First, the median sectoral response is substantially larger. The initial median markup response increases to approximately $6 \%$. The solid, thick blue line summarizes the median response. The half-life of the median response is twice as long as in the homogeneous case.

\footnotetext{
${ }^{8}$ Shimer (2009) stresses the lack of work on heterogeneity in the product market, a channel we are putting forward and expanding upon by allowing for interactions of different heterogeneities.
} 
Second, substantial dispersion exists in the markup response. The top $5^{\text {th }}$ percentile of markups increases to over $10 \%$; the bottom $5^{\text {th }}$ percentile does not increase above $2 \%$. The sectoral markups also show very different dynamic patterns: The top percentiles show a hump-shaped response that is very persistent, with a half-life of more than 30 periods. At the same time, the lowest percentiles decay exponentially with a half-life of less than one period. These very different price-markup responses directly result from the convolutions of the different underlying heterogeneities. The pattern in markup responses open up new avenues to study how the interactions shape inefficiencies in the economy.

\section{Sectoral Aggregation and Real Effects}

In this section, we study the response of our model economy to monetary policy shocks for different levels of disaggregation. The choice of aggregation results in large differences in real effects across model economies. We arrive at this conclusion in two steps.

First, we compare the two levels of granularity published by the BEA: detail (effectively 350 sectors) and summary (58 sectors). Figure 4 and Table 5 report our findings. We report robustness results for the 58-sector calibration in the online appendix. Cumulative real effects of monetary policy are 20\% larger in the more disaggregated 350-sector economy than in the 58-sector calibration. The inflation response is interesting: Upon impact, not only output but also inflation drops by more in the 350-sector economy. Inflation drops by $14 \%$ more and output by $1 \%$ more. But over the first five periods, the periods of immediate impact, the average inflation drop in the 350-sector economy and the 58-sector economy is very similar. In fact, the impulse response functions of inflation cross. In the long run, the cumulative inflation response is $20 \%$ smaller in the 350 -sector economy. This finding cautions against drawing inference for monetary policy from the impact response of inflation to monetary policy shocks.

Second, motivated by these findings as well as our theoretical results in section IV that the degree of granularity can matter for the real effects of monetary policy - we now systematically show the importance of granularity.

In Figure 5, we aggregate sectors with the most similar frequencies of price adjustments. We go from a 350-sector aggregation to economies with 200, 100, 50, 25, 10, and 8 sectors. Across aggregations, we keep the average frequency of price adjustment constant. Overall, the response of real consumption, inflation, and real marginal costs are very similar across the different levels of granularity. This result might appear surprising, but we aggregate sectors with similar frequencies of price adjustments. Based on our discussion in section IV and the results in Carvalho and Schwartzman (2015) and Alvarez 
et al. (2016b), we would expect similar real effects for different levels of aggregation if the dispersion in the frequency of price adjustment does not change across aggregations. We see in Figure A.2 of the online appendix this is indeed the case: The variance changes little and only becomes spiky once a few sectors are left.

Next, we aggregate sectors with the most similar size. In many models, sector size is a good proxy for sector technology. Figure 6 shows the results. The real effects of monetary policy are now dramatically affected. They are almost twice as large on impact for the most disaggregated economy as for the most aggregated economy with only eight sectors, even though the impact response of inflation is identical. Real effects are monotonically increasing in the granularity of the economy. Figure A.3 in the online appendix shows the dispersion in the frequency of price adjustment shrinks for less granular economies.

Finally, we go through "empirical" aggregation levels, replicating the aggregation chosen by the BEA. We aggregate sectors by industry codes starting with the actual detailed data, which have up to 6-digit NAICS codes, going to an economy with 5 digits, and so on. We find results in the current aggregation that are similar to the results we saw for the size aggregation: Real effects are largest for the most granular economy and shrink for higher levels of aggregation. The biggest jumps occur between 148 and 60, and 60 and 20 sectors, respectively. Much coarser or finer aggregation choices than these only have a marginal impact on the impulse response functions. Tables A.5 to A.7 in the online appendix contain detailed results for the different aggregations.

What mechanisms are empirically driving the aggregation effect? We find that the interactions of heterogeneities are more important than the convexification of price rigidities in creating aggregation effects, but they act with some delay. We show the relative importance by computing the total consumption price paths in a 350 and an 8 sector economy, as well as the two components from equation (47), due to convexification and interactions. Figure A.4 in the Online Appendix illustrates how the two channels contribute to the total gap.

\section{Output correlations}

Another contribution of our fully heterogeneous model lies in the realistic and wide degree of output correlations it can generate following a common monetary policy shock. We find the interaction of all three heterogeneities is important, and heterogeneity of price rigidity is a necessary but not sufficient condition to generate realistic correlations. The overall input share of I/O linkages also plays an important role.

We use the annual GDP gross output data from the BEA to study this question, 
which maps closely to $y_{k}$ in the model. Empirically, the unconditional, mean (median) sectoral output correlations for relatively more aggregate BEA data with 71 sectors is 0.2620 (0.3999), whereas for disaggregated BEA data with 403 sectors, it is 0.3920 (0.6128). These raw correlations are unconditional; that is, they do not condition on any shock. Because they include idiosyncratic shocks, they are likely too low to study output correlations after monetary policy shocks but are a useful benchmark for our analysis.

In the model simulations, we find heterogeneity of price rigidity is a necessary but not sufficient condition to generate realistic correlations. To arrive at this conclusion, we simulate output paths following a monetary policy shock, and compute summary statistics on all cross correlations. Table 6 presents the summary statistics for the baseline calibration of the parameter on inflation in the Taylor rule in panel A and a more responsive monetary policy in panel B. ${ }^{9}$ When prices are either fully flexible or homogeneously rigid, then independent of the distribution of size and I/O shares, correlations will always be 1 given a common monetary policy shock (cases 1 and 2). However, as soon as price rigidity is heterogeneous, output correlations start dropping (case 3). This drop holds regardless of the level of aggregation and regardless of the systematic response of the monetary policy to inflation.

The exact assumptions on the model heterogeneities, the level of aggregation, and specification of monetary policy all play a role in bringing correlations down to more realistic levels. Table 6 cases 3 - 6 show this result. For 350 sectors, our baseline fully heterogeneous model (case 6) generates an average correlation of 0.89 . For an economy with more responsive monetary policy, the correlation is 0.80 . Going through cases 3-6 shows each heterogeneity plays an additional role.

We also add a new case 7 , an economy with $\mathrm{I} / \mathrm{O}$ share $\delta=0.0001$. Now, the correlation drops even further to 0.45 , and to 0.38 for the more responsive monetary policy case. The $25^{\text {th }}$ percentile, in this last economy, can even become negative, following a common monetary policy shock.

\section{Concluding Remarks}

We present new theoretical and empirical insights into the transmission of monetary policy shocks when heterogeneity in price stickiness, the I/O structure, and sector size interact.

Although rich theoretical predictions exist for how heterogeneity in sector size and I/O structure interact with price stickiness to shape the real effects of monetary

\footnotetext{
${ }^{9}$ Section III in the online appendix discusses results for a calibration with a more responsive monetary policy rule.
} 
policy shocks, we find empirically that heterogeneity in price stickiness is the central mechanism for generating large and persistent real effects of nominal shocks. Empirically, heterogeneity in I/O linkages only plays a marginal role. In addition, we document that small-scale models might substantially underestimate real effects - even though the impact response of inflation is almost identical across different levels of granularity. Finally, we find that heterogeneity in price rigidity is key in determining which sectors are the most important contributors to the transmission of monetary shocks. Heterogeneity in price rigidity is also necessary to generate realistic output correlations in the model.

\section{References}

Acemoglu, D., U. Akcigit, and W. Kerr (2015). Networks and the macroeconomy: An empirical exploration. In preparation for: NBER Macroannual.

Acemoglu, D., V. M. Carvalho, A. Ozdaglar, and A. Tahbaz-Salehi (2012). The network origins of aggregate fluctuations. Econometrica 80(5), 1977-2016.

Alvarez, F. E., F. Lippi, and L. Paciello (2016a). Monetary shocks in models with inattentive producers. The Review of Economic Studies 83(2), 421-459.

Alvarez, F. E., F. Lippi, and L. Paciello (2016b). Monetary shocks in models with inattentive producers. The Review of Economic Studies 83(2), 421-459.

Barrot, J.-N. and J. Sauvagnat (2016). Input specificity and the propagation of idiosyncratic shocks in production networks. The Quarterly Journal of Economics, qjw018.

Basu, S. (1995). Intermediate goods and business cycles: Implications for productivity and welfare. The American Economic Review 85(3), 512-531.

Bhattarai, S. and R. Schoenle (2014). Multiproduct firms and price-setting: Theory and evidence from u.s. producer prices. Journal of Monetary Economics 66, 178-192.

Bigio, S. and J. Lao (2017). Financial frictions in production networks. Unpublished Manuscript, Columbia University.

Bils, M., P. J. Klenow, and B. A. Malin (2014). Resurrecting the role of the product market wedge in recessions. Technical report, National Bureau of Economic Research.

Boivin, J., M. P. Giannoni, and I. Mihov (2009). Sticky prices and monetary policy: Evidence from disaggregated U.S. data. The American Economic Review 99(1), 350384.

Bouakez, H., E. Cardia, and F. Ruge-Murcia (2014). Sectoral price rigidity and aggregate dynamics. European Economic Review 65, 1-22.

Calvo, G. A. (1983). Staggered prices in a utility-maximizing framework. Journal of Monetary Economics 12(3), 383-398.

Carvalho, C. (2006). Heterogeneity in price stickiness and the real effects of monetary shocks. The B.E. Journal of Macroeconomics 2(1), 1-56.

Carvalho, C. and J. W. Lee (2011). Sectoral price facts in a sticky-price model. Unpublished Manuscript, PUC-Rio. 
Carvalho, C. and F. Schwartzman (2015). Selection and monetary non-neutrality in time-dependent pricing models. Journal of Monetary Economics 76, 141 - 156.

Carvalho, V. M. (2014). From micro to macro via production networks. The Journal of Economic Perspectives 28(4), 23-47.

D'Acunto, F., R. Liu, C. Pflueger, and M. Weber (2016). Flexible prices and leverage. Unpublished manuscript, University of Chicago.

Gabaix, X. (2011). The granular origins of aggregate fluctuations. Econometrica $79(3)$, $733-772$.

Gali, J., M. Gertler, and J. D. Lopez-Salido (2007). Markups, gaps, and the welfare costs of business fluctuations. The review of economics and statistics 89(1), 44-59.

Gilchrist, S., R. Schoenle, J. Sim, and E. Zakrajšek (2015). Inflation dynamics during the financial crisis. Unpublished Manuscript, Brandeis University.

Goldberg, P. P. and R. Hellerstein (2011). How rigid are producer prices? FRB of New York Staff Report, 1-55.

Gorodnichenko, Y. and M. Weber (2016). Are sticky prices costly? Evidence from the stock market. American Economic Review 106(1), 165-199.

Herskovic, B. (2018). Networks in production: Asset pricing implications. The Journal of Finance 73(4), 1785-1818.

Herskovic, B., B. T. Kelly, H. Lustig, and S. Van Nieuwerburgh (2016). The common factor in idiosyncratic volatility: Quantitative asset pricing implications. Journal of Financial Economics 119(2), 249-283.

Huang, K. X. and Z. Liu (2004). Input-output structure and nominal rigidity: the persistence problem revisited. Macroeconomic Dynamics 8(2), 188-206.

Kaplan, G., B. Moll, and G. L. Violante (2018). Monetary policy according to hank. American Economic Review 108(3), 697-743.

Kelly, B., H. Lustig, and S. Van Nieuwerburgh (2013). Firm volatility in granular networks. Technical report, National Bureau of Economic Research.

Nakamura, E. and J. Steinsson (2008). Five facts about prices: A reevaluation of menu cost models. Quarterly Journal of Economics 123(4), 1415-1464.

Nakamura, E. and J. Steinsson (2010). Monetary non-neutrality in a multi-sector menu cost model. Quarterly Journal of Economics 125(3), 961-1013.

Ozdagli, A. and M. Weber (2017). Monetary policy through production networks: Evidence from the stock market. Unpublished Manuscript, University of Chicago.

Pasten, E., R. Schoenle, and M. Weber (2018). Price rigidity and the origins of aggregate fluctuations. Unpublished manuscript, University of Chicago.

Rudebusch, G. D. (2002). Term structure evidence on interest rate smoothing and monetary policy inertia. Journal of Monetary Economics 49(6), 1161-1187.

Shamloo, M. (2010). Price setting in a model with production chains: Evidence from sectoral data. IMF Working Papers, 1-50.

Shimer, R. (2009). Convergence in macroeconomics: The labor wedge. American Economic Journal: Macroeconomics 1(1), 280-297.

Weber, M. (2015). Nominal rigidities and asset pricing. Unpublished manuscript, University of Chicago Booth School of Business. 
Figure 1: Response of Real Consumption, Inflation, and Real Marginal Costs to Monetary Policy Shock
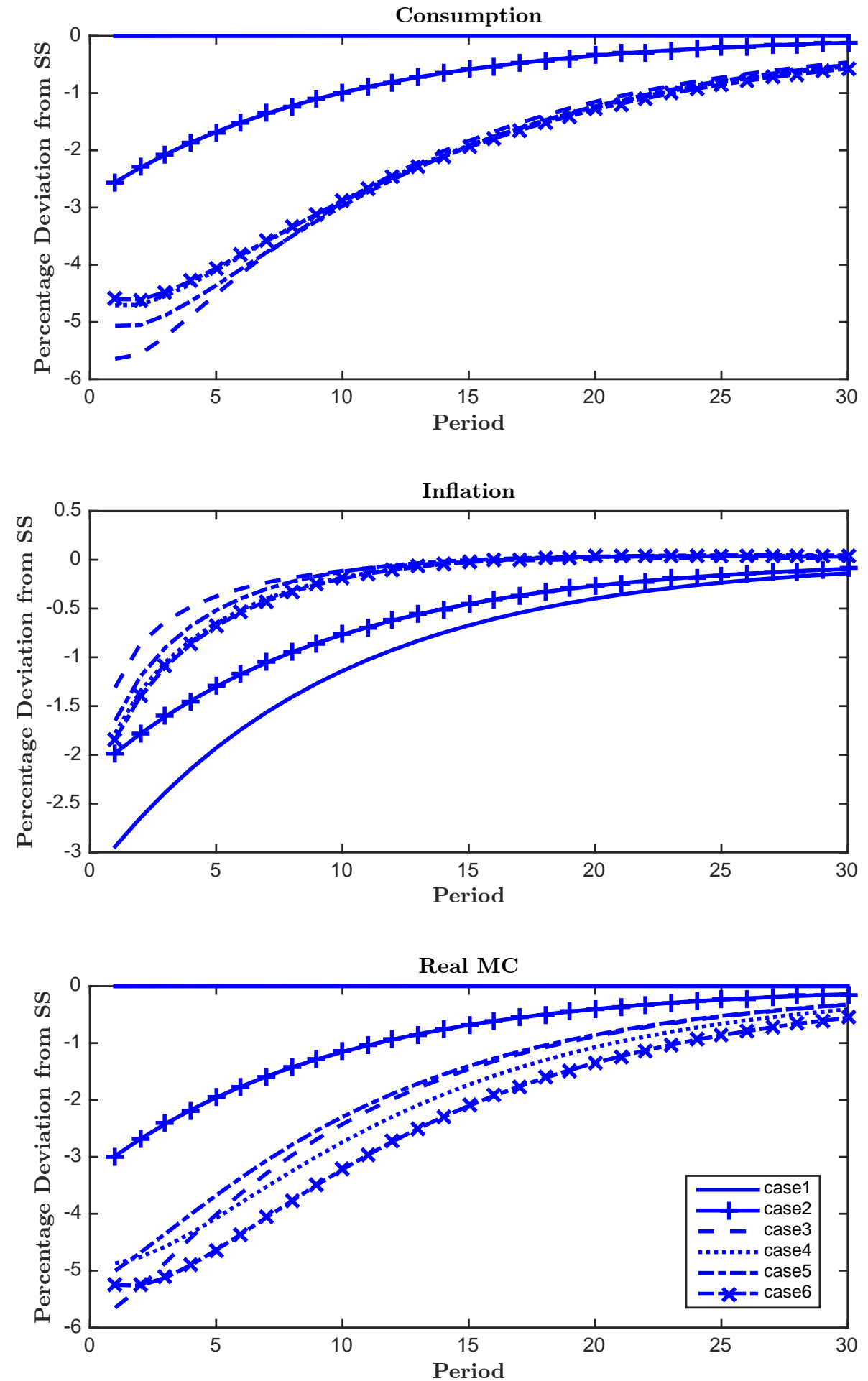

This figure plots the impulse response function of real consumption, inflation, and real marginal costs to a one-standard-deviation monetary policy shock for a 350-sector model for different cases (see Table 2 for a description of the different cases). 
Figure 2: Ranking of Sectors, Cases 3 and 6
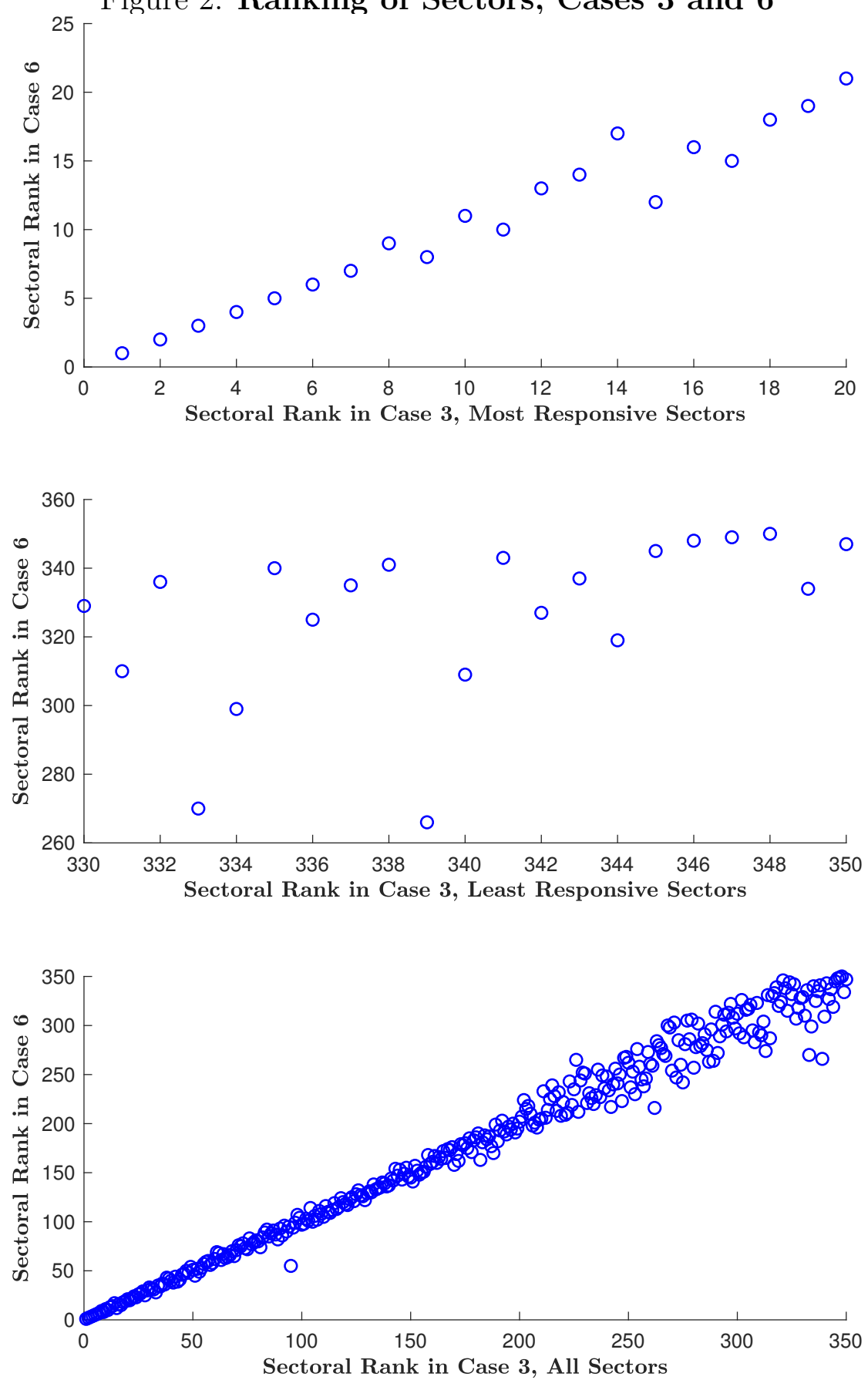

This figure plots the sectoral rankings for the cumulative IRF for case 3 against case 6 (see Table 2 for a description of the different cases). The top panel zooms in on the 20 most important sectors in case 3, the middle panel on the 20 least important sectors. The bottom panel shows all sectors. 
Figure 3: Response of Markups to Monetary Policy Shock
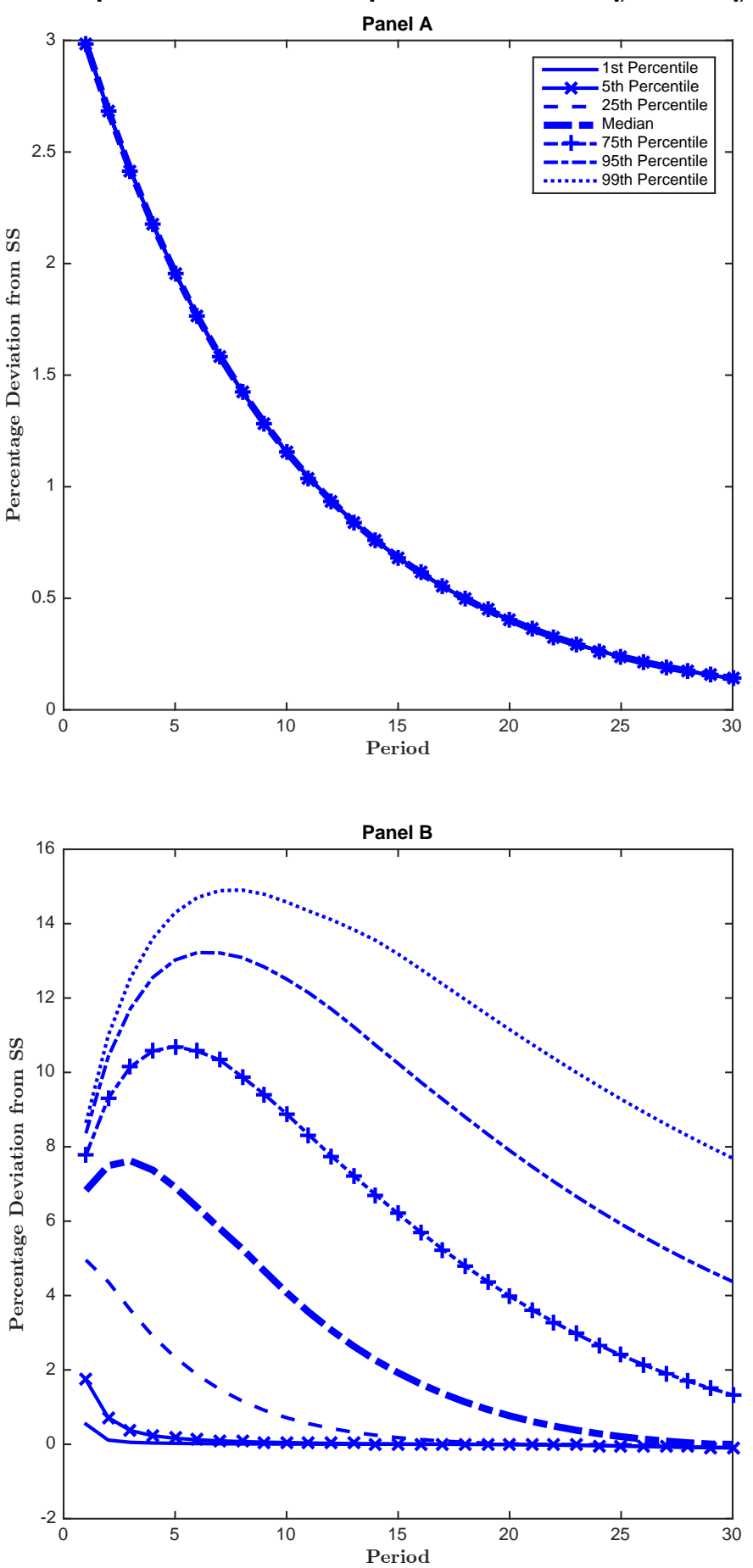

This figure plots the impulse response function of markups to a one-standard-deviation monetary policy shock for a 350-sector model for case 2 in Panel $A$ and case 6 in Panel B (see Table 2 for a description of the different cases). 
Figure 4: Response of Real Consumption, Inflation, and Real Marginal Costs to Monetary Policy Shock (58 vs 350 sector economy)
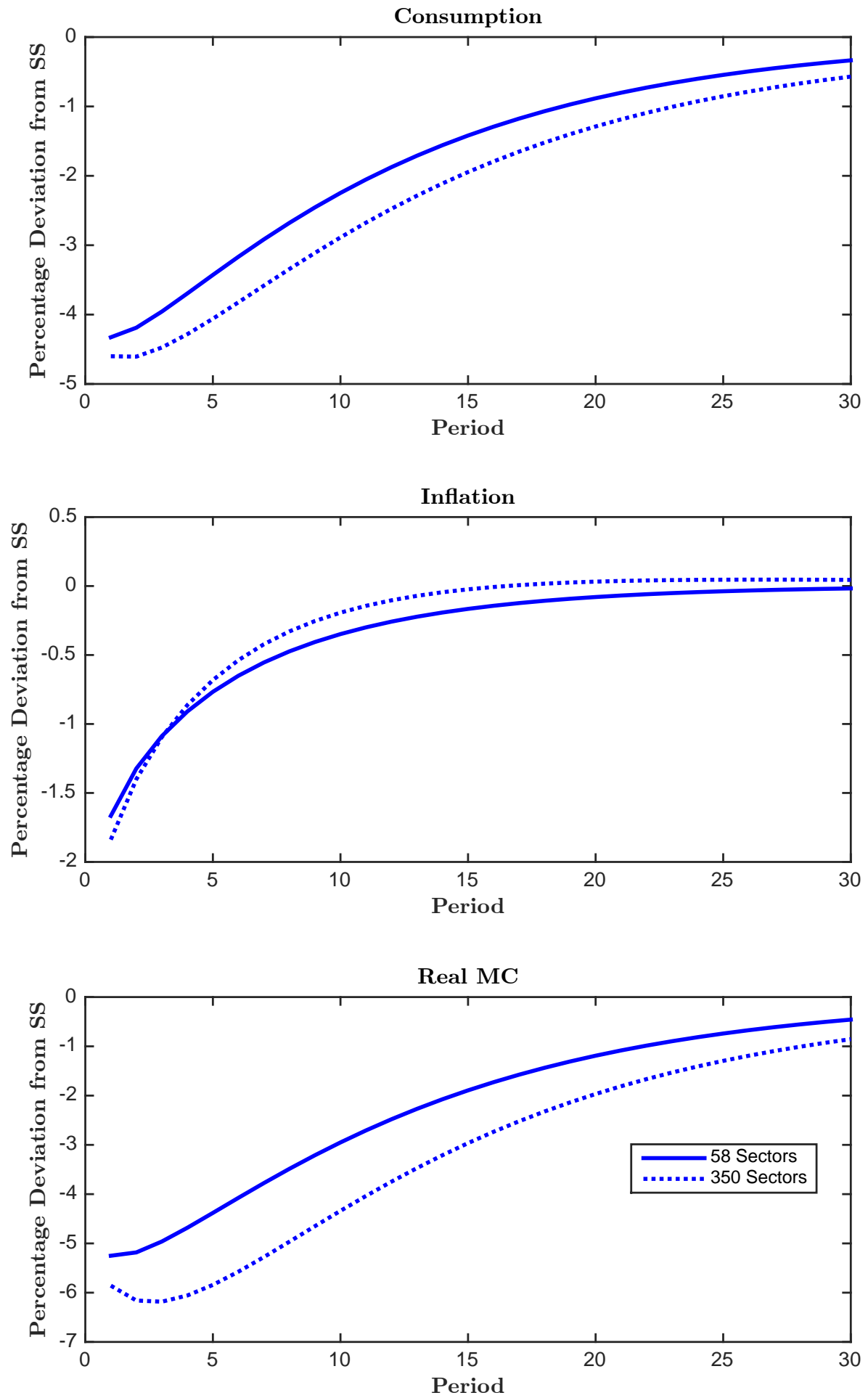

This figure plots the impulse response function of real consumption, inflation, and real marginal costs to a one-standard-deviation monetary policy shock for a 58-and 350-sector model for case 6 (see Table 2 for a description of the different cases). 
Figure 5: Response of Real Consumption, Inflation, and Real Marginal Costs: Calvo Aggregation
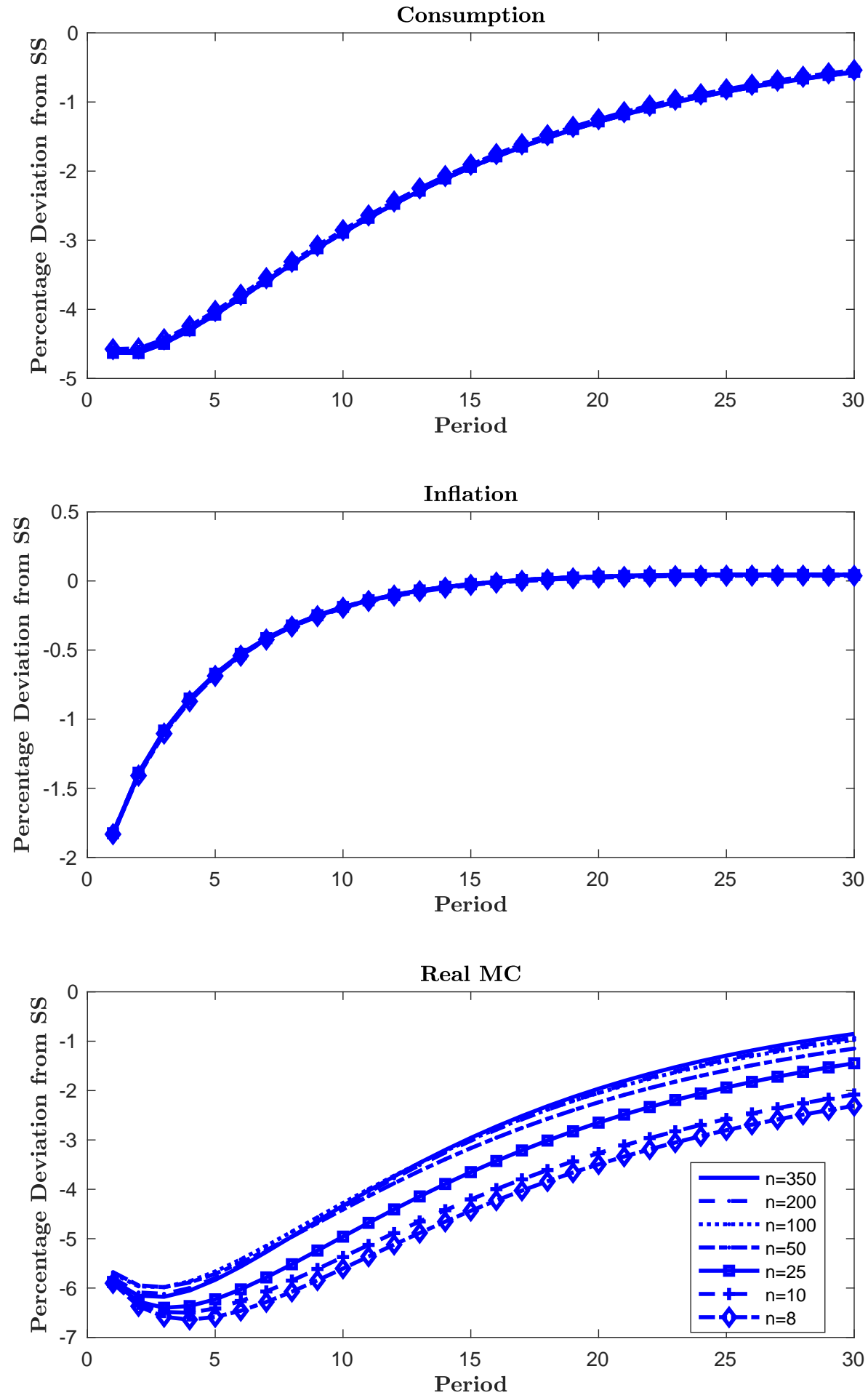

This figure plots the impulse response function of real consumption, inflation, and real marginal costs to a one-standard-deviation monetary policy shock for different levels of aggregation. We aggregate sectors by the frequency of price adjustment keeping the average frequency of price adjustment constant. 
Figure 6: Response of Real Consumption, Inflation, and Real Marginal Costs: Size Aggregation
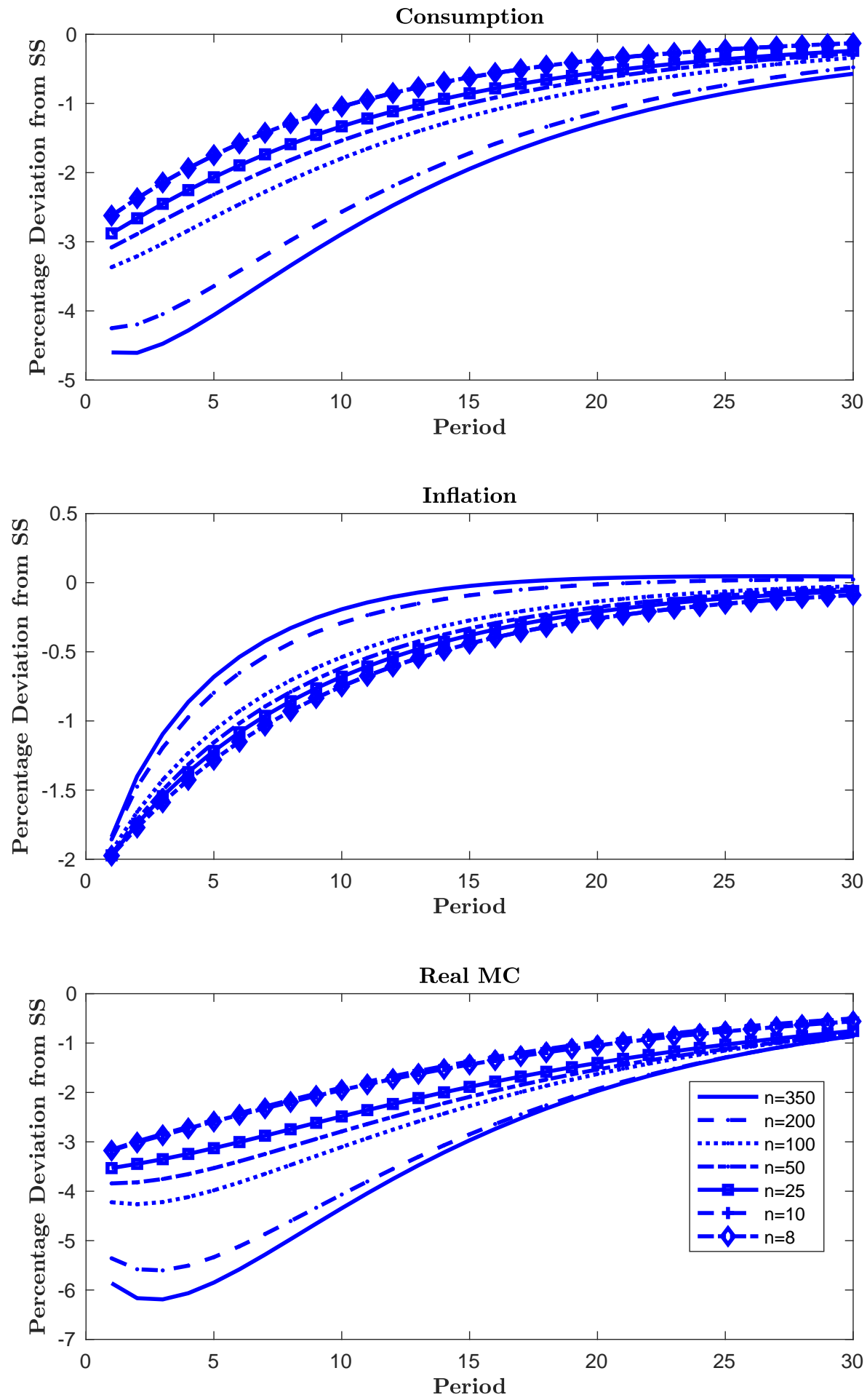

This figure plots the impulse response function of real consumption, inflation, and real marginal costs to a one-standard-deviation monetary policy shock for different levels of aggregation. We aggregate sectors by the sector size keeping the average frequency of price adjustment constant. 
Figure 7: Response of Real Consumption, Inflation, and Real Marginal Costs: Industry-Code Aggregation
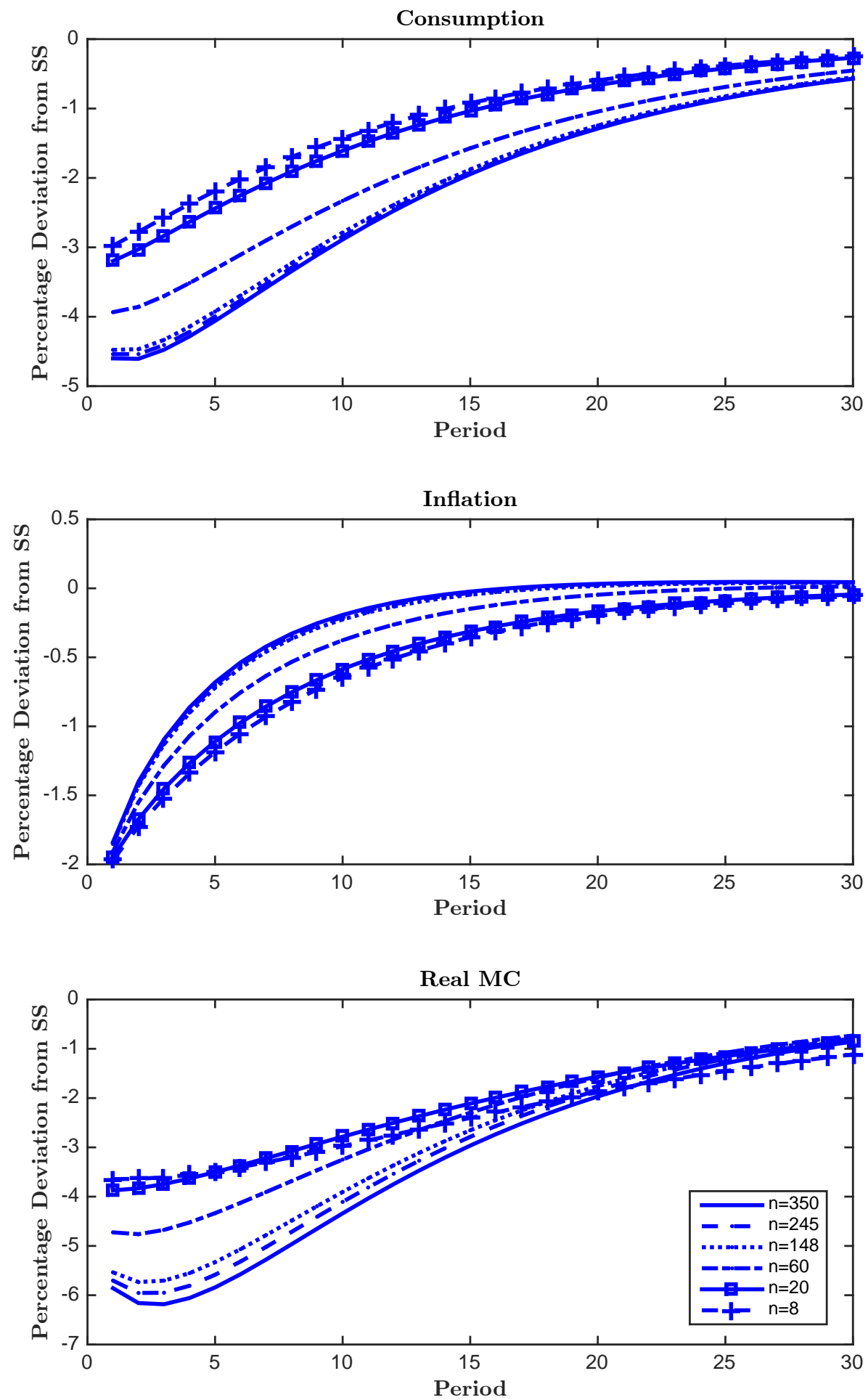

This figure plots the impulse response function of real consumption, inflation, and real marginal costs to a one-standard-deviation monetary policy shock for different levels of aggregation. We aggregate sectors by NAICS digits keeping the average frequency of price adjustment constant. 


\section{Table 1: Calibration Parameters}

This table reports the parameter values of the calibration of the model developed in Section IV.

\begin{tabular}{lll}
\hline$\beta$ & 0.9975 & Monthly discount factor \\
$\sigma$ & 1 & Relative risk aversion \\
$\varphi$ & 2 & Inverse of Frisch elasticity \\
$\delta$ & 0.5 & Average inputs share in production function \\
$\eta$ & 2 & Elasticity of substitution across sectors \\
$\theta$ & 6 & Elasticity of substitution within sectors \\
$\phi_{\pi}$ & 1.24 & Responsiveness of monetary policy to consumption inflation \\
$\phi_{c}$ & $0.33 / 12$ & Responsiveness of monetary policy to output variations \\
$\rho$ & 0.9 & Persistence of monetary policy shock \\
\hline
\end{tabular}

Table 2: Overview of Calibration Cases

This table details the assumptions on frequencies, consumption weights, and input-output linkages for the different cases employed in the calibration.

\begin{tabular}{llll}
\hline & Frequencies & Consumption Weights & Input-Output Linkages \\
\hline Case 1 & flexible & homogeneous & homogeneous \\
Case 2 & sticky, homogeneous & homogeneous & homogeneous \\
Case 3 & sticky, heterogeneous & homogeneous & homogeneous \\
Case 4 & sticky, heterogeneous & heterogeneous & heterogeneous (consumption weights) \\
Case 5 & sticky, heterogeneous & heterogeneous & homogeneous \\
Case 6 & sticky, heterogeneous & heterogeneous & heterogeneous \\
\hline
\end{tabular}

\section{Table 3: Response to Monetary Policy Shock}

This table reports the impact response, the cumulative impulse response, and the persistence of the response defined as $A R(1)$ coefficient due to a one-percent monetary policy shock for consumption (Panel A), inflation (Panel B), and real marginal costs (Panel C) for a 350-sector economy for different cases (see Table 2 for a description of the different cases).

\begin{tabular}{|c|c|c|c|c|c|c|}
\hline & Case 1 & Case 2 & Case 3 & Case 4 & Case 5 & Case 6 \\
\hline & \multicolumn{6}{|c|}{ Panel A. Consumption } \\
\hline Impact & -0.00 & -2.56 & -5.64 & -4.71 & -5.07 & -4.60 \\
\hline Cumulative IRF & -0.03 & -24.49 & -68.75 & -66.01 & -68.34 & -66.35 \\
\hline \multirow[t]{2}{*}{ Persistence } & 0.87 & 0.87 & 0.85 & 0.87 & 0.85 & 0.89 \\
\hline & \multicolumn{6}{|c|}{ Panel B. Inflation } \\
\hline Impact & -2.94 & -1.98 & -1.31 & -1.78 & -1.65 & -1.84 \\
\hline Cumulative IRF & -28.16 & -18.98 & -4.74 & -7.19 & -5.90 & -7.48 \\
\hline \multirow[t]{2}{*}{ Persistence } & 0.87 & 0.87 & 0.87 & 0.90 & 0.87 & 0.90 \\
\hline & \multicolumn{6}{|c|}{ Panel C. Real Marginal Costs } \\
\hline Impact & -0.00 & -2.98 & -6.58 & -5.78 & -5.90 & -5.86 \\
\hline Cumulative IRF & -0.03 & -28.58 & -80.21 & -91.14 & -79.39 & -96.80 \\
\hline Persistence & 0.87 & 0.87 & 0.90 & 0.93 & 0.91 & 0.93 \\
\hline
\end{tabular}


Table 4: Response to Monetary Policy Shock: Sorted by Cumulative Response

This table reports the cumulative real consumption response to a one-percent monetary policy shock for a 350-sector economy for different cases (see Table 2 for a description of the different cases). Panel A reports the response of the least responsive sectors and Panel $B$ reports the response of the most responsive sectors.

\begin{tabular}{|c|c|c|c|c|c|c|c|}
\hline & & Case 1 & Case 2 & Case 3 & Case 4 & Case 5 & Case 6 \\
\hline & & Panel A. & Cumulati & ve Consum & ption Resp & onse: Least & Responsive \\
\hline \multirow[t]{10}{*}{ Least responsive } & 1 & -0.05 & -44.91 & -47.52 & -45.71 & -52.93 & -17.45 \\
\hline & 2 & -0.05 & -44.91 & -47.41 & -45.60 & -52.83 & -17.17 \\
\hline & 3 & -0.05 & -44.91 & -46.78 & -44.95 & -52.20 & -16.96 \\
\hline & 4 & -0.05 & -44.91 & -46.75 & -44.92 & -52.17 & -16.18 \\
\hline & 5 & -0.05 & -44.91 & -46.73 & -44.90 & -52.15 & -16.11 \\
\hline & 6 & -0.05 & -44.91 & -46.69 & -44.86 & -52.11 & -15.51 \\
\hline & 7 & -0.05 & -44.91 & -46.53 & -44.70 & -51.96 & -15.20 \\
\hline & 8 & -0.05 & -44.91 & -46.51 & -44.68 & -51.94 & -12.13 \\
\hline & 9 & -0.05 & -44.91 & -46.50 & -44.67 & -51.93 & -11.78 \\
\hline & 10 & -0.05 & -44.91 & -46.25 & -44.42 & -51.68 & -11.61 \\
\hline \multirow{11}{*}{ Most responsive } & & Panel B. & Cumulati & e Consum & ption Resp & onse: Most & Responsive \\
\hline & 1 & -0.05 & -44.91 & -375.63 & -505.96 & -441.47 & -525.73 \\
\hline & 2 & -0.05 & -44.91 & -324.40 & -430.29 & -379.08 & -454.48 \\
\hline & 3 & -0.05 & -44.91 & -297.53 & -391.07 & -346.56 & -407.01 \\
\hline & 4 & -0.05 & -44.91 & -296.68 & -389.83 & -345.53 & -406.21 \\
\hline & 5 & -0.05 & -44.91 & -291.68 & -382.56 & -339.49 & -399.59 \\
\hline & 6 & -0.05 & -44.91 & -287.35 & -376.27 & -334.26 & -391.49 \\
\hline & 7 & -0.05 & -44.91 & -278.02 & -362.73 & -323.00 & -376.47 \\
\hline & 8 & -0.05 & -44.91 & -262.75 & -340.64 & -304.60 & -353.03 \\
\hline & 9 & -0.05 & -44.91 & -260.51 & -337.41 & -301.91 & -352.99 \\
\hline & 10 & -0.05 & -44.91 & -255.53 & -330.22 & -295.91 & -347.50 \\
\hline
\end{tabular}




\section{Table 5: Response to Monetary Policy Shock (58 versus 350 sector economy)}

This table reports the impact response, the cumulative impulse response, and the persistence of the response defined as $A R(1)$ coefficient due to a one-percent monetary policy shock for consumption (Panel A), inflation (Panel B), and real marginal costs (Panel C) for a 350-sector economy and a 58-sector economy for case 6 (see Table 2 for a description of the different cases).

\begin{tabular}{lcc}
\hline & 58 Sectors & 350 Sectors \\
\hline & Panel A. Consumption \\
Impact & -4.53 & -4.60 \\
Cumulative IRF & -55.35 & -66.35 \\
Persistence & 0.90 & 0.89 \\
& \multicolumn{2}{c}{ Panel B. Inflation } \\
Impact & -1.61 & -1.84 \\
Cumulative IRF & -9.38 & -7.48 \\
Persistence & 0.79 & 0.90 \\
& Panel C. Real Marginal Costs \\
Impact & -5.49 & -5.86 \\
Cumulative IRF & -71.78 & -96.80 \\
Persistence & 0.91 & 0.93 \\
\hline
\end{tabular}

\section{Table 6: Output Correlations to Monetary Policy Shocks}

This table reports means and percentiles of the distribution of output correlations after a 1\% monetary policy shock from model simulated data under different assumptions on heterogeneities in frequencies of price adjustment, sector size, and I/O structure for different cases (see Table 2 for a description of the different cases). Case 7 replicates Case 6 with an intermediate input share of $\delta=0.0001$.

\begin{tabular}{lcccccccc}
\hline \multicolumn{7}{c}{58 sectors } & \multicolumn{5}{c}{350 sectors } \\
& Mean & Median & $25^{\text {th }}$ Per & $75^{\text {th }}$ Per & Mean & Median & $25^{\text {th }}$ Per & $75^{\text {th }}$ Per \\
\hline & & & & Panel A. $\phi_{\pi}=1.24$ & & \\
Case 1 & 1.00 & 1.00 & 1.00 & 1.00 & 1.00 & 1.00 & 1.00 & 1.00 \\
Case 2 & 1.00 & 1.00 & 1.00 & 1.00 & 1.00 & 1.00 & 1.00 & 1.00 \\
Case 3 & 0.96 & 0.98 & 0.93 & 0.99 & 0.96 & 0.97 & 0.93 & 0.99 \\
Case 4 & 0.95 & 0.97 & 0.92 & 0.99 & 0.92 & 0.96 & 0.88 & 0.99 \\
Case 5 & 0.95 & 0.98 & 0.93 & 0.99 & 0.95 & 0.97 & 0.92 & 0.99 \\
Case 6 & 0.93 & 0.96 & 0.89 & 0.99 & 0.89 & 0.94 & 0.83 & 0.99 \\
Case 7 & 0.58 & 0.80 & 0.43 & 0.96 & 0.45 & 0.72 & 0.12 & 0.94 \\
& & & & Panel B. $\phi_{\pi}=2.5$ & & & \\
Case 1 & 1.00 & 1.00 & 1.00 & 1.00 & 1.00 & 1.00 & 1.00 & 1.00 \\
Case 2 & 1.00 & 1.00 & 1.00 & 1.00 & 1.00 & 1.00 & 1.00 & 1.00 \\
Case 3 & 0.95 & 0.97 & 0.92 & 0.99 & 0.93 & 0.97 & 0.90 & 0.99 \\
Case 4 & 0.93 & 0.97 & 0.90 & 0.99 & 0.86 & 0.94 & 0.81 & 0.98 \\
Case 5 & 0.94 & 0.97 & 0.91 & 0.99 & 0.90 & 0.96 & 0.87 & 0.99 \\
Case 6 & 0.91 & 0.95 & 0.86 & 0.99 & 0.80 & 0.90 & 0.72 & 0.98 \\
Case 7 & 0.54 & 0.77 & 0.35 & 0.95 & 0.38 & 0.63 & -0.05 & 0.92 \\
\hline
\end{tabular}




\section{Online Appendix: \\ Production Networks and the Propagation of Monetary Policy Shocks}

Ernesto Pasten, Raphael Schoenle, and Michael Weber

Not for Publication

\section{Proofs}

\section{Proposition 1}

Proof. When $\alpha_{k}=\alpha$ for all $k$, we aggregate equations (43) using consumption weights to obtain

$$
p_{t}^{c}(\alpha)=\frac{(1-\delta)(1-\alpha)}{1-\delta(1-\alpha)} m_{t}+\frac{\alpha}{1-\delta(1-\alpha)} p_{t-1}^{c}(\alpha)
$$

Equation (45) follows by using the previous expression to solve for $p_{t}^{c}(\alpha)$ when a permanent monetary shock $m$ hits at $t^{*}$. (1) and (2) follow directly from equation (45).

\section{Proposition 2}

Proof. The restriction $\omega_{k k^{\prime}}=\omega_{c k^{\prime}}$ for all $k, k^{\prime}$ implies $p_{t}^{k}=p_{t}^{c}$ for all $k$. Thus, according to equation (43), sectoral prices solve

$$
p_{k t}=\left(1-\alpha_{k}\right)\left[(1-\delta) m_{t}+\delta p_{t}^{c}\right]+\alpha_{k} p_{k t-1}
$$

Iterating backwards and using $p_{t}^{c}=\sum_{k=1}^{K} \omega_{c k} p_{k t}$ yields equation (46).

(1) follows from setting $p_{k t}=0$ for $t<t^{*}$ and for $t=t^{*},\left(\sum_{k} \omega_{c k} \alpha_{k}-\bar{\alpha}\right)=0$.

For $(2)$, let denote $\widetilde{p}_{t}^{c}(\alpha)$ the solution for aggregate consumption prices in Proposition 1. Further assume $p_{t-s}^{c}=\widetilde{p}_{t-s}^{c}(\alpha)$. Hence,

$p_{t}^{c}-\widetilde{p}_{t}^{c}(\bar{\alpha})=-\frac{(1-\delta) m}{1-\delta(1-\bar{\alpha})}\left(\sum_{k=1}^{K} \omega_{c k} \alpha_{k}^{t-t^{*}+1}-\bar{\alpha}^{t-t^{*}+1}\right)+\frac{\delta}{1-\delta(1-\bar{\alpha})} \sum_{\tau=1}^{t-t^{*}}\left(\sum_{k=1}^{K} \omega_{c k} \alpha_{k}^{\tau}\left(1-\alpha_{k}\right)-\bar{\alpha}^{\tau}(1-\bar{\alpha})\right) p_{t-\tau}^{c}$.

Jensen's inequality, $\widehat{p}_{t}^{c}-\widetilde{p}_{t}^{c}(\bar{\alpha}) \leq 0$ and decreases in the dispersion of price stickiness across sectors, $\left\{\alpha_{k}\right\}_{k=1}^{k}$. In addition, $p_{t-s}^{c} \leq \widetilde{p}_{t-s}^{c}$ for all $s \geq 1$, which reinforces the result.

\section{Proposition 3}


Proof. Let denote $\widehat{p}_{t}^{c}$ the response of aggregate consumption prices in Proposition 2 . Assume $p_{k t-s}=\widehat{p}_{k t-s}$ for all $s \geq 1$. Subtracting equation (46) from equation (47) yields

$$
\begin{array}{r}
p_{t}^{c}-\widehat{p}_{t}^{c}=\delta \sum_{k=1}^{K}\left(u_{k} p_{k t}-(1-\bar{\alpha}) \omega_{c k} \widetilde{p}_{k t}\right)+ \\
\delta \sum_{\tau=1}^{t-t^{*}}\left(\sum_{k^{\prime}=1}^{K} \omega_{c k^{\prime}} \alpha_{k^{\prime}}^{\tau}\left(1-\alpha_{k^{\prime}}\right)\right) \sum_{k=1}^{K}\left(\bar{\omega}_{k}-\omega_{c k}\right) p_{k t-\tau} \\
+\delta K \sum_{\tau=1}^{t-t^{*}} \sum_{k=1}^{K} C O V\left(\omega_{c k^{\prime}} \alpha_{k^{\prime}}^{\tau}\left(1-\alpha_{k^{\prime}}\right), \omega_{k^{\prime} k}\right) p_{k t-\tau}
\end{array}
$$

for $u_{k} \equiv \sum_{k^{\prime}=1}^{K} \omega_{c k^{\prime}}\left(1-\alpha_{k^{\prime}}\right) \omega_{k^{\prime} k}$ and $\bar{\omega}_{k} \equiv \frac{1}{K} \sum_{k^{\prime}=1}^{K} \omega_{k^{\prime} k}$.

For (1), we use $p_{k t}=0$ for $t<t^{*}$, so $p_{t}^{c}<\widehat{p}_{t}^{c}$ when $\sum_{k=1}^{K}\left(u_{k} p_{k t}-(1-\bar{\alpha}) \omega_{c k} \widetilde{p}_{k t}\right)<0$. This inequality holds when for the sectors with most sticky prices $u_{k}>(1-\bar{\alpha}) \omega_{c k}$.

For (2), two additional terms come to play. The second term of equation (A.1) is negative when for the sectors with most sticky prices $\bar{\omega}_{k}>\omega_{c k}$. The third term of equation (A.1) is negative when the covariance term is positive for the most sticky sectors and negative for the most flexible sectors. Relaxing the assumption that $p_{k t-s}=\widehat{p}_{k t-s}$ reinforces these results.

Finally, we can derive an expression that only contains parameters and the monetary policy shock on the right-hand side. We have that

$$
p_{k t}=(1-\delta)\left(1-\alpha_{k}\right) m+\delta\left(1-\alpha_{k}\right) p_{t}^{k}+\alpha_{k} p_{k t-1}
$$

which in matrix form using the sectoral price vector $p_{t}$ becomes

$$
p_{t}=[\mathbb{I}-\delta(\mathbb{I}-A) \Omega]^{-1}\left[(1-\delta)(\mathbb{I}-A) \iota m+A p_{t-1}\right]
$$

where $\iota$ is a vector of ones and $A$ is a diagonal matrix of $\alpha_{k}$. Solving backwards yields

$$
\begin{aligned}
& e_{k} \Omega^{C}(1-\delta)\left[\mathbb{I}-[\mathbb{I}-\delta(\mathbb{I}-A) \Omega]^{-1}(\mathbb{I}-A)\right]^{-1}\left[\mathbb{I}-\left([\mathbb{I}-\delta(\mathbb{I}-A) \Omega]^{-1}(\mathbb{I}-A)\right)^{t-t^{*}+1}\right] \\
& {[\mathbb{I}-\delta(\mathbb{I}-A) \Omega]^{-1}(\mathbb{I}-A) \iota m}
\end{aligned}
$$

\section{Proposition 4}


Proof. When $\delta=0$,

$$
p_{k t}=\left(1-\alpha_{k}\right) m_{t}+\alpha_{k} p_{k t-1} \quad \text { for all } \quad k
$$

such that

$$
\begin{aligned}
& p_{t}^{c}=\left(1-\sum_{k=1}^{K} \omega_{c k} \alpha_{k}^{t-t^{*}+1}\right) m \\
& \bar{p}_{t}^{c}=\left(1-\sum_{k^{\prime}=1}^{K / 2} \bar{\omega}_{c k^{\prime}} \bar{\alpha}_{k^{\prime}}^{t-t^{*}+1}\right) m
\end{aligned}
$$

Thus,

$$
\bar{p}_{t}^{c}-p_{t}^{c}=\sum_{k^{\prime}=1}^{K / 2} \bar{\omega}_{c k^{\prime}}\left[\lambda_{k^{\prime}} \alpha_{2 k^{\prime}-1}^{t-t^{*}+1}+\left(1-\lambda_{k^{\prime}}\right) \alpha_{2 k^{\prime}}^{t-t^{*}+1}-\bar{\alpha}_{k^{\prime}}^{t-t^{*}+1}\right]
$$

for any period $t \geq t^{*}$.

It follows from Jensen's inequality

$$
\lambda_{k^{\prime}} \alpha_{2 k^{\prime}-1}^{t-t^{*}+1}+\left(1-\lambda_{k^{\prime}}\right) \alpha_{2 k^{\prime}}^{t-t^{*}+1}-\bar{\alpha}_{k^{\prime}}^{t-t^{*}+1}>0
$$

for $\alpha_{2 k^{\prime}-1} \neq \alpha_{2 k^{\prime}}$ and $t>t^{*}$. The previous expression decreases in $\left|\alpha_{2 k^{\prime}-1}-\alpha_{2 k^{\prime}}\right|$ and reaches its minimum for

$$
\lambda^{*}(t)=\frac{\left[\frac{1}{t-t^{*}+1}\left(\alpha_{2 k^{\prime}-1}^{t-t^{*}+1}-\alpha_{2 k^{\prime}}^{t-t^{*}+1}\right)\right]^{\frac{1}{t-t^{*}}}}{\left(\alpha_{2 k^{\prime}-1}-\alpha_{2 k^{\prime}}\right)^{\frac{t-t^{*}+1}{t-t^{*}}}}-\frac{\alpha_{2 k^{\prime}}}{\alpha_{2 k^{\prime}-1}-\alpha_{2 k^{\prime}}}
$$

given $\alpha_{2 k^{\prime}-1}$ and $\alpha_{2 k^{\prime}}$.

\section{Proposition 5}

Proof. Sectoral prices now solve

$$
p_{k t}=\left(1-\alpha_{k}\right)\left[(1-\delta) m_{t}+\delta p_{t}^{c}\right]+\alpha_{k} p_{k t-1} \quad \text { for all } k
$$


such that

$$
\begin{aligned}
& p_{t}^{c}=\frac{1-\delta}{1-\delta(1-\bar{\alpha})}\left(1-\sum_{k=1}^{K} \omega_{c k} \alpha_{k}^{t-t^{*}+1}\right) m+\frac{\delta}{1-\delta(1-\bar{\alpha})} \sum_{\tau=1}^{t-t^{*}}\left(\sum_{k=1}^{K} \omega_{c k} \alpha_{k}^{\tau}\left(1-\alpha_{k}\right)\right) p_{t-\tau}^{c}, \\
& \bar{p}_{t}^{c}=\frac{1-\delta}{1-\delta(1-\bar{\alpha})}\left(1-\sum_{k^{\prime}=1}^{K / 2} \bar{\omega}_{c k^{\prime}} \bar{\alpha}_{k^{\prime}}^{t-t^{*}+1}\right) m+\frac{\delta}{1-\delta(1-\bar{\alpha})} \sum_{\tau=1}^{t-t^{*}}\left(\sum_{k^{\prime}=1}^{K / 2} \bar{\omega}_{c k^{\prime}} \bar{\alpha}_{k}^{\tau}\left(1-\bar{\alpha}_{k}\right)\right) \bar{p}_{t-\tau}^{c} .
\end{aligned}
$$

for any period $t \geq t^{*}$.

Assume that $p_{t-\tau}^{c}=\bar{p}_{t-\tau}^{c}$ for all $\tau \geq 1$, so

$$
\begin{aligned}
p_{t}^{c}-\bar{p}_{t}^{c}= & -\frac{1-\delta}{1-\delta(1-\bar{\alpha})} \sum_{k^{\prime}=1}^{K / 2} \bar{\omega}_{c k^{\prime}}\left(\lambda_{k^{\prime}} \alpha_{2 k^{\prime}-1}^{t-t^{*}+1}+\left(1-\lambda_{k^{\prime}}\right) \alpha_{2 k^{\prime}}^{t-t^{*}+1}-\bar{\alpha}_{k^{\prime}}^{t-t^{*}+1}\right) m \\
& +\frac{\delta}{1-\delta(1-\bar{\alpha})} \sum_{\tau=1}^{t-t^{*}}\left(\sum_{k^{\prime}=1}^{K / 2} \bar{\omega}_{c k^{\prime}}\left[\begin{array}{c}
\lambda_{k^{\prime}}\left(1-\alpha_{2 k^{\prime}-1}\right) \alpha_{2 k^{\prime}-1}^{\tau}+\left(1-\lambda_{k^{\prime}}\right)\left(1-\alpha_{2 k^{\prime}}\right) \alpha_{2 k^{\prime}}^{\tau} \\
-\left(1-\bar{\alpha}_{k^{\prime}}\right) \bar{\alpha}_{k^{\prime}}^{\tau}
\end{array}\right] \lambda_{A q} q_{t} \underline{0} \underline{\tau}\right)
\end{aligned}
$$

The difference $p_{t}^{c}-\bar{p}_{t}^{c}$ is a sum of two terms. The first term in equation (A.10) is a rescaled version of economy 1 so results $1-4$ of Economy 1 still apply. The second term is a measure of the amplification of monetary non-neutrality due to strategic complementarity introduced by intermediate inputs. The higher this term, the smaller is the $p_{t}^{c}$ relative to $\bar{p}_{t}^{c}$.

From Jensen's inequality

$$
\lambda_{k^{\prime}}\left(1-\alpha_{2 k^{\prime}-1}\right) \alpha_{2 k^{\prime}-1}^{\tau}+\left(1-\lambda_{k^{\prime}}\right)\left(1-\alpha_{2 k^{\prime}}\right) \alpha_{2 k^{\prime}}^{\tau}-\left(1-\bar{\alpha}_{k^{\prime}}\right) \bar{\alpha}_{k^{\prime}}^{\tau}<0
$$

for $\alpha_{2 k^{\prime}-1} \neq \alpha_{2 k^{\prime}}$ and $t>t^{*}$.

Thus, the difference in the consumption price response between baseline and merged economies, $\bar{p}_{t}^{c}-p_{t}^{c}$, is larger when the difference in frequencies, $\alpha$, is higher for merged sectors with higher combined weight, $\bar{\omega}_{c k^{\prime}}$. Relaxing the assumption $p_{t-\tau}^{c}=\bar{p}_{t-\tau}^{c}$ for all $\tau \geq 1$ reinforces the result regarding frequencies.

\section{Industry by Industry Input-Output Matrix}

We use the make table $(M A K E)$ to determine the share of each commodity $c$ that each industry $i$ produces. We define the market share ("SHARE") of industry $i$ 's production 
of commodity $c$ as

$$
S H A R E=M A K E \odot(\mathbb{I} \times M A K E)_{i, j}^{-1},
$$

where $\mathbb{I}$ is a matrix of 1 s with suitable dimensions.

We multiply the share and use tables $(U S E)$ to calculate the dollar amount that industry $i$ sells to industry $j$. We label this matrix revenue share (REVSHARE), which is a supplier industry-by-consumer industry matrix,

$$
R E V S H A R E=(S H A R E \times U S E) .
$$

We use the revenue share matrix to calculate the percentage of industry $j$ 's inputs purchased from industry $i$ and label the resulting matrix SUPPSHARE:

$$
S U P P S H A R E=R E V S H A R E \odot\left((M A K E \times \mathbb{I})_{i, j}^{-1}\right)^{\top}
$$

The input-share matrix in equation (A.14) is an industry-by-industry matrix and therefore consistently maps into our model.

\section{Robustness}

In this subsection, we first show the specification of monetary policy crucially affects our conclusions. We then analyze how changes in parameters and tails of the frequency distribution affect our findings.

As the first set of robustness checks, we vary the parameters of the Taylor rule. We also study a specification with exogenous nominal demand, rather than closing the model with a Taylor rule. We report the results in Figure A.6 and Table A.2 for the same six cases we studied in the previous section.

As our first experiment, we increase $\phi_{\pi}$, the systematic response of monetary policy to inflation in the Taylor rule, from a baseline value of 1.24 to 2.5.

We see in Figure A.6 a similar response of inflation independent of whether we study heterogeneous or homogeneous price stickiness, sector size, and I/O structure. The impact response of inflation is, however, roughly cut to one-third compared to our baseline in 
Figure 1, which comes from weaker demand effects. The inflation response tends to be slightly more persistent with all three forms of heterogeneity, but the cumulative inflation responses in an economy with $\phi_{\pi}=2.5$ are still smaller than in an economy with $\phi_{\pi}=1.24$ (compare panel B of Table 3 and Table A.2).

The higher systematic response to inflation in the Taylor rule reduces the impact response of consumption by a factor of up to four across different cases (compare panel A of Table 3 and Table A.2). A model with heterogeneous price stickiness but homogeneous sector size and I/O structure has an almost twice as large impact response compared to an economy in which all three forms of heterogeneities interact (case 3 vs. case 6). A higher weight on inflation stabilization in the Taylor rule for a given demand shock results in a larger stabilization of output in the standard New Keynesian model. Once we allow for heterogeneous price stickiness, the cumulative real effects of monetary policy shocks contract by $40 \%$, with a more stringent response to inflationary pressure in the Taylor rule. We see similar results once we add heterogeneity in sector size and I/O structure. We see in Panels $\mathrm{A}$ and $\mathrm{C}$ of Table 3 and Table A.2 that the different forms of heterogeneity introduce a slightly more sluggish and persistent response in consumption and real marginal costs, which explains the large real effects of demand shocks, despite the smaller effects on impact. This finding is reminiscent of the responder-nonresponder framework discussed in Carvalho (2006) and the selection effect of Carvalho and Schwartzman (2015).

Changes in the systematic response to output growth have little impact on the response of real consumption, inflation, or real marginal costs (not tabulated).

In our second experiment, we close the model by positing exogenous nominal demand. Figure A.7 report our findings. The dashed blue line represents our baseline response with the Taylor rule, and the dash-dotted blue line represents the response for a model with exogenous nominal demand. Real marginal costs barely move in the model with exogenous demand, resulting in a small and transient impact response of inflation and a one-percentage-point response of consumption on impact. The impact response of consumption is smaller by a factor of five than the impact response with a Taylor rule.

As a second set of robustness checks, we analyze how changes in parameters and tails of the frequency distribution affect our findings. First, we study the effect of changes in risk aversion, $\sigma$, the Frisch elasticity, $\varphi$, the average input share in production, $\delta$, the elasticity of substitution within and across sectors, $\eta, \theta$, and the persistence of monetary 
policy shocks, $\rho$, in our full-blown model (case 6 in Table 2). Specifically, we set (baseline parameters in parentheses) $\sigma=2(1), \varphi=1(2), \delta=0.7(0.5), \eta=6(2), \theta=10(6)$, and $\rho=0.95(0.90)$. Figure A.8 and Table A.3 report our findings.

Overall, we see our results in the baseline calibration of Table 3 and Figure 1 are robust to variations in parameter values. The only exception is the increase of the coefficient of relative risk aversion, $\sigma$, from a baseline value of 1 to 2 . The intratemporal rate of substitution from leisure to consumption determines the real wage. The drop in consumption results in a drop in the real wage, which increases in $\sigma$. Lower real wages lower the response of real marginal costs and the overall demand pressure.

Second, Figure A.13 and Figure A.14 plot the impulse response functions for a trimmed distribution in the frequency of price adjustment. Specifically, we compare the response of our baseline calibration for case 6 with a calibration that trims the $20 \%$ stickiest sectors and a calibration with a large left tail rather than a large right tail as the empirical distribution of the frequency of price adjustment. We keep the mean frequency of price adjustment identical across calibrations. The economy with a right-trimmed tail has the lowest real effects even though the economy with the large left tail has a similar impact drop in output but then has much more persistent output dynamics. Our baseline case has the largest initial drop. 
Figure A.1: Distribution of the Frequency of Price Adjustment

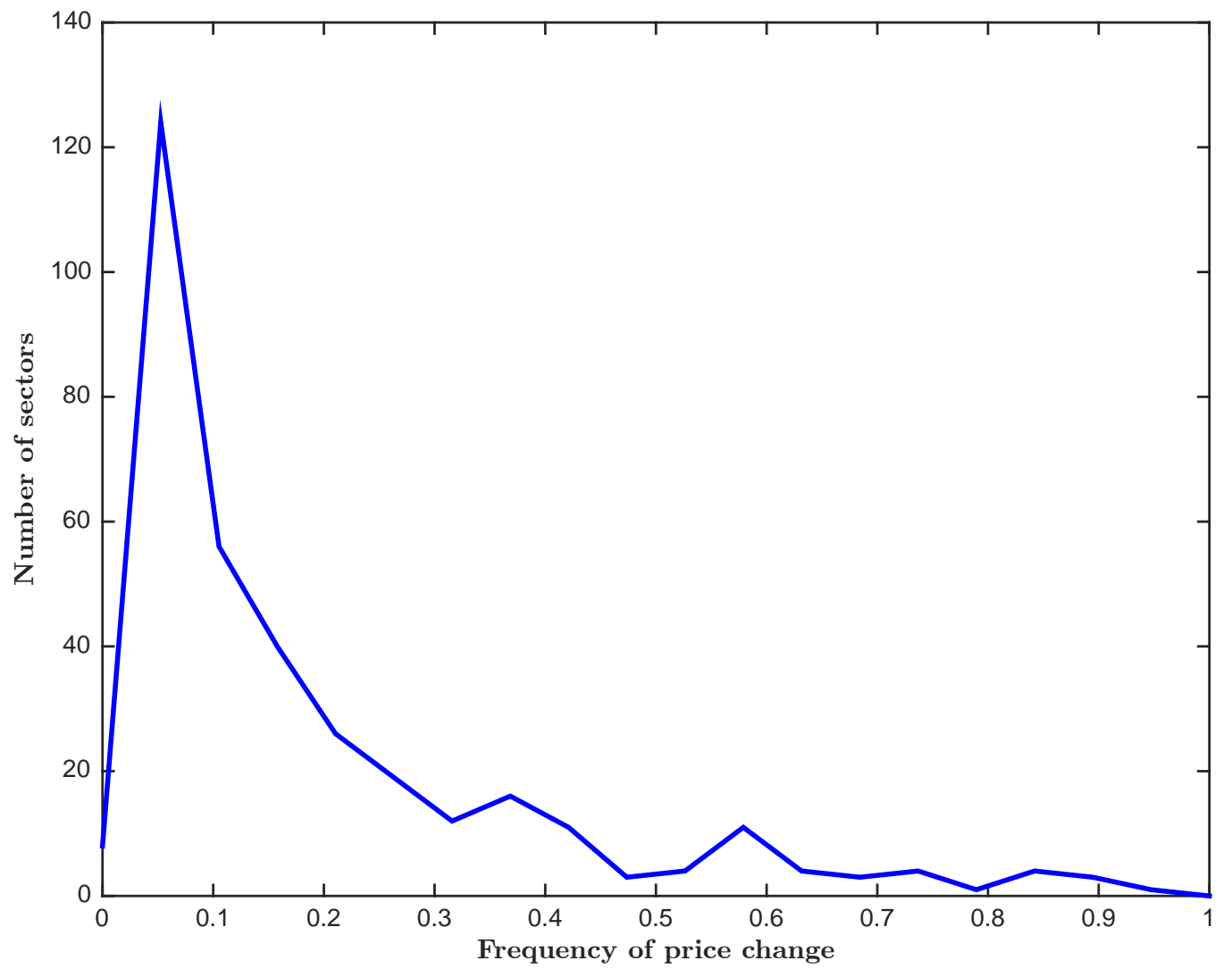

This figure plots the distribution of the frequency of price adjustment for a 350-sector model using the microdata underlying the PPI from the BLS. 
Figure A.2: Variance of Frequency of Price adjustment: Calvo Aggregation

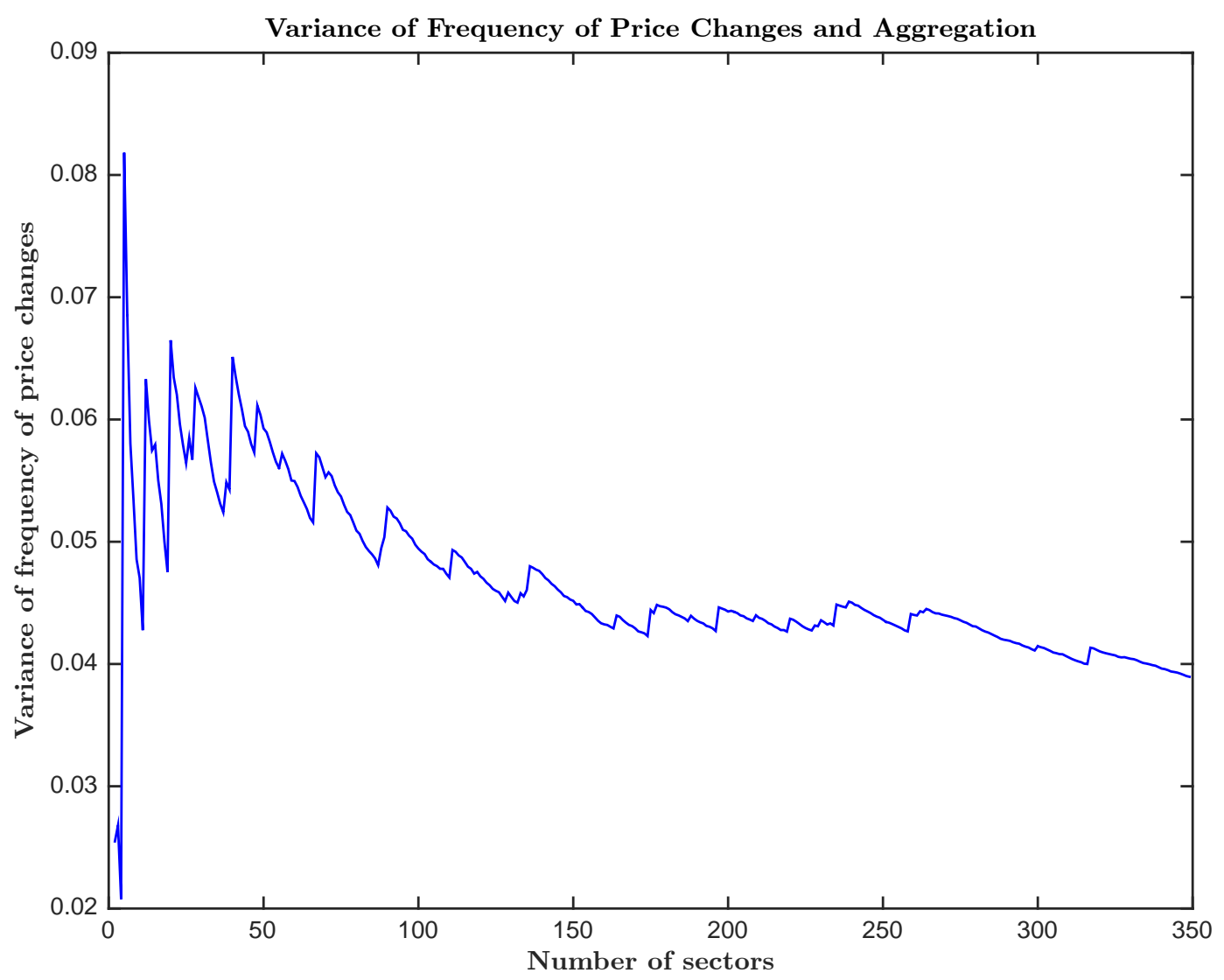

This figure plots the variance of the frequency of price adjustments for different levels of aggregation. We aggregate sectors by the frequency of price adjustment keeping the average frequency of price adjustment constant. 
Figure A.3: Variance of Frequency of Price adjustment: Size Aggregation

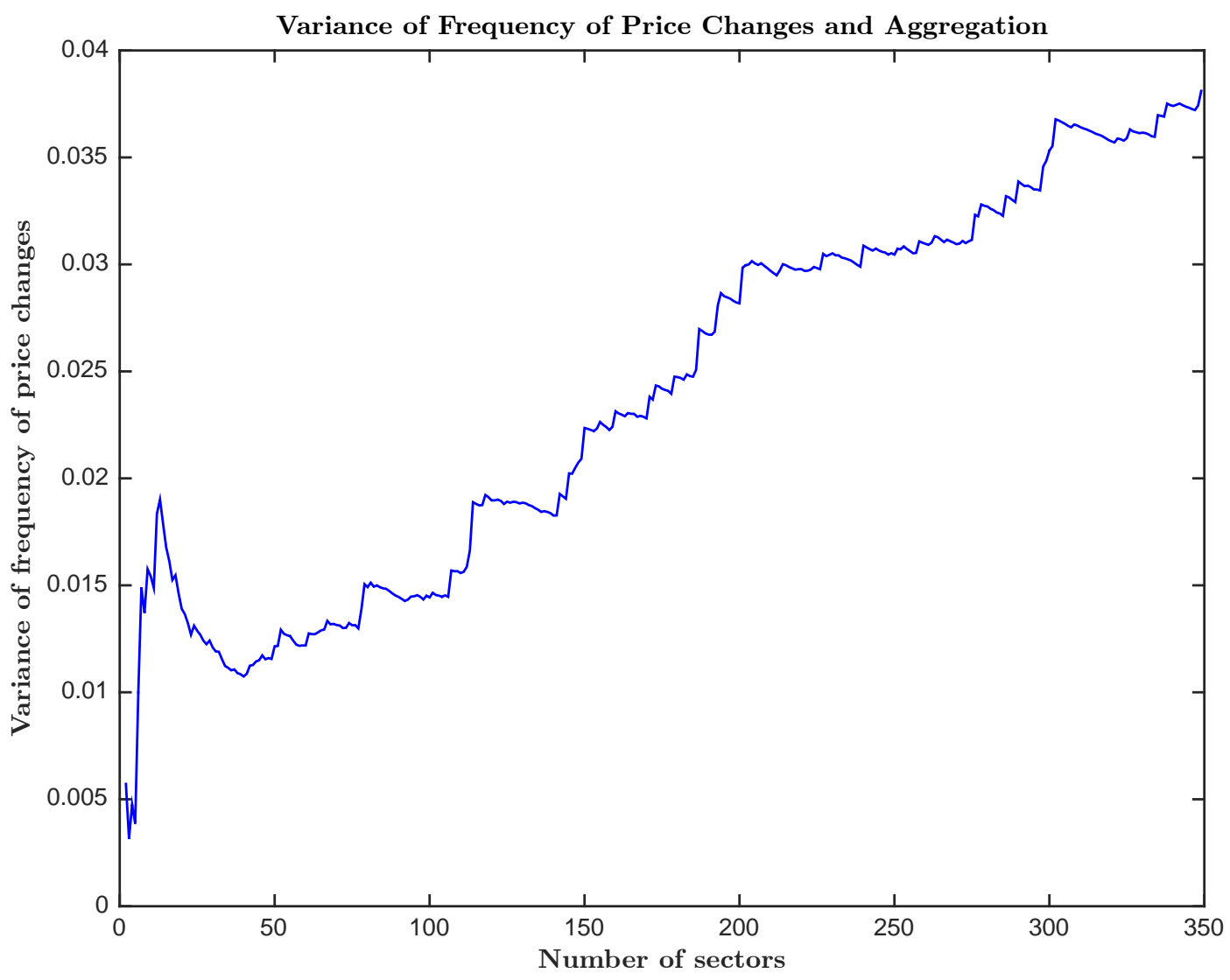

This figure plots the variance of the frequency of price adjustments for different levels of aggregation. We aggregate sectors by the sector size keeping the average frequency of price adjustment constant. 
Figure A.4: Price Gap and Components, 350 and 8 Sectors

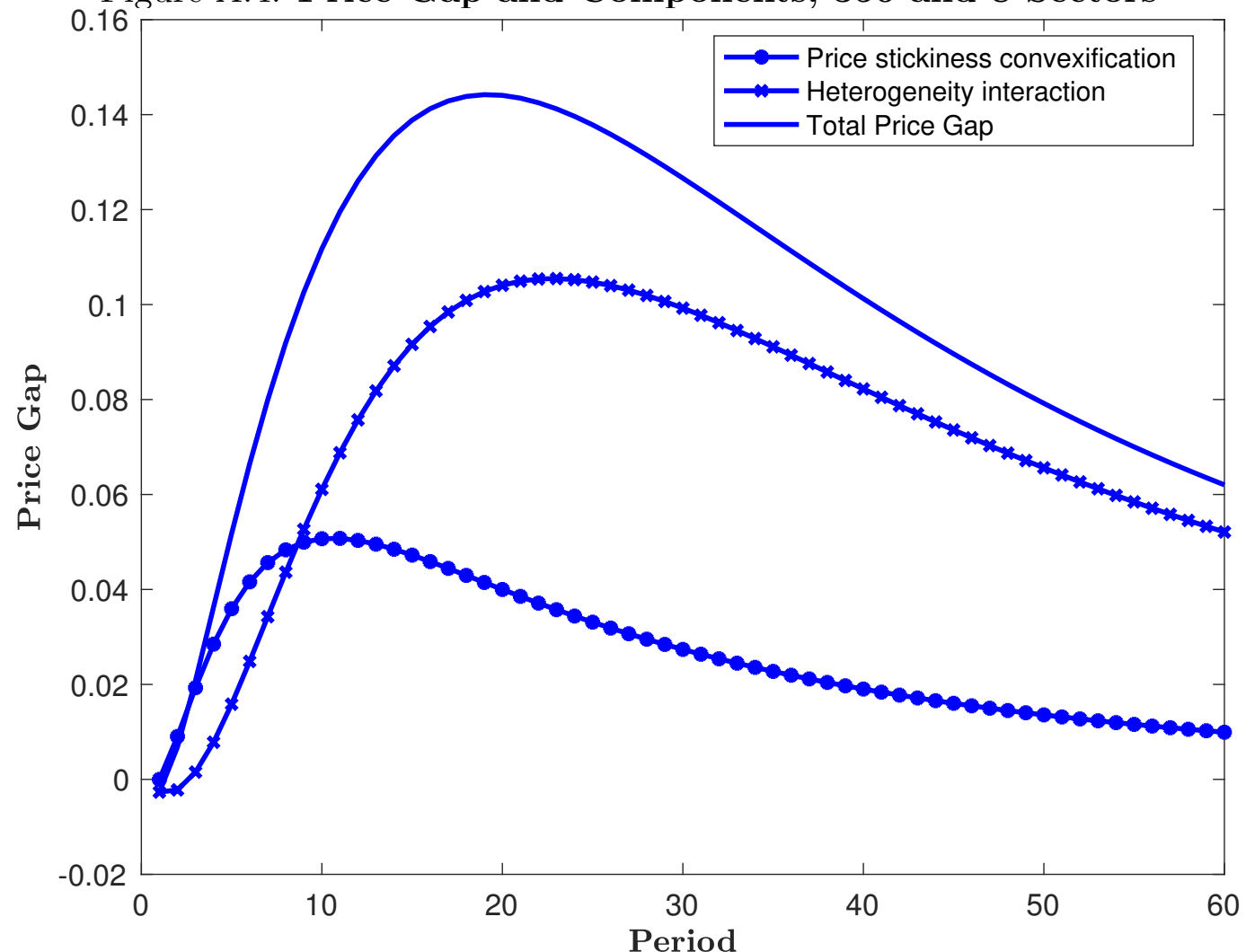

This figure plots the the price gap of the 8 less the 350 sector CPI price path, and the difference in the convexification and interaction components implied by Proposition 3 that make up the price paths. 
Figure A.5: Response of Real Consumption, Inflation, and Real Marginal Costs to Monetary Policy Shock $\left(\phi_{\pi}=2.5\right)$
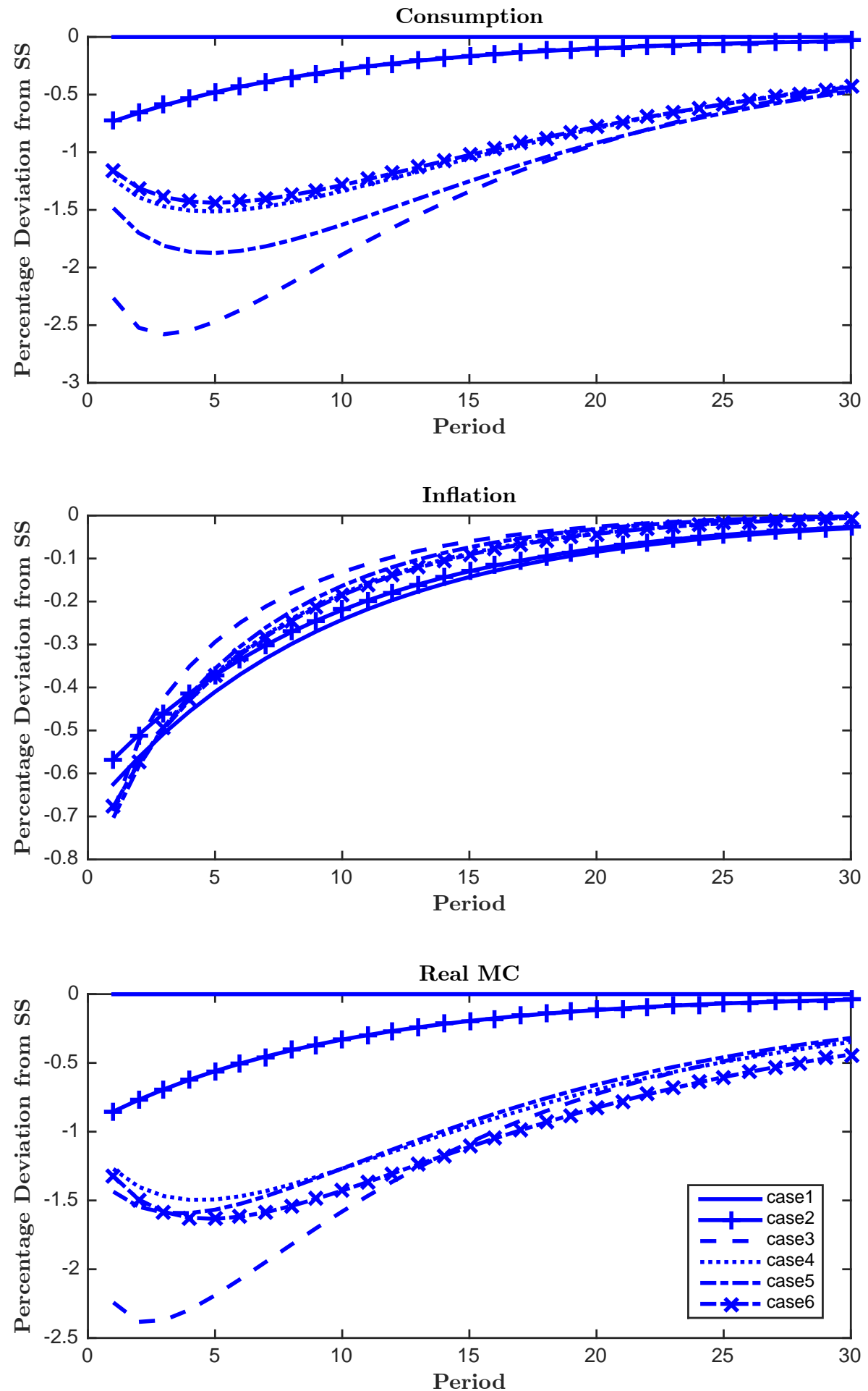

This figure plots the impulse response function of real consumption, inflation, and real marginal costs to a one-standard-deviation monetary policy shock for a 350-sector model for different cases (see Table 2 for a description of the different cases) with a coefficient on inflation in the Taylor rule of $\phi_{\pi}=2.5$. 
Figure A.6: Response of Real Consumption, Inflation, and Real Marginal Costs to Monetary Policy Shock (exogenous nominal demand)
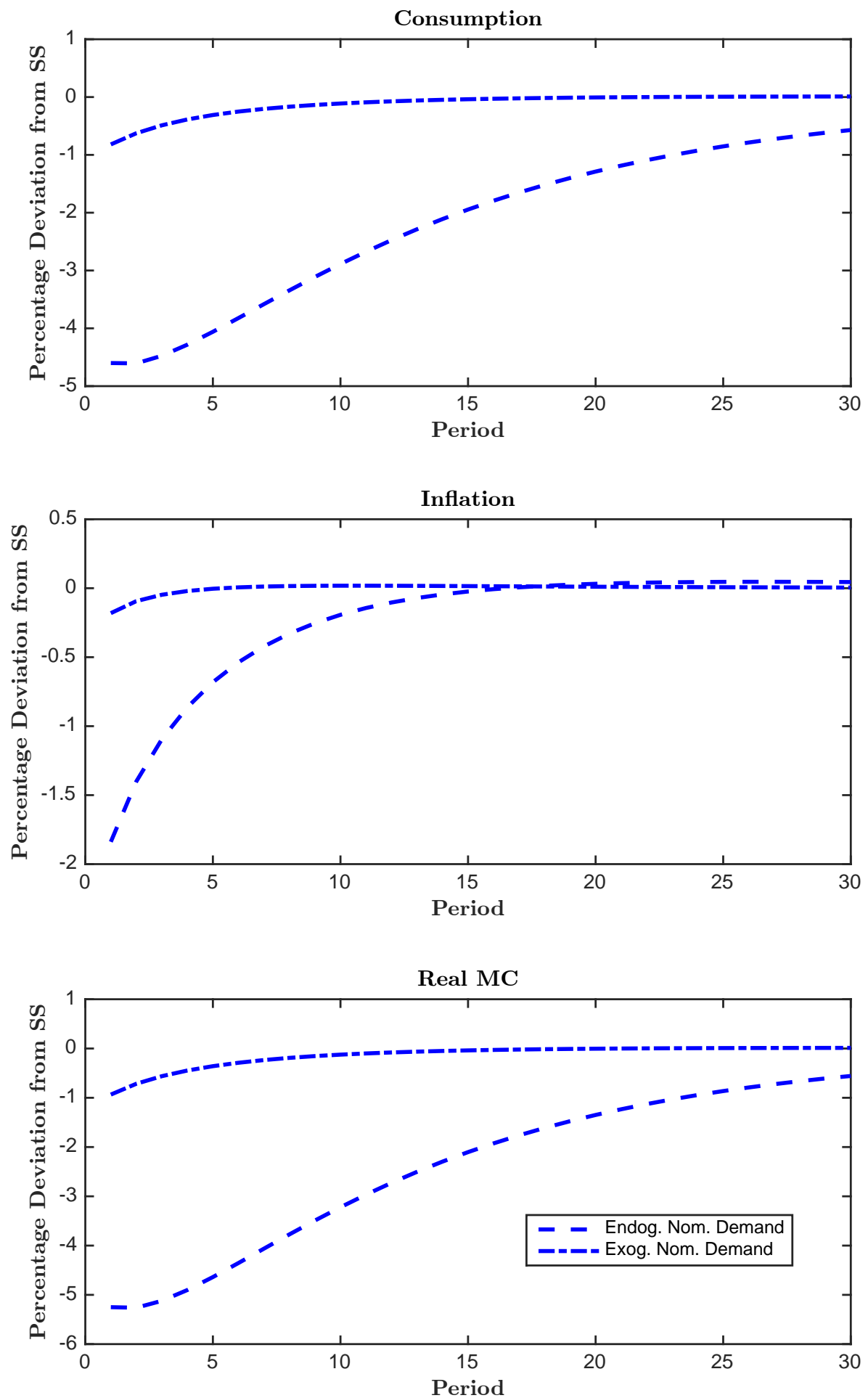

This figure plots the impulse response function of real consumption, inflation, and real marginal costs to a one-standard-deviation monetary policy shock for a 350-sector model for case 6 (see Table 2 for a description of the different cases), closing the model with positing exogenous nominal demand. 
Figure A.7: Response of Real Consumption, Inflation, and Real Marginal Costs to Monetary Policy Shock (variations in parameters)
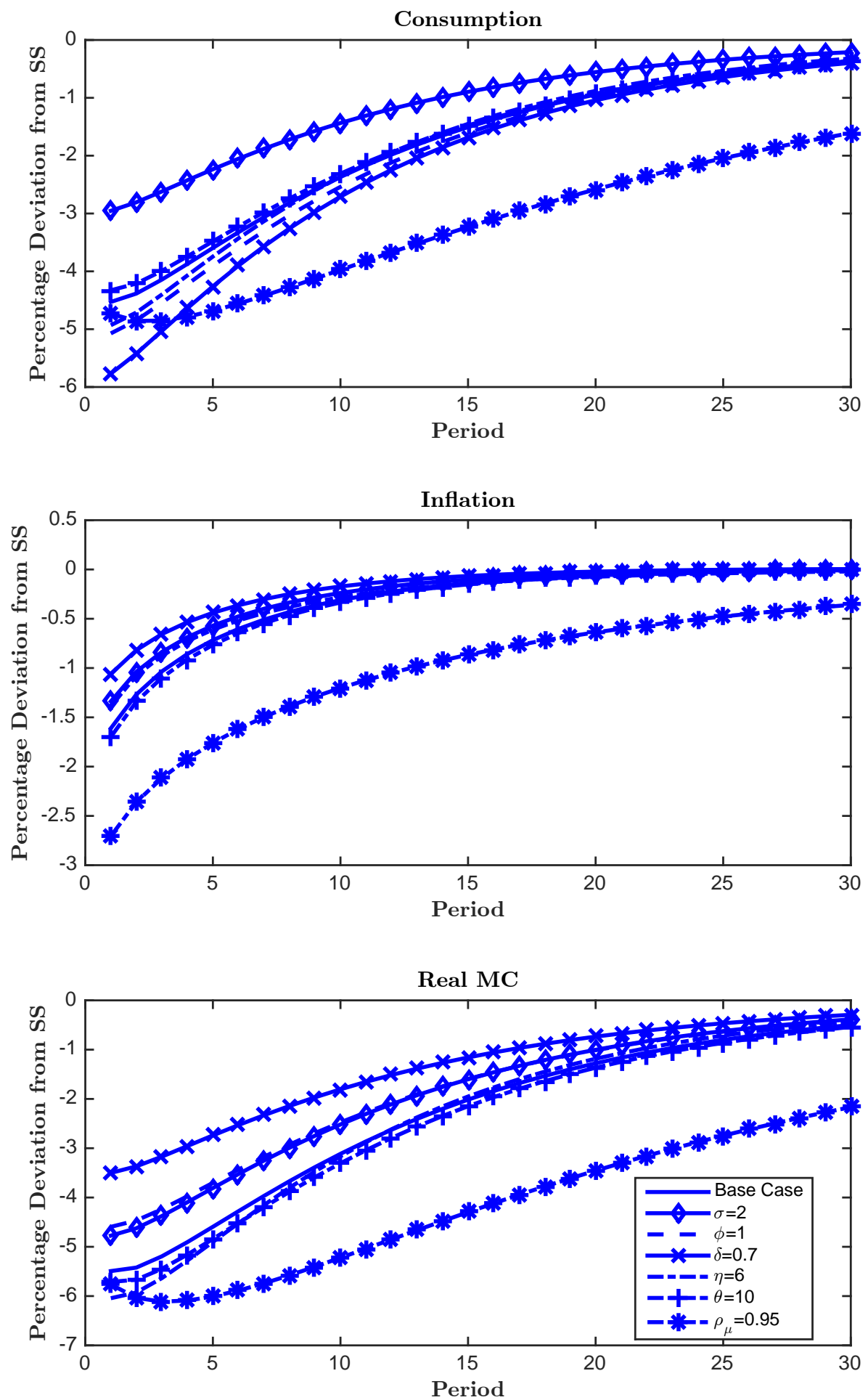

This figure plots the impulse response function of real consumption, inflation, and real marginal costs to a one-standard-deviation monetary policy shock for a 350-sector model for different cases (see Table 2 for a description of the different cases) for different values of structural parameters. 
Figure A.8: Distribution of the Frequency of Price Adjustment (58 Sectors)

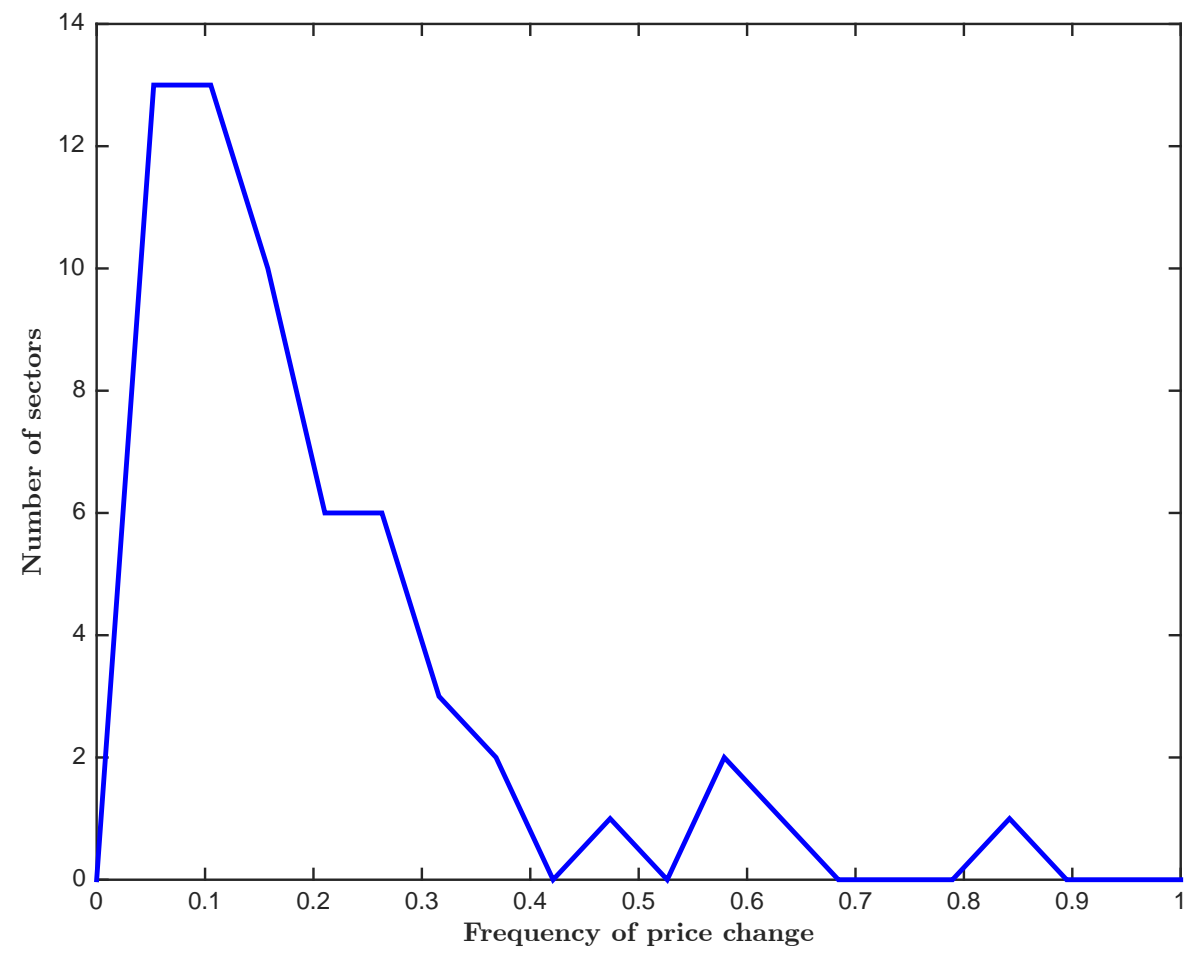

This figure plots the distribution of the frequency of price adjustment for a 58-sector model using the microdata underlying the PPI from the BLS. 
Figure A.9: Response of Real Consumption, Inflation, and Real Marginal Costs to Monetary Policy Shock (58 Sectors)
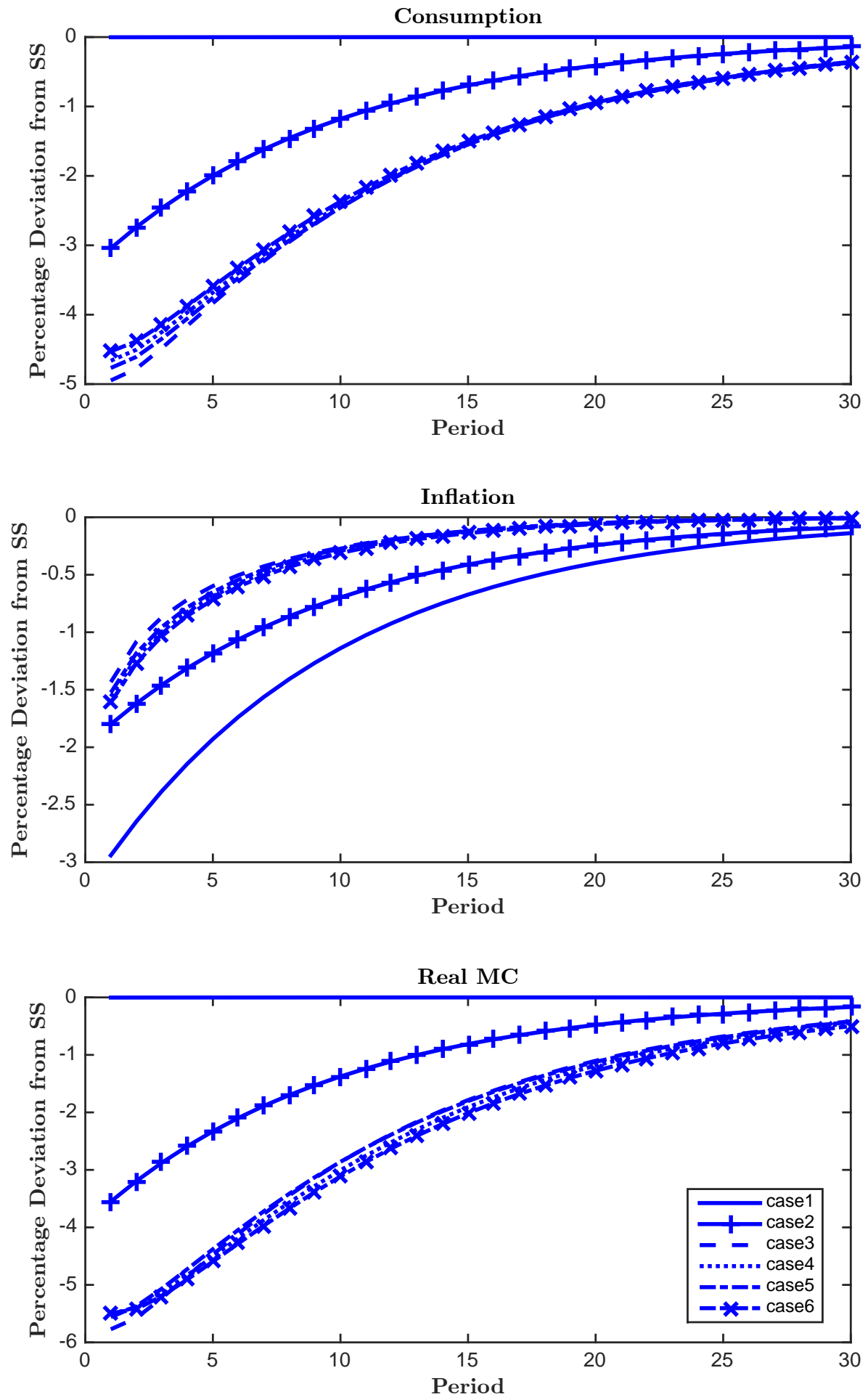

This figure plots the impulse response function of real consumption, inflation, and real marginal costs to a one-standard deviation monetary policy shock for a 58-sector model for different cases (see Table 2 for a description of the different cases). 
Figure A.10: Response of Real Consumption, Inflation, and Real Marginal Costs to Monetary Policy Shock (58 Sectors, $\phi_{\pi}=2.5$ )
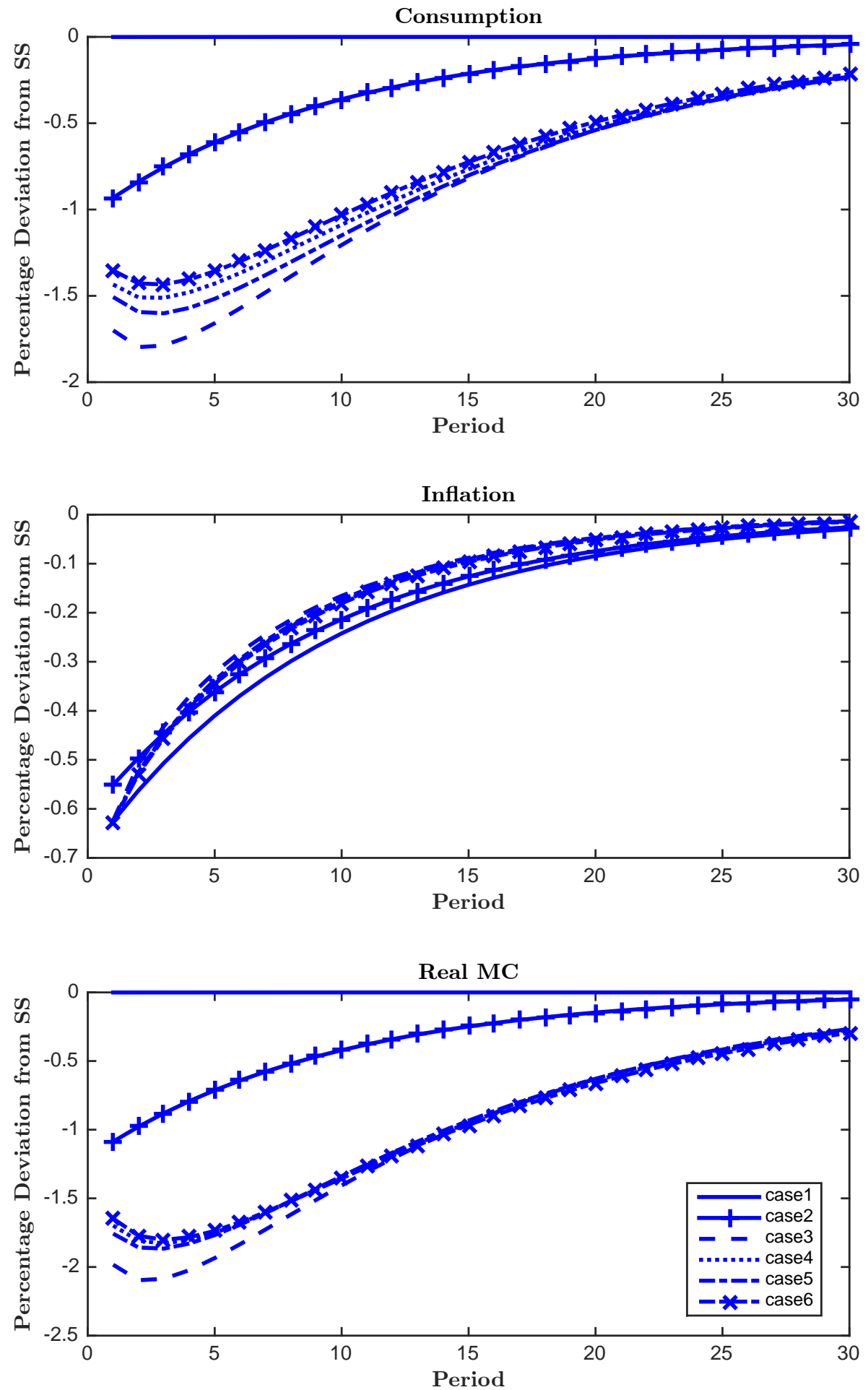

This figure plots the impulse response function of real consumption, inflation, and real marginal costs to a one-standard-deviation monetary policy shock for a 58-sector model for different cases (see Table 2 for a description of the different cases) with a coefficient on inflation in the Taylor rule of $\phi_{\pi}=2.5$. 
Figure A.11: Response of Real Consumption, Inflation, and Real Marginal Costs to Monetary Policy Shock (58 Sectors, Variations in parameters)
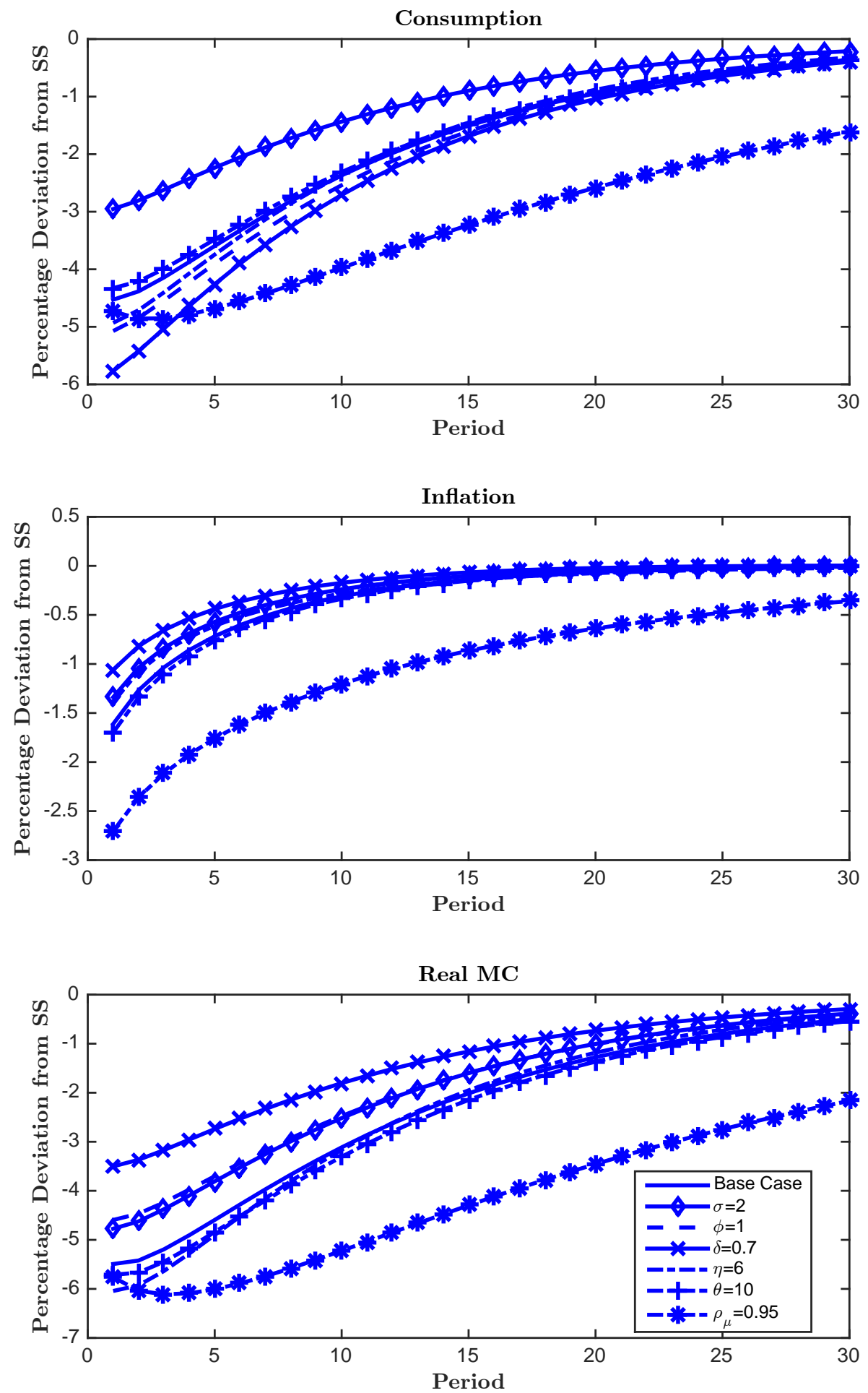

This figure plots the impulse response function of real consumption, inflation, and real marginal costs to a one-standard-deviation monetary policy shock for a 58-sector model for different cases (see Table 2 for a description of the different cases) for different values of structural parameters. 
Figure A.12: Trimmed Distribution of the Frequency of Price Adjustment
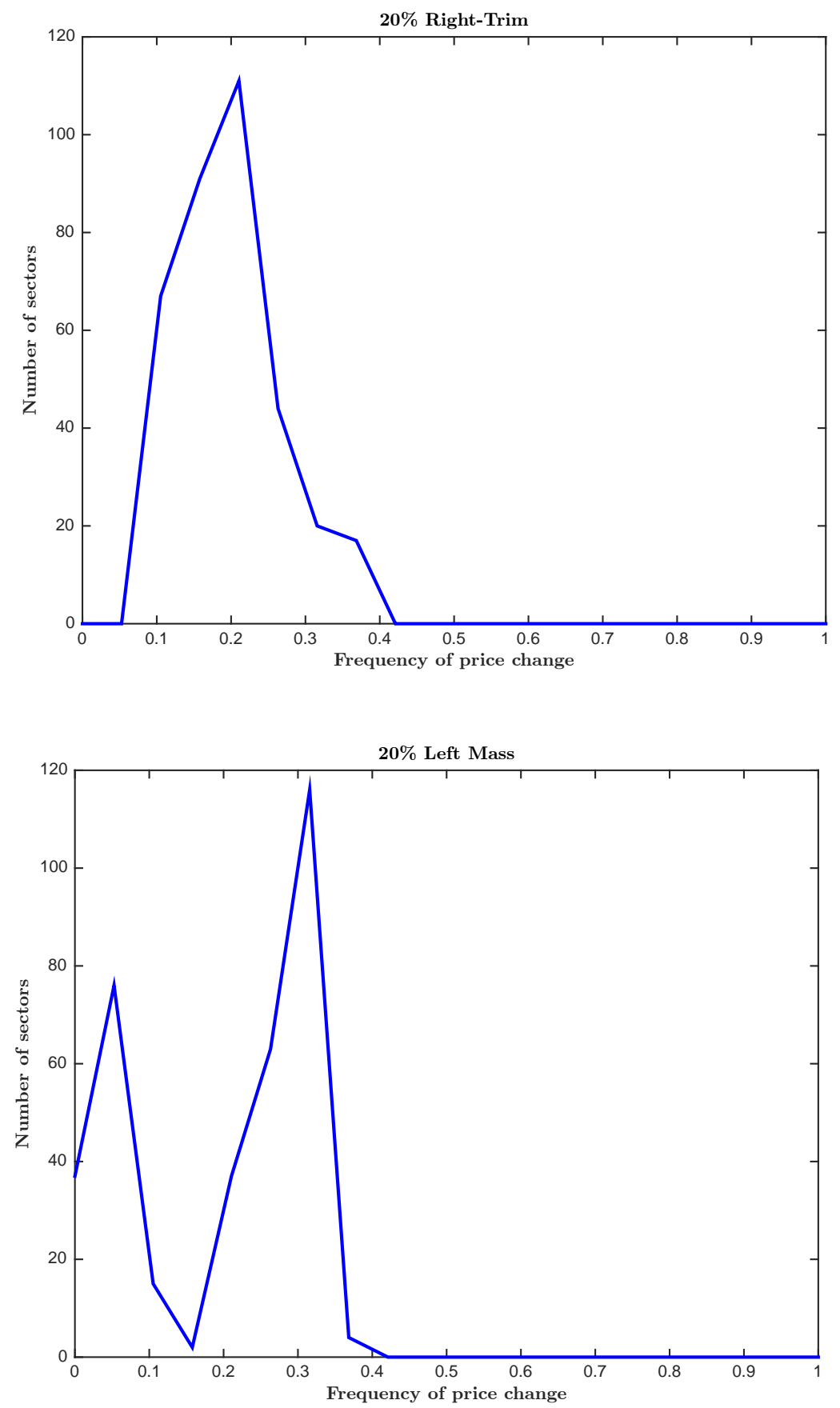

This figure plots the distribution of the frequency of price adjustment for a 350-sector model. The top panel trims the 20\% stickiest sectors, whereas the bottom panel generates a heavy left tail. 
Figure A.13: Response of Real Consumption, Inflation, and Real Marginal Costs to Monetary Policy Shock: Trimmed Tail
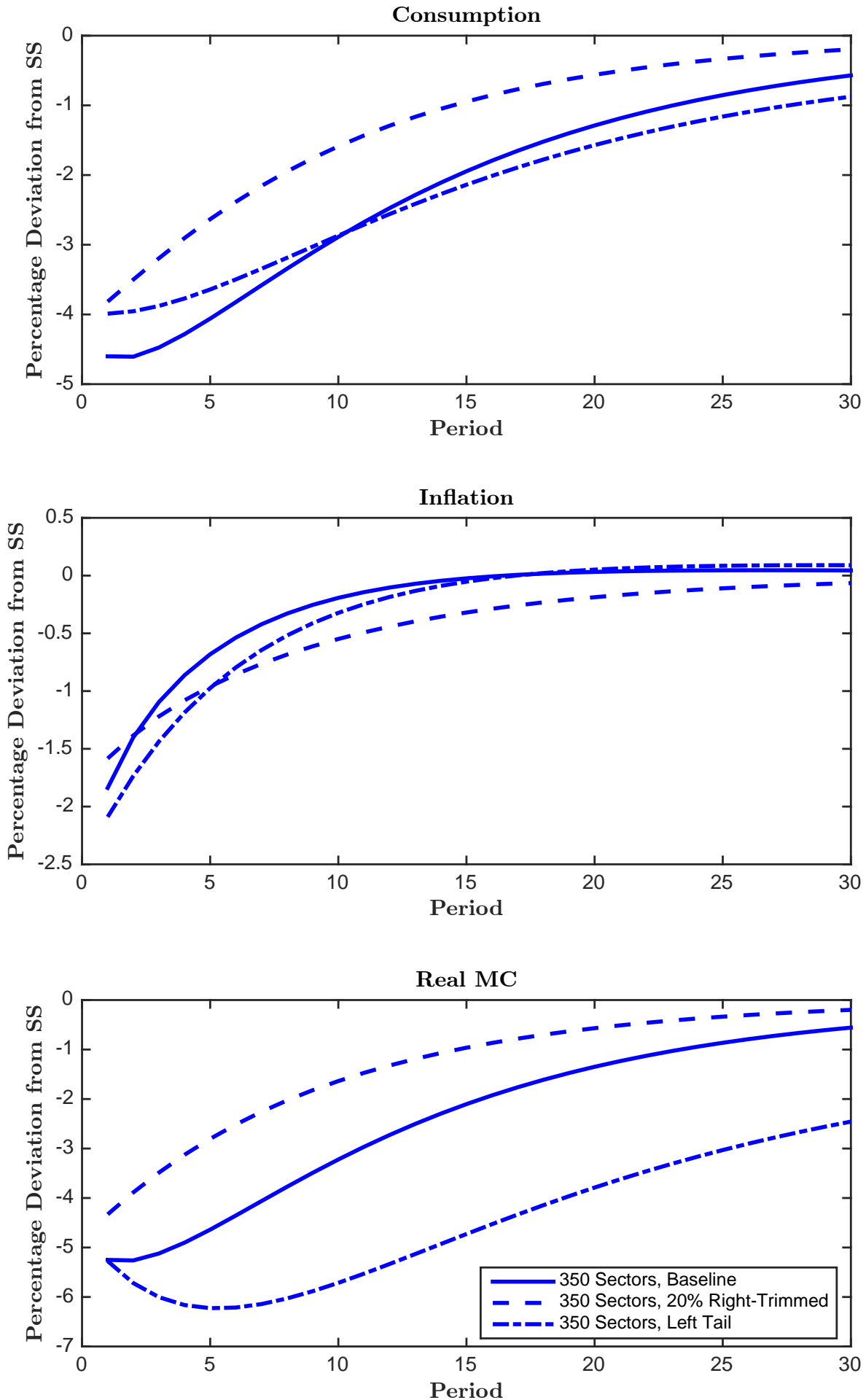

This figure plots the impulse response function of real consumption, inflation, and real marginal costs to a one-standard-deviation monetary policy shock for a 350-sector model for case 6 (see Table 2 for a description of the different cases) for trimmed distributions of the frequency of price adjustment. 
Figure A.14: Response of Markups to Monetary Policy Shock (58 Sectors)
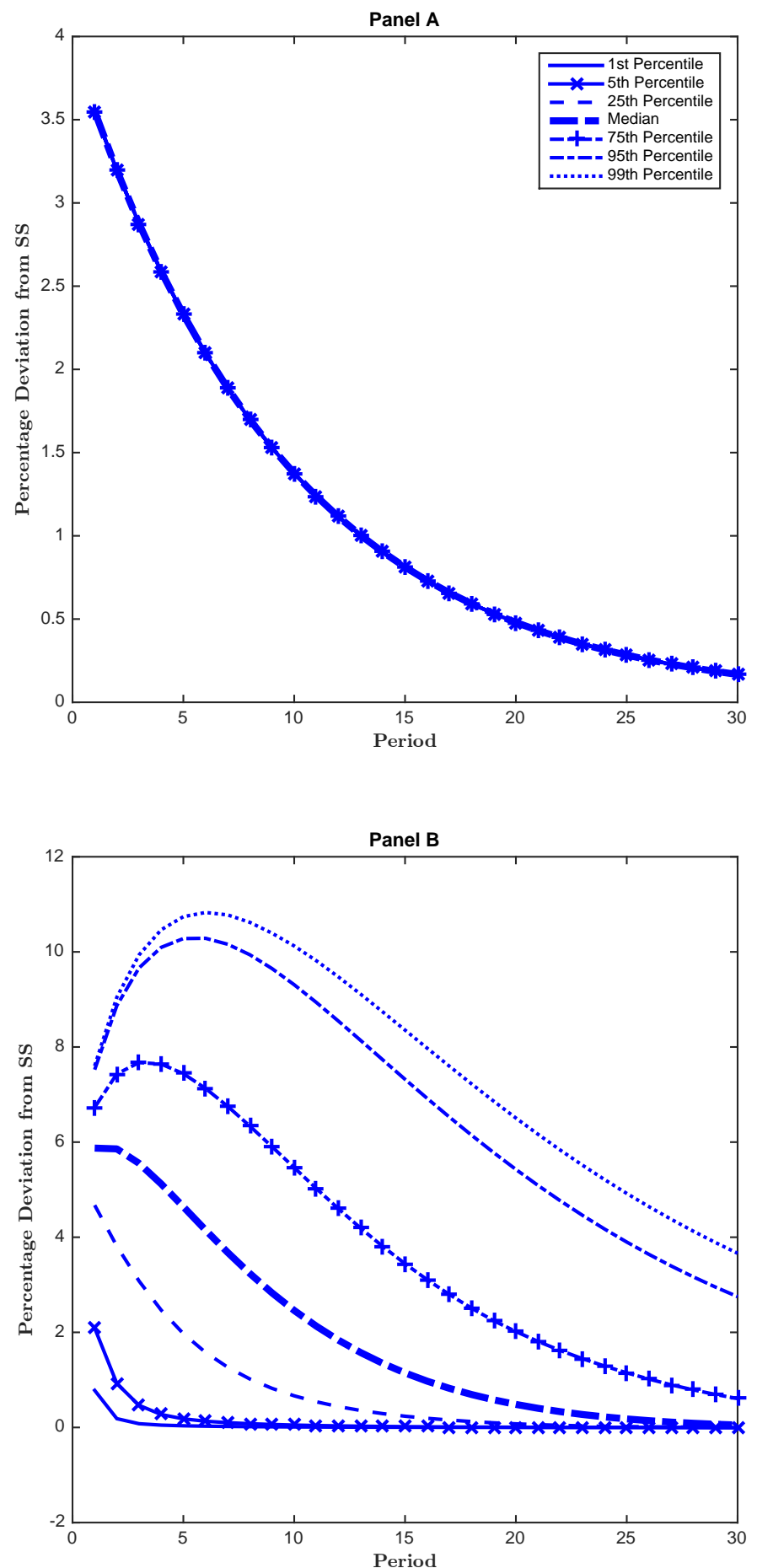

This figure plots the impulse response function of markups to a one-standard-deviation monetary policy shock for a 58-sector model for different case 2 in Panel $A$ and case 6 in Panel B (see Table 2 for a description of the different cases). 
Figure A.15: Ranking of Sectors, Cases 3 and 6 (58 Sectors)
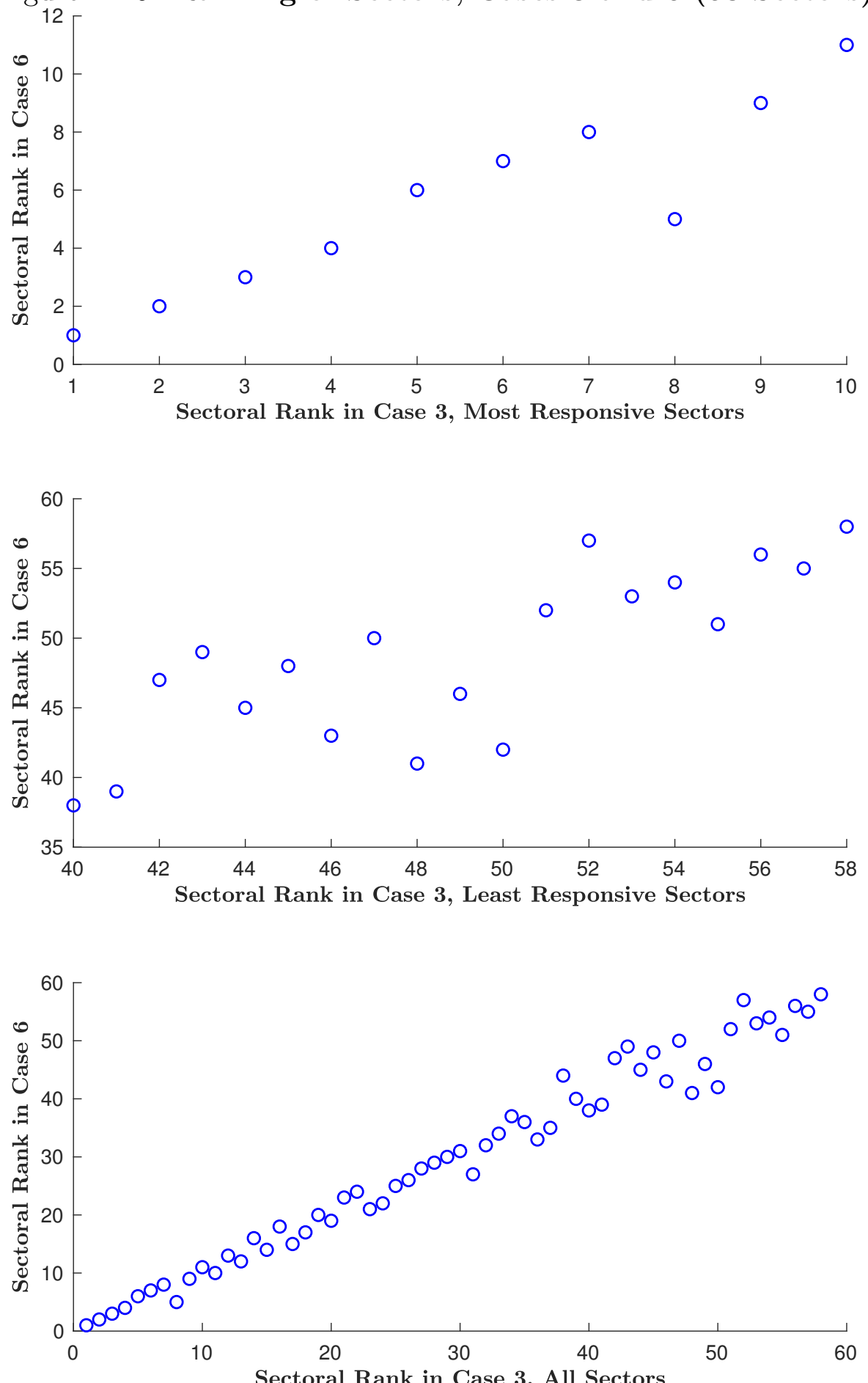

This figure plots the sectoral rankings for the cumulative IRF for case 3 against case 6 (see Table 2 for a description of the different cases). The top panel zooms in on the 10 most important sectors in case 3, the middle panel on the 18 least important sectors. The bottom panel shows all sectors. 
Table A.1: Descriptive Statistics

The table reports the moments of the frequency of price adjustment, FPA, distribution for a 58-sector model in panel $A$ and a 350-sector model in panel B using the microdata underlying the PPI from the BLS.

\begin{tabular}{cccccc}
\hline & Mean & Median & Std & $25^{\text {th }}$ Pct & $75^{\text {th }}$ Pct \\
\hline \multicolumn{5}{c}{ Panel A. 58 Sector Economy } \\
FPA & 0.19 & 0.12 & 0.20 & 0.06 & 0.26 \\
FPA & 0.19 & 0.14 & 0.16 & 0.08 & 0.25 \\
\hline
\end{tabular}




\section{Table A.2: Response to Monetary Policy Shock $\left(\phi_{\pi}=2.5\right)$}

This table reports the impact response, the cumulative impulse response, and the persistence of the response defined as $A R(1)$ coefficient due to a one-percent monetary policy shock for consumption (Panel A), inflation (Panel B), and real marginal costs (Panel C) for a 350-sector economy for different cases (see Table 2 for a description of the different cases) with a coefficient on inflation in the Taylor rule of $\phi_{\pi}=2.5$.

\begin{tabular}{|c|c|c|c|c|c|c|}
\hline & Case 1 & Case 2 & Case 3 & Case 4 & Case 5 & Case 6 \\
\hline & \multicolumn{6}{|c|}{ Panel A. Consumption } \\
\hline Impact & -0.00 & -0.73 & -2.26 & -1.24 & -1.48 & -1.16 \\
\hline Cumulative IRF & -0.01 & -7.00 & -42.54 & -30.26 & -36.23 & -29.31 \\
\hline \multirow[t]{2}{*}{ Persistence } & 0.87 & 0.87 & 0.90 & 0.92 & 0.91 & 0.93 \\
\hline & \multicolumn{6}{|c|}{ Panel B. Inflation } \\
\hline Impact & -0.62 & -0.57 & -0.69 & -0.68 & -0.70 & -0.68 \\
\hline Cumulative IRF & -5.98 & -5.43 & -3.91 & -4.82 & -4.56 & -4.90 \\
\hline \multirow[t]{2}{*}{ Persistence } & 0.87 & 0.87 & 0.92 & 0.94 & 0.93 & 0.94 \\
\hline & \multicolumn{6}{|c|}{ Panel C. Real Marginal Costs } \\
\hline Impact & -0.00 & -0.85 & -2.64 & -1.54 & -1.73 & -1.50 \\
\hline Cumulative IRF & -0.01 & -8.17 & -49.63 & -42.11 & -42.09 & -43.15 \\
\hline Persistence & 0.87 & 0.87 & 0.94 & 0.94 & 0.94 & 0.94 \\
\hline
\end{tabular}




\section{Table A.3: Response to Monetary Policy Shock (variations in parameters)}

This table reports the impact response, the cumulative impulse response, and the persistence of the response defined as $A R(1)$ coefficient due to a one-percent monetary policy shock for consumption (Panel A), inflation (Panel B), and real marginal costs (Panel C) for a 350-sector economy for different cases (see Table 2 for a description of the different cases) for different values of structural parameters.

\begin{tabular}{|c|c|c|c|c|c|c|c|}
\hline & Base & $\sigma=2$ & $\phi=1$ & $\delta=0.7$ & $\eta=6$ & $\theta=10$ & $\rho=0.95$ \\
\hline & \multicolumn{7}{|c|}{ Panel A. Consumption } \\
\hline Impact & -4.60 & -3.06 & -5.14 & -5.86 & -5.25 & -4.38 & -5.24 \\
\hline Cumulative IRF & -66.35 & -39.96 & -69.51 & -72.78 & -67.46 & -65.06 & -129.99 \\
\hline \multirow[t]{2}{*}{ Persistence } & 0.89 & 0.87 & 0.89 & 0.90 & 0.81 & 0.89 & 0.91 \\
\hline & \multicolumn{7}{|c|}{ Panel B. Inflation } \\
\hline Impact & -1.84 & -1.53 & -1.58 & -1.21 & -1.50 & -1.94 & -3.03 \\
\hline Cumulative IRF & -7.48 & -5.67 & -5.94 & -4.06 & -5.79 & -8.16 & -26.68 \\
\hline \multirow[t]{2}{*}{ Persistence } & 0.90 & 0.89 & 0.90 & 0.89 & 0.85 & 0.90 & 0.92 \\
\hline & \multicolumn{7}{|c|}{ Panel C. Real Marginal Costs } \\
\hline Impact & -5.86 & -5.18 & -4.83 & -3.69 & -6.99 & -6.07 & -6.73 \\
\hline Cumulative IRF & -96.80 & -77.58 & -74.08 & -53.10 & -102.77 & -103.37 & -191.35 \\
\hline Persistence & 0.93 & 0.92 & 0.92 & 0.91 & 0.93 & 0.93 & 0.94 \\
\hline
\end{tabular}


Table A.4: Response to Monetary Policy Shock: Sorted by Cumulative Response

This table reports the cumulative real consumption response to a one-percent monetary policy shock for a 58-sector economy for different cases (see Table 2 for a description of the different cases). Panel A reports the response of the least responsive sectors and Panel $B$ reports the response of the most responsive sectors.

\begin{tabular}{cccccccc}
\hline & & Case 1 & Case 2 & Case 3 & Case 4 & Case 5 & Case 6 \\
\hline \multirow{2}{*}{ Least responsive } & 1 & -0.05 & -53.43 & -56.03 & -55.76 & -57.40 & -50.11 \\
& 2 & -0.05 & -53.43 & -55.45 & -55.14 & -56.80 & -39.41 \\
& 3 & -0.05 & -53.43 & -52.94 & -52.49 & -54.23 & -37.37 \\
& 4 & -0.05 & -53.43 & -50.38 & -49.81 & -51.62 & -36.46 \\
& 5 & -0.05 & -53.43 & -48.68 & -48.04 & -49.88 & -34.74 \\
6 & -0.05 & -53.43 & -44.91 & -44.14 & -46.07 & -29.36 \\
& 7 & -0.05 & -53.43 & -42.93 & -42.11 & -44.07 & -25.77 \\
8 & -0.05 & -53.43 & -42.85 & -42.02 & -43.98 & -24.38 \\
9 & -0.05 & -53.43 & -41.92 & -41.08 & -43.05 & -24.31 \\
10 & -0.05 & -53.43 & -39.57 & -38.71 & -40.71 & -22.69 \\
& & & & & & \\
& & Panel B. Cumulative Consumption Response: Most & Responsive \\
& 1 & -0.05 & -53.43 & -245.19 & -262.68 & -255.66 & -270.10 \\
2 & -0.05 & -53.43 & -239.51 & -256.42 & -249.68 & -261.61 \\
3 & -0.05 & -53.43 & -227.84 & -243.56 & -237.39 & -249.64 \\
4 & -0.05 & -53.43 & -210.89 & -224.90 & -219.55 & -227.69 \\
5 & -0.05 & -53.43 & -189.72 & -201.60 & -197.28 & -212.87 \\
6 & -0.05 & -53.43 & -184.21 & -195.53 & -191.48 & -207.42 \\
7 & -0.05 & -53.43 & -183.44 & -194.69 & -190.67 & -200.63 \\
8 & -0.05 & -53.43 & -180.88 & -191.87 & -187.98 & -196.91 \\
9 & -0.05 & -53.43 & -173.49 & -183.74 & -180.21 & -190.42 \\
10 & -0.05 & -53.43 & -165.74 & -175.22 & -172.06 & -179.08 \\
\hline
\end{tabular}


Table A.5: Response of Real Consumption, Inflation, and Real Marginal Costs:

\section{Calvo Aggregation}

This table reports the impact response, the cumulative impulse response, and the persistence of the response defined as $A R(1)$ coefficient due to a one-percent monetary policy shock for consumption (Panel A), inflation (Panel B), and real marginal costs (Panel C) for different levels of aggregation. We aggregate sectors by the frequency of price adjustment keeping the average frequency of price adjustment constant.

\begin{tabular}{|c|c|c|c|c|c|c|c|}
\hline & 8 sectors & 10 sectors & 25 sectors & 50 sectors & 100 sectors & 200 sectors & 350 sectors \\
\hline & \multicolumn{7}{|c|}{ Panel A. Consumption } \\
\hline Impact & -4.58 & -4.60 & -4.63 & -4.63 & -4.62 & -4.61 & -4.60 \\
\hline Cumulative IRF & -65.26 & -65.57 & -66.35 & -66.49 & -66.43 & -66.40 & -66.35 \\
\hline \multirow[t]{2}{*}{ Persistence } & 0.84 & 0.85 & 0.94 & 0.94 & 0.94 & 0.89 & 0.89 \\
\hline & \multicolumn{7}{|c|}{ Panel B. Inflation } \\
\hline Impact & -1.83 & -1.82 & -1.83 & -1.83 & -1.83 & -1.84 & -1.84 \\
\hline Cumulative IRF & -7.64 & -7.58 & -7.39 & -7.39 & -7.43 & -7.45 & -7.48 \\
\hline \multirow[t]{2}{*}{ Persistence } & 0.94 & 0.94 & 0.94 & 0.94 & 0.87 & 0.90 & 0.90 \\
\hline & \multicolumn{7}{|c|}{ Panel C. Real Marginal Costs } \\
\hline Impact & -5.90 & -5.90 & -5.88 & -5.68 & -5.71 & -5.80 & -5.86 \\
\hline Cumulative IRF & -133.82 & -127.68 & -113.72 & -100.81 & -96.70 & -97.73 & -96.80 \\
\hline Persistence & 0.94 & 0.94 & 0.94 & 0.93 & 0.93 & 0.93 & 0.93 \\
\hline
\end{tabular}


Table A.6: Response of Real Consumption, Inflation, and Real Marginal Costs: Size Aggregation

This table reports the impact response, the cumulative impulse response, and the persistence of the response defined as $A R(1)$ coefficient due to a one-percent monetary policy shock for consumption (Panel A), inflation (Panel B), and real marginal costs (Panel C) for different levels of aggregation. We aggregate sectors by the sector size keeping the average frequency of price adjustment constant.

\begin{tabular}{lrrrrrrr}
\hline & 8 sectors & 10 sectors & 25 sectors & 50 sectors & 100 sectors & 200 sectors & 350 sectors \\
\hline & & \multicolumn{7}{c}{ Panel A. Consumption } \\
Impact & -2.62 & -2.62 & -2.88 & -3.08 & -3.37 & -4.25 & -4.60 \\
Cumulative IRF & -25.63 & -25.68 & -32.31 & -36.63 & -42.40 & -59.09 & -66.35 \\
Persistence & 0.80 & 0.93 & 0.91 & 0.90 & 0.86 & 0.86 & 0.89 \\
& & & & & & & \\
& & & & Panel B. Inflation & & \\
Impact & -1.97 & -1.97 & -1.97 & -1.96 & -1.94 & -1.86 & -1.84 \\
Cumulative IRF & -18.64 & -18.62 & -17.12 & -15.91 & -14.31 & -9.41 & -7.48 \\
Persistence & 0.90 & 0.90 & 0.88 & 0.86 & 0.89 & 0.90 & 0.90 \\
& & & & & & & \\
Impact & -3.18 & -3.16 & -3.53 & -3.84 & -4.22 & -5.36 & -5.86 \\
Cumulative IRF & -47.03 & -45.41 & -59.10 & -65.63 & -71.79 & -91.04 & -96.80 \\
Persistence & 0.90 & 0.90 & 0.91 & 0.92 & 0.92 & 0.93 & 0.93 \\
\hline
\end{tabular}


Table A.7: Response of Real Consumption, Inflation, and Real Marginal Costs: Industry-Code Aggregation

This table reports the impact response, the cumulative impulse response, and the persistence of the response defined as $A R(1)$ coefficient due to a one-percent monetary policy shock for consumption (Panel A), inflation (Panel B), and real marginal costs (Panel C) for different levels of aggregation. We aggregate sectors by NAICS digits keeping the average frequency of price adjustment constant.

\begin{tabular}{lrrrrrr}
\hline & 8 sectors & 20 sectors & \multicolumn{6}{c}{60 sectors } & 148 sectors & 245 sectors & 350 sectors \\
\hline & \multicolumn{7}{c}{ Panel A. Consumption } \\
Impact & -2.98 & -3.20 & -3.93 & -4.48 & -4.54 & -4.60 \\
Cumulative IRF & -34.33 & -38.13 & -54.14 & -64.14 & -65.48 & -66.35 \\
Persistence & 0.89 & 0.86 & 0.93 & 0.89 & 0.93 & 0.89 \\
& & & & & \\
& & & Panel B. Inflation & \\
Impact & -1.97 & -1.95 & -1.91 & -1.85 & -1.85 & -1.84 \\
Cumulative IRF & -16.50 & -15.29 & -11.03 & -8.14 & -7.79 & -7.48 \\
Persistence & 0.83 & 0.88 & 0.93 & 0.93 & 0.90 & 0.90 \\
& & & & & & \\
Impact & -3.65 & -3.87 & -4.73 & -5.54 & -5.70 & -5.86 \\
Cumulative IRF & -71.78 & -66.00 & -74.63 & -87.77 & -91.84 & -96.80 \\
Persistence & 0.92 & 0.91 & 0.92 & 0.93 & 0.93 & 0.93 \\
\hline
\end{tabular}

